Naira Hossepian Salles de Lima HoJalJ

\title{
Preditores do envelhecimento saudável: fatores epigenéticos e o gene APOE
}

Tese apresentada à Faculdade de Medicina da Universidade de São Paulo para obtenção de título de Doutor em Ciências

Programa de Ciências Médicas

Área de concentração: Educação e Saúde

Orientador: Prof. Dr. Wilson Jacob Filho

São Paulo 
Dados Internacionais de Catalogação na Publicação (CIP)

Preparada pela Biblioteca da

Faculdade de Medicina da Universidade de São Paulo

Creprodução autorizada pelo autor

Hojaij, Naira Hossepian Salles de Lima

Preditores do envelhecimento saudável : fatores

epigenéticos e o gene APOE / Naira Hossepian Salles

de Lima Hojaij. -- São Paulo, 2018.

Tese (doutorado)--Faculdade de Medicina da

Universidade de São Paulo.

Programa de Ciências Médicas. Área de

Concentração: Educação e Saúde.

Orientador: Wilson Jacob Filho.

Descritores: 1.Envelhecimento saudável

2.Polimorfismo genético 3. Multimorbidade 4.Exercício

5.Prognóstico

$\mathrm{USP} / \mathrm{FM} / \mathrm{DBD}-499 / 18$

Responsável: Erinalva da Conceição Batista, CRB-8 6755 


\section{Dedicatória}

Aos meus pais, Oliver e Naicyr, fonte eterna de amor e do meu saber.

Ao Flavio, por todo o cuidado que me dedica e amor incondicional que construímos.

Aos meus filhos, Matheus, Lara e João, pelo privilégio de participar de suas vidas em transformação, que regam a minha existência. 


\section{Agradecimento especial}

Ao Prof. Dr. Wilson Jacob Filho, meu querido mestre e amigo Wilson, que tanto se dedicou a mim em todos os momentos da minha jornada na Medicina, e de tantas as formas, que só um ser de extrema capacidade de doação, poderia fazê-lo.

Além de sua habilidade em liderança, que o fez agregar e estimular tantas e diversas pessoas ao redor de um único objetivo, o da contínua construção do nosso Serviço de Geriatria do HC-FMUSP, admiro o genuíno respeito e cuidado que tem pela vida do outro, paciente, familiar, aluno e colega.

Agradeço pela sua existência, por ter me ensinado a voar, e continuar observando e corrigindo meu vôo. 


\section{Agradecimentos}

Aos pacientes do GAMIA, por entregarem-se de corpo e alma aos nossos cuidados e aos inúmeros pedidos de colaboração em pesquisas e aulas.

Aos funcionários do Hospital das Clínicas que me auxiliaram na fase inicial do estudo, em especial às enfermeiras Neide Fernandes, responsável pelo ambulatório e GAMIA, e Sonia Thiago, responsável pelo Hospital Dia, a quem agradeço toda a disponibilidade em favorecer ambiente adequado à coleta dos dados.

À Profa. Dra. Suely Kazue Nagahashi Marie e toda sua equipe do LIM/15 - Laboratorio de Investigacao em Neurologia, da FMUSP, que disponibilizaram a coleta dos dados genéticos e da entrevista inicial. Agradeço à Profa. por todo o acolhimento em seu laboratório, e, em especial, à sua enorme disponibilidade e respeitosa contribuição na qualificação do meu trabalho.

À Profa. Maria Lucia Bueno Garcia, meu eterno agradecimento pelos seus ensinamentos, que fundamentaram as bases de minha formação médica e humanística. Agradeço em especial aos últimos anos de convivência acadêmica, quando pude compartilhar do seu amor pelo ensino da Medicina. Agradeço sua disponibilidade e contribuições na qualificação do estudo, que foram valiosas no aprimoramento do olhar clínico dentro da pesquisa. 
Ao Prof. Dr. Itamar Santos, pelo seu interesse e participação na qualificação, com sugestões metodológicas importantes que direcionaram a finalização do estudo.

Ao Prof. Dr. Jose Antonio Esper Curiati, pela disponibilidade e interesse na qualificação do estudo, mas especialmente, por todo o ensinamento que me passou na geriatria, fundamental para minha formação médica e de pesquisa.

Ao Dr. Luis Fernando Rangel, que me auxiliou neste projeto em todas as suas fases, elaboração de protocolos, coleta de dados, elaboração do banco eletrônico de dados. Agradeço principalmente pelo interesse crescente pelo tema, pela imensa disponibilidade e profunda amizade.

Ao Dr. Márlon Juliano Romero Aliberti, colega de tantos anos e de todas as horas da pós-graduação, por todo o carinhoso incentivo e pela prestimosa análise estatística dos dados. Agradeço todos os dias o privilégio da amizade profunda e cumplicidade que nasceu da nossa convivência e que tem nos unido nesses anos de vida e profissão.

Aos Prof. Dr. Thiago Junqueira Avelino da Silva e Prof. Dr. Daniel Apolinário, por me estimularem e mostrarem o caminho na etapa de idealização do estudo longitudinal e realização do banco eletrônico de dados.

Ao aluno João Hossepian Hojaij pelo imenso auxílio na realização dos gráficos apresentados na tese. 
À Dra. Elina Lika Kikuchi, pela sua amizade e cumplicidade, que me inspiram a seguir no ensino da graduação, e por todo o apoio incondicional nas minhas necessidades junto às atividades da pósgraduação.

Às colegas e amigas Dra. Cristiane Comelato e Dra. Priscila Gonçalves Serrano, por toda a ajuda e cuidados que me dispensaram em todos esses anos, para que me dedicasse à realização da pósgraduação.

Aos colegas e amigos do Serviço de Geriatria, em especial, Prof. Dr. Alexandre Busse, Dr. Jose Renato das Graças Amaral, Profa. Dra. Beatriz Trezza, Dra. Vanessa Suller, Dr. Rafael Sasdelli, pela compreensão e apoio nos ambulatórios na minha ausência para atividades junto à pós-graduação.

À toda equipe de apoio do Serviço de Geriatria, em especial às secretárias Neusa e Ângela, pela imensa ajuda em todas as etapas da pós-graduação. À secretaria da pós-graduação, em especial à Angélica, que auxiliou de forma atenciosa e cuidadosa, para que todas as etapas fossem bem cumpridas nesse processo.

À amiga Enf. Mônica Manfredi, por cuidar da minha vida em todos os sentidos e ter me apoiado junto aos pacientes na minha ausência para a realização da pós-graduação. À Celia, Jessica, Rosa e Valdete, por todos os cuidados para que eu pudesse me dedicar a este projeto. 


\section{Normalização}

Esta tese está de acordo com as seguintes normas, em vigor no momento desta publicação:

Referências: adaptado de International Committee of Medical Journals Editors (Vancouver).

Universidade de São Paulo, Faculdade de Medicina. Divisão de Biblioteca e Documentação. Guia de apresentação de dissertações, teses e monografias. Elaborado por Anneliese Carneiro da Cunha, Maria Julia de A. L. Freddi, Maria F. Crestana, Marinalva de Souza Aragão, Suely Campos Cardoso, Valéria Vilhena, $3^{a}$ ed. São Paulo: Divisão de Biblioteca e documentação; 2011.

Abreviaturas dos títulos dos periódicos de acordo com List of Journals Indexed in Index Medicus. 


\section{Sumário}

Lista de Siglas e Abreviaturas

Lista de Figuras

Lista de Tabelas

Lista de Quadros

Resumo

Abstract

1 INTRODUÇÃO E RELEVÂNCIA DO TEMA …….............................. 1

1.1 Panorama do processo de envelhecimento no mundo e no Brasil - transição demográfica, epidemiológica e carga de

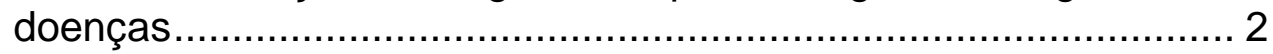

1.2 Os conceitos de Envelhecimento, Envelhecimento BemSucedido e Envelhecimento Saudável

1.3 Medidas de Envelhecimento Saudável como marcadores biológicos sistêmicos prognósticos do envelhecimento

1.3.1 O acúmulo de doenças e a multimorbidade como marcadores prognósticos do envelhecimento

1.3.2 Índices de fragilidade ou acúmulo de déficits na avaliação do prognóstico do envelhecimento

1.3.3 A composição dos Índices de Multimorbidade e Fragilidade para 0 estudo do prognóstico do envelhecimento

1.4 Fatores preditores do envelhecimento saudável - genéticos e epigenéticos

$1.5 \mathrm{O}$ papel dos genes na longevidade humana $\mathrm{e}$ no envelhecimento

1.6 Influência do gene da apolipoproteína E (APOE) nos fenótipos do envelhecimento

1.6.1 Apresentação do gene APOE, sua variação genética e associações fenotípicas significativas (longevidade e traços fenotípicos de doenças)

1.6.2 Associações do gene APOE com outros fenótipos relacionados ao envelhecimento (funcionalidade, sobrevivência livre de doenças, multimorbidade e envelhecimento saudável) 


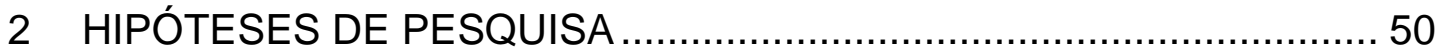

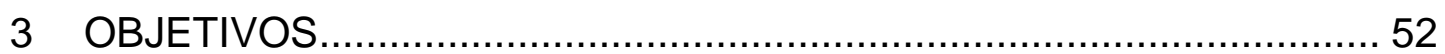

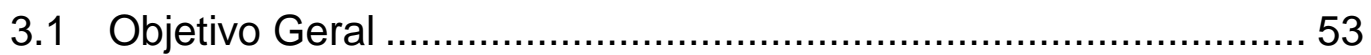

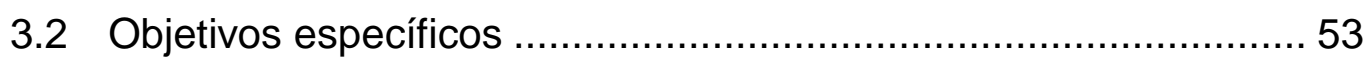

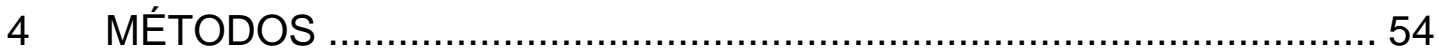

4.1 Delineamento da pesquisa ....................................................... 55

4.2 Recrutamento, local e participantes da pesquisa ......................... 55

4.3 Avaliação inicial da amostra no ano de 2004 ............................. 56

4.4 Avaliação longitudinal da amostra no seguimento de dez anos

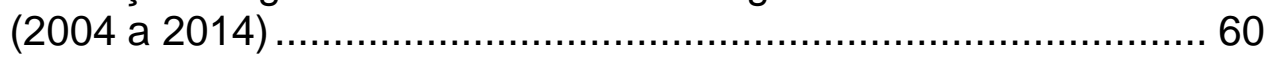

4.4.1 Avaliação de multimorbidade .......................................... 63

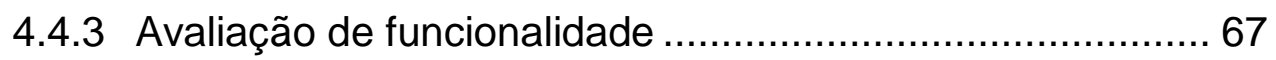

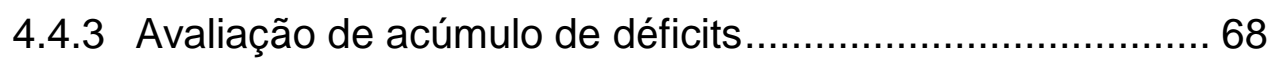

4.4.4 Avaliação de mortalidade.................................................. 70

4.4.5 Desfechos e variáveis de interesse .................................. 71

4.4.5.1 Desfechos .......................................................... 71

4.4.5.2 Variáveis preditoras ................................................ 71

4.5 Considerações éticas da pesquisa ............................................... 72

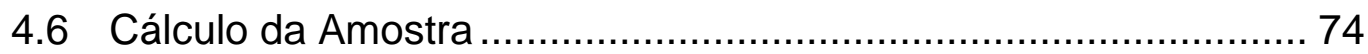

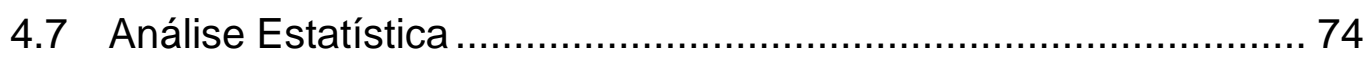

4.7.1 Análises descritivas e bivariadas........................................... 75

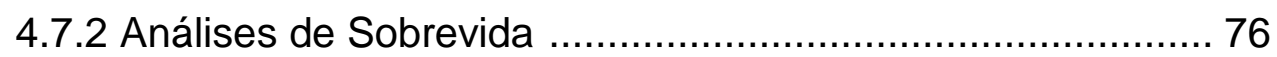

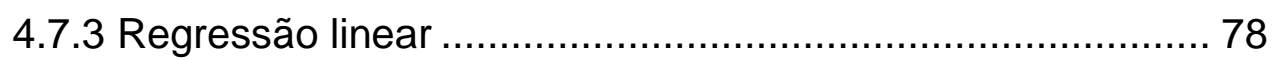

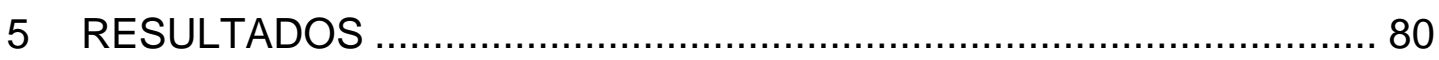

5.1 Caracterização da amostra inicial no ano de 2004 ....................... 81

5.2 Avaliação longitudinal da amostra em relação aos desfechos ...... 89

5.3 Associação univariada dos fatores genéticos e epigenéticos com os desfechos em dez anos .............................................. 93

5.4 Análises de sobrevida para a perda de funcionalidade, 0 aumento do índice de acúmulo de déficits e a mortalidade............ 99

5.4.1 Avaliação do alelo $\varepsilon 4$ do gene APOE ............................... 99

5.4.2 Avaliação do alelo ع2 do gene APOE ............................ 102

5.4.3 Avaliação dos fatores epigenéticos ................................ 105

5.5 Análise de ganho de multimorbidade ...................................... 107 
5.6 Análise da evolução anual dos índices prognósticos em

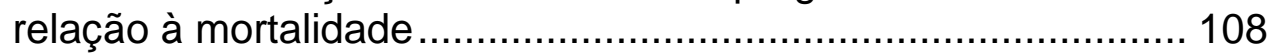

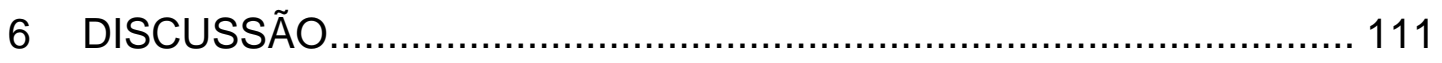

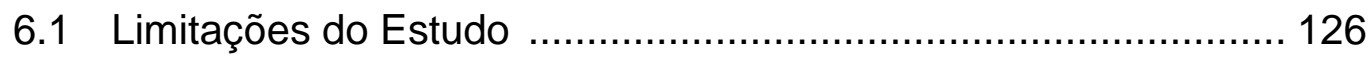

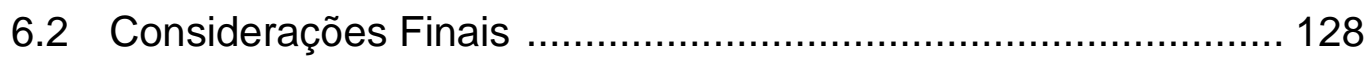

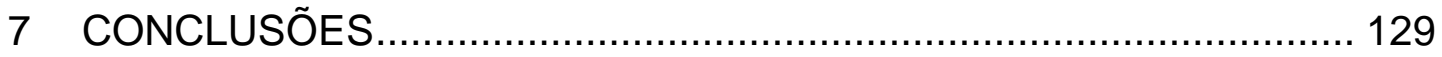

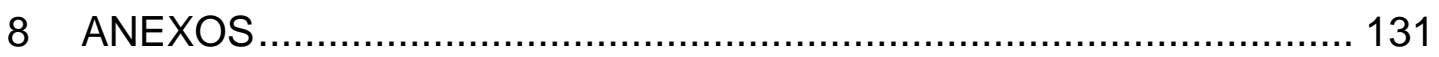

8.1 Anexo A - Termo de Consentimento Livre e Esclarecido ........... 132

8.2 Anexo B - Protocolo de Pesquisa - Avaliação inicial e no

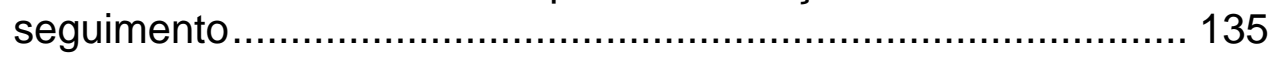

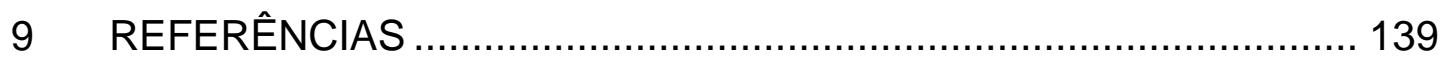




\section{Listas}

\section{ABREVIATURAS E SIGLAS}

ABVD Atividades Básicas de Vida Diária

AIVD Atividades Instrumentais de Vida Diária

Apo E Apolipoproteína E

APOE Gene da apolipoproteína E

CAPPesq Comitê de Ética para Análise de Projetos de Pesquisa

$\mathrm{CCl} \quad$ Charlson comorbidity index

CEP Comitê de Ética em Pesquisa

CIRS Cumulative IIIness Rating Scale

CIRS-G Cumulative IIIness Rating Scale

CONEP Comissão Nacional de Ética em Pesquisa

DALY Disability-Adjusted Life-Years

DI I Índice de acúmulo de déficits

DNA Ácido desoxirribonucleico

ES Envelhecimento saudável

FMUSP Faculdade de Medicina da Universidade de São Paulo

GAMIA Grupo de Assistência Multidisciplinar ao Idoso Ambulatorial

GBD Global Burden of Disease

GWAS Genome-Wide Association Studies

HALE Healthy Life Expectancy

HC Hospital das Clínicas 


$\begin{array}{ll}\text { HR } & \text { Hazard Ratio } \\ \text { IBGE } & \text { Instituto Brasileiro de Geografia e Estatística } \\ \text { IC } & \text { Intervalo de Confiança } \\ \text { ICED } & \text { Index of Co-Existent Diseases } \\ \text { IIQ } & \text { Intervalo Interquartil } \\ \text { IM } & \text { Idade Média } \\ \text { LIM } & \text { Laboratório de Investigação Médica } \\ \text { OMS } & \text { Organização Mundial da Saúde } \\ \text { YLD } & \text { Years Lost due to Disability } \\ \text { YLL } & \text { Years of Life Lost } \\ \varepsilon 2 & \text { alelo } \varepsilon 2 \text { do gene da apolipoproteína E } \\ \varepsilon 3 & \text { alelo } \varepsilon 3 \text { do gene da apolipoproteína E } \\ \varepsilon 4 & \text { alelo } \varepsilon 4 \text { do gene da apolipoproteína E }\end{array}$




\section{FIGURAS}

Figura 1 - Projeção da população do Brasil por idade para o período 2010 a 2060

Figura 2 - Expectativa média de vida e expectativa média de vida saudável (HALE=healthy life expectancy), Brasil, 2017

Figura 3 - Relação da Capacidade Funcional e Capacidade Intrínseca na promoção do Envelhecimento Saudável

Figura 4 - Aumento exponencial do Índice de acúmulo de déficits relacionado à idade cronológica

Figura 5 - Frequências dos alelos $\varepsilon 2$, $\varepsilon 3$ e $\varepsilon 4$ no mundo

Figura 6 - Processo de recrutamento da amostra; ambulatório de geriatria do HC-FMUSP - 2004

Figura 7 - Prevalência das principais doenças e condições crônicas de saúde da amostra no início do estudo; ambulatório de geriatria do HC-FMUSP - 2004

Figura 8 - Polimorfismo genético da apolipoproteína E (APOE) e frequência dos alelos na amostra total $(\mathrm{N}=125)$

Figura 9 - Evolução do Índice de acúmulo de déficits (DI) na amostra ao longo dos dez anos de acompanhamento, DI observado e DI fisiológico $(\mathrm{N}=125)$

Figura 10 - Evolução da pontuação média do índice de multimorbidade CIRS-G na amostra ao longo do seguimento de dez anos $(\mathrm{N}=125)$

Figura 11 - Evolução da pontuação média do índice de multimorbidade Charlson comorbidity index $(\mathrm{CCl})$ ao longo do seguimento em dez anos ( $\mathrm{N}=125)$

Figura 12 - Prevalência das principais doenças e condições crônicas de saúde da amostra no início e final do estudo; ambulatório de geriatria do HC-FMUSP - 2004.

Figura 13 - Curva do índice de acúmulo de déficits (DI) dos participantes que morreram em relação aos que estavam vivos após dez anos de seguimento $(\mathrm{N}=125)$ 
Figura 14 - Curva do índice de multimorbidade CIRS-G dos participantes que morreram em relação aos que estavam vivos após dez anos de seguimento $(\mathrm{N}=125)$

Figura 15 - Curva do índice de multimorbidade CIRS-G CM2 dos participantes que morreram em relação aos que estavam vivos após dez anos de seguimento $(\mathrm{N}=125)$

Figura 16 - Curva do índice de multimorbidade Charlson comorbidity index $(\mathrm{CCl})$ dos participantes que morreram em relação aos que estavam vivos após dez anos de seguimento $(\mathrm{N}=125)$

Figura 17 - Curvas de Kaplan-Meier para perda do envelhecimento fisiológico conforme a presença ou ausência do alelo $\varepsilon 4$ do gene APOE $(\mathrm{N}=125)$

Figura 18 - Curvas de Kaplan-Meier para sobrevida conforme a presença ou ausência do alelo $\varepsilon 4$ do gene APOE $(\mathrm{N}=125)$.. 109

Figura 19 - Curvas de Kaplan-Meier para perda de envelhecimento fisiológico conforme a presença ou ausência do alelo $\varepsilon 2$ do gene APOE $(\mathrm{N}=125)$

Figura 20 - Curvas de Kaplan-Meier para sobrevida conforme a presença ou ausência do alelo $\varepsilon 2$ do gene APOE $(\mathrm{N}=125)$.. 110 
TABELAS

Tabela 1 - Características da amostra na avaliação inicial do estudo ( $\mathrm{N}=125)$; ambulatório de geriatria do HC-FMUSP - 2004 82

Tabela 2 - Características basais dos participantes de acordo com o Cumulative IIIness Rating Scale for Geriatrics (CIRS-G) no início do estudo; ambulatório geriatria do HC-FMUSP 2004

Tabela 3 - Características basais dos participantes de acordo com o Charlson comorbidity index (CCl) no início do estudo; ambulatório geriatria do HC-FMUSP - 2004 .

Tabela 4 - Associação das características dos participantes no início do estudo com perda do envelhecimento fisiológico em 10 anos; ambulatório geriatria do HC-FMUSP - 2004 a 2014 ..... 94

Tabela 5 - Associação das características dos participantes no início do estudo com perda funcional em 10 anos; ambulatório de geriatria HC-FMUSP - 2004 a 2014.

Tabela 6 - Associação das características dos participantes no início do estudo com mortalidade em 10 anos; ambulatório de geriatria HC-FMUSP - 2004 a 2014

Tabela 7 - Modelos de regressão de Cox para associação da presença do alelo $\varepsilon 4$ do gene APOE com desfechos em 10 anos; ambulatório de geriatria HC-FMUSP - 2004 a 2014

Tabela 8 - Modelos de regressão de Cox para associação da presença do alelo $\varepsilon 2$ do gene APOE com desfechos em 10 anos; ambulatório de geriatria HC-FMUSP - 2004 a 2014

Tabela 9 - Modelos de regressão de Cox para associação dos fatores epigenéticos com desfechos em 10 anos; ambulatório de geriatria HC-FMUSP - 2004 a 2014 


\section{QUADROS}

Quadro 1 - Preditores do envelhecimento bem-sucedido. Adaptado de Depp CA e Jeste DV. Definitions and Predictors of Successful Aging: A Comprehensive Review of Larger Quantitative Studies. Am J Geriatr Psychiatric 2006;14:620

Quadro 2 - Critérios de inclusão e exclusão da população na avaliação inicial.....

Quadro 3 - Descrição das características sociodemográficas e clínicas, hábitos de vida, auto avaliação da saúde, e características genéticas da avaliação inicial.

Quadro 4 - Critérios de inclusão e exclusão - Avaliação retrospectiva...... 61

Quadro 5 - Índice Cumulative Illness Rating Scale for Geriatrics (CIRS-G)

Quadro 6 - Charlson comorbidity index (CCI) 66 


\section{Resumo}

Hojaij NHSL. Preditores do envelhecimento saudável: fatores epigenéticos e - gene APOE [tese]. São Paulo: Faculdade de Medicina, Universidade de São Paulo; 2018.

INTRODUÇÃO: Fatores genéticos estão associados a fenótipos do envelhecimento como a longevidade e algumas doenças relacionadas à idade, mas a identificação dos genes envolvidos no fenótipo complexo do envelhecimento permanece um desafio. Estudos de associação genômica ampla (GWAS), têm apontado o gene da Apolipoproteína E (APOE) como o único associado de maneira consistente à longevidade e alguns fenótipos do envelhecimento. Até o momento, entretanto, a associação do gene APOE com fenótipos alternativos como o envelhecimento saudável (ES), não tem sido demonstrada de maneira consistente. OBJETIVOS: determinar a influência do polimorfismo do APOE na variação de índices prognósticos do envelhecimento (multimorbidade, funcionalidade e acúmulo de déficits) em dez anos. MÉTODOS: estudo longitudinal de coorte retrospectiva de 125 idosos independentes inicialmente para atividades de vida diária (ABVD e AIVD), de um ambulatório assistencial em um hospital escola, em São Paulo. Na avaliação inicial, foram identificados o polimorfismo do gene APOE (alelos $\varepsilon 2$, $\varepsilon 3$ e $\varepsilon 4$ ), variável preditora primária, e algumas variáveis epigenéticas (clínicas, sociodemográficas e hábitos de vida). No seguimento, avaliações anuais de prontuários foram realizadas para identificar associações com perdas de envelhecimento fisiológico (índice de acúmulo de déficits, DI), ganho de multimorbidade (Cumulative IIIness Rating Scale for Geriatrics, CIRS-G e Charlson comorbidity index, $\mathrm{CCl}$ ) e dependência em ABVD/AIVD, e morte, em dez anos. Curvas de Kaplan-Meier e modelos de regressão de Cox foram utilizados para associações dos fatores genéticos e epigenéticos com piora funcional e morte, e de regressão linear múltipla para associações com os índices CIRS-G, CCl e DI. RESULTADOS: 125 participantes da avaliação inicial, idade média de 74,9 anos, $76,8 \%$ mulheres, e $81,6 \%$ brancos. A média do CIRS-G foi de 10,24. A distribuição dos alelos: $\varepsilon 210 \%$, $\varepsilon 350,8 \%$, e $\varepsilon 439,2 \%$. A presença de $\varepsilon 2$ e $\varepsilon 4$ em relação ao grupo controle $\varepsilon 3 / \varepsilon 3$ não foram preditoras de piora nos índices prognósticos do envelhecimento. Alguns fatores epigenéticos apresentaram associações com desfechos em dez anos. Maior acúmulo de déficits: idade mais elevada $p<0,001$; sedentarismo $p=0,02$; tabagismo $p=0,02$. Maior dependência em ABVD: idade mais elevada $p=0,002$; sexo masculino $p=0,01$; pontuação maior no CIRS-G $p=0,02$; sedentarismo $p=0,02$. Maior dependência para AIVD: idade mais elevada $p<0,001$; sexo masculino $p=0,01$; sedentarismo $p=0,02$. Mortalidade: idade mais elevada $p=0,002$, pontuações maiores $\mathrm{CCl} p=0,001$. Atividades metabólicas $(\beta=-4,37$; $p=0.003)$ e morar sozinho $(\beta=-2,28 ; p=0.005)$ foram associados com níveis mais baixos de CIRS-G em 10 anos, e etilismo ( $\beta=1,78 ; p=0.04)$ com níveis mais altos de CIRS-G. CONCLUSÕES: O polimorfismo do gene APOE não 
influenciou o prognóstico do envelhecimento. O ganho inesperado de acúmulo de déficits apresentou associação com alguns preditores epigenéticos em idosos ambulatoriais (idade $\geq 80$ anos, sedentarismo e tabagismo). A idade $\geq 80$ anos, sexo masculino e sedentarismo, foram associados a perda em dez anos de funcionalidade para ABVD e AIVD. Atividades metabólicas e morar sozinho foram associados a menor multimorbidade em dez anos. Mortalidade em dez anos foi associada a idade $\geq 80$ anos e alta multimorbidade através do $\mathrm{CCl}$.

Descritores: envelhecimento saudável; polimorfismo genético; multimorbidade; exercício; prognóstico. 


\section{Abstract}

Hojaij NHSL. Predictors of healthy aging: epigenetic factors and the APOE gene [thesis]. São Paulo: "Faculdade de Medicina, Universidade de São Paulo"; 2018.

BACKGROUND: While genetic factors are linked to longevity and agerelated diseases, the identification of genes responsible for different aging phenotypes remains unclear. Previous studies, including the genome-wide association studies (GWAS), have indicated that Apolipoprotein E (APOE) gene is associated with longevity and other aging phenotypes. However, little is still known on the association of the APOE gene with healthy aging. OBJECTIVES: To determine the influence of the APOE gene polymorphism on the variation of aging prognostic indices (functionality, multimorbidity, and accumulation of deficits) over 10 years. METHODS: A retrospective cohort study comprising 125 older adults who were independent in activities of daily living (ADL and IADL) at baseline. Participants were evaluated at an ambulatory setting from an academical medical center at the University of Sao Paulo Medical School. Baseline assessment included the identification of the APOE gene polymorphism (alleles $\varepsilon 2, \varepsilon 3$, and $\varepsilon 4$ ), which was the primary predictor, and other epigenetic variables such as sociodemographic factors, multimorbidity, and behavior measures. Annual follow-up evaluations over 10 years were conducted to identify dependencies in ADL and IADL, multimorbidity, and death using the hospital medical charts. A cumulative deficit index was computed using the patients' multimorbidity and functionality every year. Kaplan-Meier curves and Cox proportional hazard models were used to associate the genetic and epigenetic factors with time to dependence in ADL and IADL and death. Multiple linear regression models examined the association of risk factors with the scores of the Cumulative Illness Rating Scale for Geriatrics (CIRS-G), Charlson comorbidity index, and deficit index at 10 years. RESULTS: Participants had a mean age of 74.9 years; $76.8 \%$ were female, and $81.6 \%$ white. The mean score in CIRS-G was 10.2 points. The distribution of the alleles of APOE was $10 \%$ for $\varepsilon 2,50.8 \%$ $\varepsilon 3$, and $39.2 \% \varepsilon 4$. Compared to the allele $\varepsilon 3 / \varepsilon 3$ (control group), the presence of allele $\varepsilon 2$ did not predict dependence in ADL and IADL. The presence of allele $\varepsilon 4$ did not predict any outcome. Some epigenetic risk factors were associated with the outcomes over 10 years. For significant increase in deficit index: older age, $\mathrm{p}<0,001$; sedentarism, $\mathrm{p}=0,02$; tobacco consumption $p=0,02$.For dependence in $A D L$ : older age, $p=0.002$; men $p=0,01$; higher scores in the CIRS-G, $p=0.02$; sedentarism, $p=0.02$. For dependence in IADL: older age, $p<0.001$; men $p=0,01$; sedentarism, $p=0.02$ For mortality: older age, $p=0,002$; higher score in the Charlson comorbidity index, $p=0.001$. While metabolic activities $(\beta=-4,37 ; p=0.003)$ and living alone $(\beta=-2,28$; $p=0.005$ ) were associated with a lower score in the CIRS-G at 10 years of follow-up, alcohol consumption $(\beta=1,78 ; p=0.04)$ was associated with higher scores in this index. CONCLUSIONS: The APOE gene polymorphism did not 
influence the prognosis of aging. Older age, sedentarism and tobacco consumption were associated with a significant increase in deficit index. Older age, men and sedentarism were predictors of functional loss. Metabolic activities and living alone were associated with a lower score in the CIRS-G at 10 years of follow-up. Older age and multimorbidity at baseline were predictors of mortality.

Descriptors: healthy aging; polymorphism, genetic; multimorbidity; exercise; prognosis. 
1 Introdução e Relevância do Tema 


\section{INTRODUÇÃO E RELEVÂNCIA DO TEMA}

\subsection{Panorama do processo de envelhecimento no mundo e no Brasil - transição demográfica, epidemiológica e carga de doenças}

O envelhecimento é um processo natural em toda forma de vida. Pela primeira vez na história da humanidade, a maioria da população do mundo pode ter a expectativa de viver além dos sessenta anos.

Em 2017, existiam aproximadamente 962 milhões de pessoas com 60 anos ou mais no mundo. A população mundial de idosos cresce numa razão de cerca de $3 \%$ ao ano. Estima-se que os idosos chegarão a 1,4 bilhão de pessoas em 2030 e a dois bilhões em 2050. Com esse rápido envelhecimento populacional previsto, estima-se que em 2050 , um quarto ou mais da população de todas as regiões, exceto África, terá idade igual ou superior a 60 anos. Globalmente, a expectativa de vida ao nascer deve aumentar dos atuais 73 anos para 77 anos em 2050 (United Nations, Department of Economic and Social Affairs, Population Division, 2017).

No Brasil, o mais recente relatório do IBGE (Instituto Brasileiro de Geografia e Estatística), de 2018, projeta estimativa de 58,2 milhões (25,5\%) de indivíduos com 65 anos ou mais de idade em 2060, um significativo aumento em relação aos 19,2 milhões $(9,2 \%)$ observado no atual ano de 2018 (IBGE, 2018). Como observamos na Figura 1, em 2039 a proporção de jovens com menos de 15 anos (25,7\%) e idosos (25,8\%) será equivalente, e, 
portanto, $51,5 \%$ da população brasileira será dependente do grupo considerado economicamente produtivo, de 15 a 64 anos. Essa chamada ‘razão de dependência' nos dias de hoje é de 44\%, mas em 2060 deverá ser significativamente mais alta $(67,2 \%)$ no Brasil, prevendo consequências socioeconômicas preocupantes para um país em desenvolvimento e economicamente instável (IBGE, 2018).

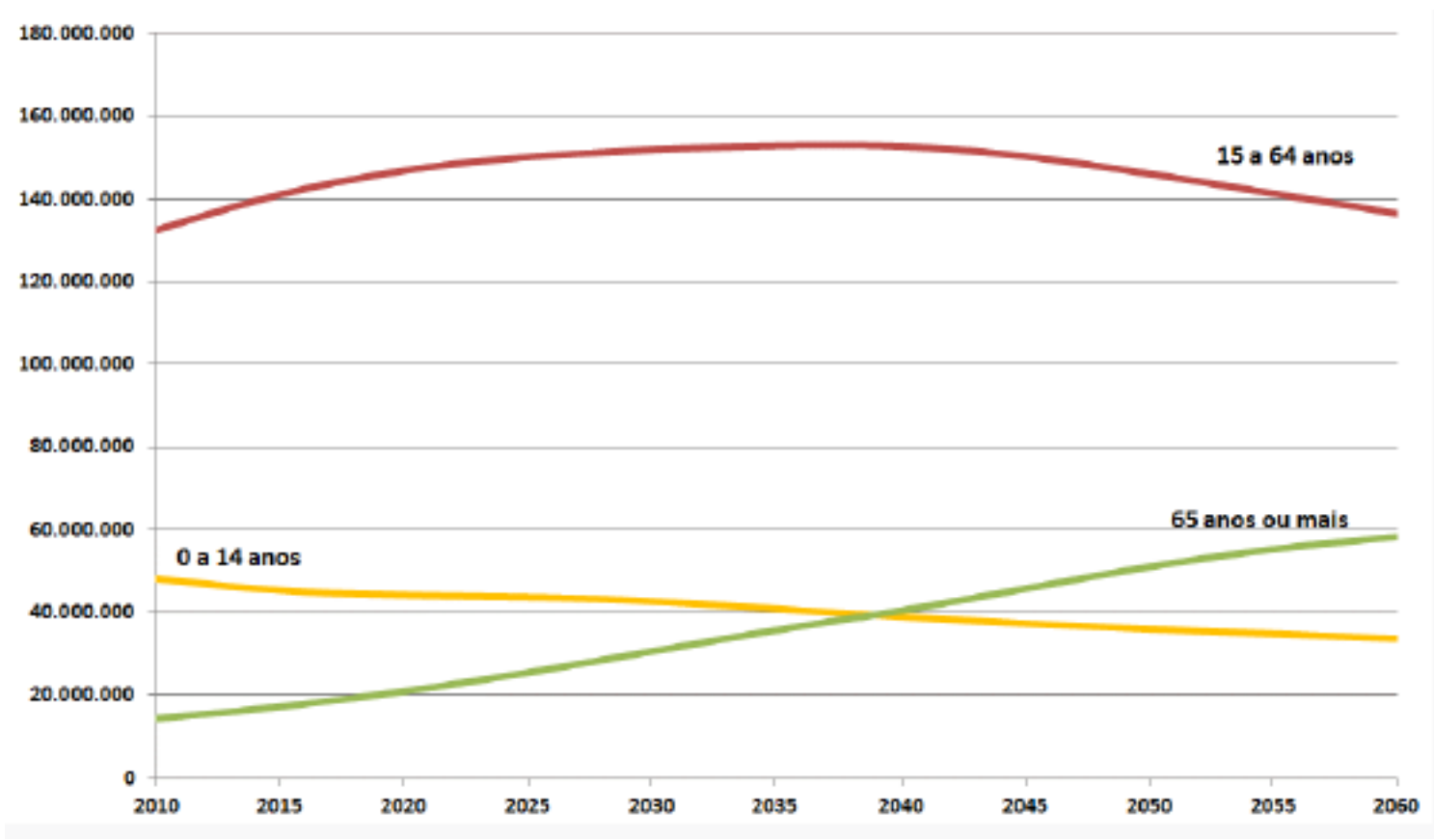

FONTE: Projeções da população: Brasil e unidades da federação: revisão 2018/ IBGE, Coordenação de População e Indicadores Sociais. - 2. ed. - Rio de Janeiro: IBGE, 2018.

Figura 1 - Projeção da população do Brasil por idade para o período 2010 a 2060

As reduções combinadas nos índices de fecundidade e de mortalidade ocorridas principalmente a partir da década de 1970 no Brasil, e cerca de 50 anos antes nos países desenvolvidos, determinaram essa transição 
demográfica favorável ao envelhecimento populacional. Com o envelhecimento e aumento de sobrevida, mudanças epidemiológicas ocorreram, observando-se exponencial aumento na incidência e prevalência de condições crônicas de saúde, com impactos significativos na complexidade dos cuidados à saúde do indivíduo e da população. E, de fato, segundo recente relatório da Organização Mundial da Saúde (OMS), atualmente as doenças crônicas não transmissíveis são responsáveis por $71 \%$ de todas as mortes no mundo, e $74 \%$ das mortes no Brasil, embora vivenciemos em nosso país uma dupla carga de doenças, onde existe também preocupante impacto das doenças infectocontagiosas, e de condições associadas a desnutrição, saúde materna, saúde perinatal, e acidentes (World Health Organization, 2018).

Em 2017, o grupo responsável pelo estudo multicêntrico e observacional Global Burden of Diseases, Injuries, and Risk Factors Study (GBD) publicou seus novos índices de saúde para o globo e para os 195 países envolvidos a partir de 359 doenças e danos. O GBD foi idealizado há 28 anos com o objetivo de analisar sistematicamente as causas de mortalidade e o impacto das doenças na saúde da população mundial e regional. Desde o seu início, em 1990, vem trazendo contribuições periódicas no entendimento de tendências em saúde populacional no mundo, aplicáveis ao desenvolvimento de estratégias de ação em saúde (GBD 2017, Disease and Injury Incidence and Prevalence Collaborators, 2018). 
Segundo o GBD 2017, as doenças crônicas não transmissíveis foram responsáveis por $71,1 \%$ da carga de doenças no Brasil. A carga de doença é uma medida mais sensível da saúde de uma população e é estimada pelo índice $D A L Y$ (do inglês Disability-Adjusted Life-Years), onde um DALY equivale a um ano perdido de vida saudável. O DALY é a somatória de dois outros dois índices, o YLL (do inglês Years of Life Lost) que mede os anos perdidos por morte prematura, e o YLD (do inglês Years Lost due to Disability) que mede os anos vividos com incapacidades em uma população. Em suma, o $D A L Y$ representa a diferença entre a real saúde medida de uma população e uma situação ideal de saúde na qual os anos de vida ganhos com o aumento da expectativa de vida se mantenham livres de incapacidades relacionadas a doenças. É um índice muito útil no entendimento de quais doenças ou danos afetam a saúde, auxiliando tomadas de decisões e implementação de estratégias para melhoria da saúde naquela população. Globalmente, as doenças crônicas não transmissíveis foram responsáveis por $62 \%$ do total $D A L Y s$, sendo que nos últimos dez anos (entre 2007 e 2017), 12 grupos de causas apresentaram impacto mais significativo: diabetes, doenças renais, doenças dos órgãos sensoriais, doenças neurológicas, desordens de abuso de substâncias, doenças cardiovasculares, doenças respiratórias crônicas, doenças de pele e subcutâneo, doenças mentais, doenças digestivas, e violência, incluindo violência contra si mesmo). Das causas, as que mais impactaram em número $(15,4 \%$ do total do $D A L Y)$ foram: doença isquêmica do coração, acidente vascular cerebral, e doença pulmonar obstrutiva crônica; sendo que 
houve aumento mais significativo nos dez anos de: câncer de fígado secundário a NASH (Non-Alcoholic SteatoHepatitis, ou doença hepática gordurosa não alcoólica), doença renal crônica secundária a diabetes, e diabetes tipo 2 (GBD, 2017; DALYs and HALE Collaborators, 2018).

Nos últimos anos, o GBD tem analisado mais um índice interessante, o HALE (Healthy Life Expectancy), ou expectativa de vida saudável, que quantifica os anos esperados para serem vividos em boa saúde. Este é um índice bastante interessante para avaliar o impacto real na saúde dos anos ganhos de vida com o aumento da expectativa de vida e longevidade da população. Os dados do último GBD 2017 mostram que, na maioria dos países, o aumento do índice $H A L E$ foi menor que o aumento na expectativa de vida, indicando mais anos vividos com pior saúde. A expectativa de vida ao nascer no Brasil, segundo GBD 2017, é de 75,5 anos, sendo 72 anos para homens, e 79,1 anos para mulheres. Como ilustrado na Figura 2, a diferença ao nascer entre a expectativa de vida e o HALE, no Brasil, é de cerca de 10 anos (expectativa de vida ao nascer de 75,51 anos e HALE de 65,4 anos de expectativa de vida saudável), sendo que com o avançar da idade, quando a carga intrínseca de doenças torna-se progressivamente maior, essa diferença diminui (GBD, 2017; DALYs and HALE Collaborators, 2018). 
Diferenças entre a Expectativa de vida e HALE, população brasileira, 2017

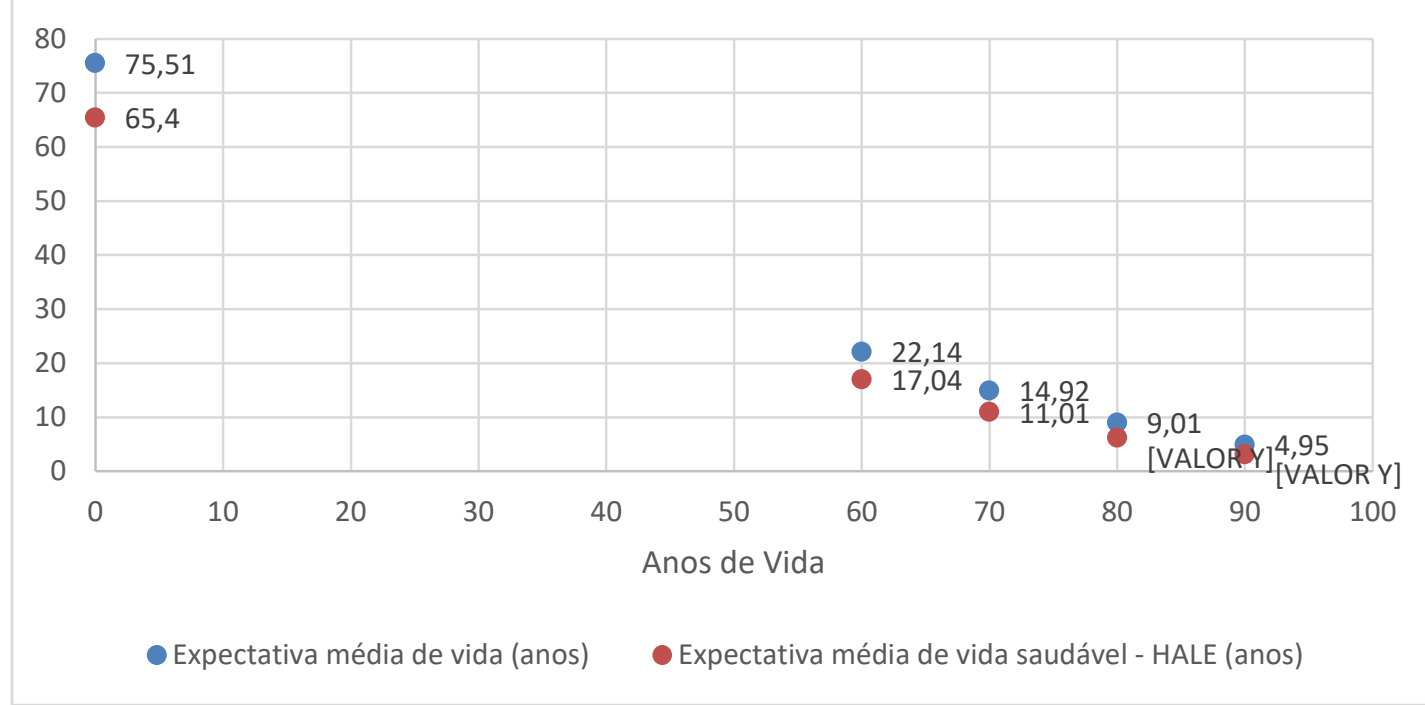

Fonte: GBD 2017 - Global Burden of Diseases, Injuries, and Risk Factors Study. Lancet. 2018; 392:1859-922.

Figura 2 - Expectativa média de vida e expectativa média de vida saudável (HALE=healthy life expectancy), Brasil, 2017

Podemos imaginar o seguinte panorama na saúde mundial e brasileira na atualidade: vivemos mais tempo, o suficiente para um ganho crescente de doenças e condições crônicas não transmissíveis, com impacto significativo em ganho de incapacidades, redução de tempo de vida saudável, e aumento de necessidades de recursos humanos, estruturais e financeiros. No Brasil, acrescenta-se ainda a esse panorama, uma significativa carga de doenças infecciosas e materno-infantis em algumas regiões, e crescente aumento de causas de mortalidade por causas externas (injúrias e acidentes). 
Nosso grande desafio será o de trazer o máximo de benefícios para a saúde dessa população mais longeva que apresenta múltiplas condições crônicas de saúde, objetivando o mínimo de ganho de incapacidades e de inequidade social (Beard et al, 2016).

Para tanto, um dos caminhos necessários será o do entendimento dos fatores que desviam o processo de envelhecimento do seu caminho fisiologicamente esperado, buscando-se efetivar, a partir de então, estratégias de cuidados à saúde em benefício de mais anos de vida saudável e plenamente capaz.

\subsection{Os conceitos de Envelhecimento, Envelhecimento Bem-Sucedido e Envelhecimento Saudável}

O envelhecimento parece ser um princípio universal para todos os organismos vivos, paradoxalmente é um processo extremamente individual e complexo. Do ponto de vista biológico, o envelhecimento é caracterizado pela progressiva perda da integridade fisiológica, ocasionando prejuízo funcional e aumento da vulnerabilidade e morte (López-Otín et al., 2013). No nível celular, as mudanças funcionais e estruturais relacionadas à idade são cumulativas, progressivas, intrínsecas e deletérias (Arking, 2008).

Mas, o envelhecer não é um fenômeno linear, de outra forma, é lento e individual, de maneira que podemos considerar o seu processo como único para cada ser. E a velhice tampouco é apenas um fenômeno biológico, é, por outro lado, permeada de vivências e acometimentos de ordem 
psicossocial e ambiental, que a tornam mais heterogênea e complexa ainda. Dessa forma, entendendo que a vida é contínua e multidimensional, cada ser experimenta de forma única o seu envelhecer, o que torna ainda mais difícil o entendimento científico desse processo tão complexo e único. Simone de Beauvoir, em seu livro "A Velhice", partilhou sua vivência: "não aceitaremos mais com indiferença a infelicidade da idade avançada, mas sentiremos que é algo que nos diz respeito", sendo que "a velhice não pode ser entendida senão em sua totalidade" (Beauvoir, 1990).

Através desse olhar, foram necessárias definições mais abrangentes do envelhecimento. Definições essas que pudessem trazer para o entendimento do processo, além dos parâmetros biológicos, parâmetros funcionais e percepções subjetivas do indivíduo que envelhece.

Em 1999, Rowe e Kahn, propuseram a definição de envelhecimento bem-sucedido a partir dos estudos de coorte de idosos realizados na MacArthur Foundation Research Network on Aging. Para esses autores, o envelhecimento pode ser considerado bem-sucedido quando ocorrem três comportamentos ou características essenciais: baixo risco de doenças e de incapacidades relacionadas com as doenças; funcionamento físico e mental elevados; e envolvimento e compromisso ativo com a vida (Rowe; Kahn, 1999). Este foi um avanço no entendimento de que o envelhecimento não necessariamente deve ser visto como negativo, visão pessimista nomeada de "etarismo", do inglês “ageism", por Robert Butler (Butler, 1980).

Desde então, várias definições de envelhecimento "positivo" (com boa saúde e bem-estar) têm sido propostas. Cosco et al., em revisão sistemática, 
encontraram 105 definições operacionais para o envelhecimento bemsucedido e saudável (Cosco et al., 2014). As definições são baseadas em dois modelos: um biomédico, com ênfase em parâmetros físicos, funcionais e em capacidade cognitiva; outro com ênfase em dimensões psicossociais, como bem-estar e participações sociais. Atualmente, a perspectiva subjetiva do indivíduo tem sido valorizada e incluída em algumas definições (Strawbridge et al., 2002; Depp; Jeste, 2006).

Muitas críticas têm sido feitas às definições iniciais de Rowe e Khan, apesar do reconhecimento por eles terem sido responsáveis por uma mudança na visão negativista do envelhecimento. A primeira grande crítica é a rigidez com que a definição de bem-sucedido, sem doenças incapacitantes, pode menosprezar a capacidade individual de ajustes para as incapacidades, com resiliência e percepções subjetivas de bem-estar. Para Baltes e Smith, um modelo melhor seria o de otimização seletiva com compensação, onde os idosos seriam os protagonistas dos seus ajustes para as perdas, com foco nos seus objetivos e prioridades, e, portanto, a percepção subjetiva deveria ser um dos parâmetros para o estudo do envelhecimento positivo (Baltes; Smith, 1997). Curb et al. complementam esse pensamento com sua definição de envelhecimento 'efetivo', o qual englobaria os bem-sucedidos sem doenças e aqueles com doenças compensadas (Curb et al., 1990). A outra grande crítica é que a separação entre bem-sucedidos ou não pode ser fruto de uma inequidade social, e que talvez diferenças de oportunidades para o envelhecimento bem-sucedido 
sejam tão preditoras quanto as escolhas individuais durante a vida (Katz; Colasanti, 2015).

Diante da falta de uma definição para o envelhecimento considerado positivo, que conseguisse refletir parâmetros favoráveis de saúde em idosos com doenças crônicas controladas, e portanto, separar aqueles considerados saudáveis dos não-saudáveis para estratégias de saúde pública, a Organização Mundial da Saúde (OMS) definiu o envelhecimento saudável como "o processo de desenvolvimento e manutenção da capacidade funcional que permite o bem-estar em idade avançada". Essa definição foi baseada em dois conceitos propostos nesse relatório da OMS de 2015, o de capacidade intrínseca, que se refere ao "composto de todas as capacidades físicas e mentais de um indivíduo", e o de capacidade funcional, definida como "atributos relacionados à saúde que permitem que as pessoas sejam ou façam aquilo que racionalmente valorizam" (WHO World report on ageing and health, 2015).

A capacidade intrínseca é composta pela herança genética do indivíduo, suas características pessoais e sua saúde física e mental. A capacidade funcional, por sua vez, é derivada da capacidade intrínseca do indivíduo e da interação deste com características do ambiente em que ele vive.

O envelhecimento saudável torna-se, então, um conceito dinâmico, determinado pela trajetória de vida do indivíduo, onde cada um pode interferir no seu próprio envelhecimento, dependendo de suas escolhas e do acesso aos cuidados à saúde. Quando esses cuidados à saúde envolvem 
escolhas difíceis diante da complexidade heterogênea do envelhecimento, essa visão torna-se fundamental, onde a saúde e o bem-estar dessa população passam a ter foco na promoção de estratégias que promovam e elevem as capacidades individuais, como ilustrado na Figura 3 (Anand, 2005; WHO World report on ageing and health, 2015).

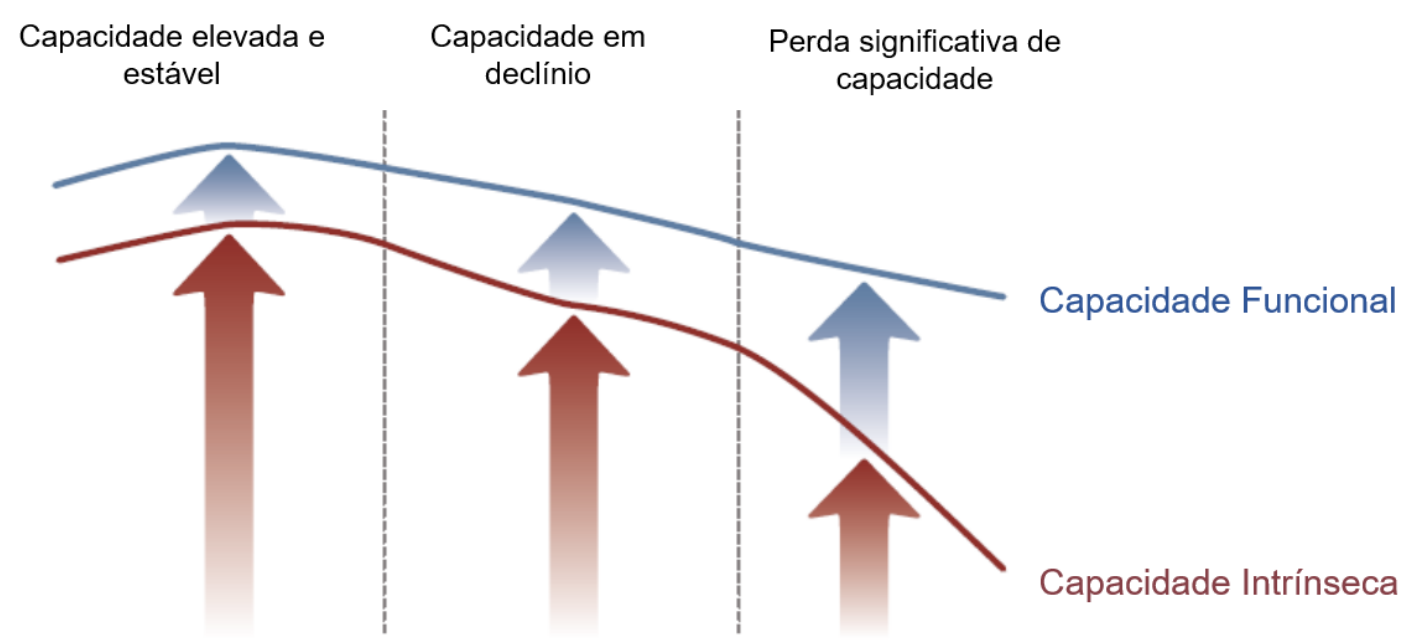

FONTE: World Health Organization, 2017. Adaptado de Integrated care for older people: guidelines on community-level interventions to manage declines in intrinsic capacity. Geneva: World Health Organization, 2017

Figura 3 - Relação da Capacidade Funcional e Capacidade Intrínseca na promoção do Envelhecimento Saudável

Com essa nova perspectiva, o envelhecimento passa a ser considerado saudável quando apresenta doenças bem controladas e que não incapacitam o indivíduo para as suas escolhas e objetivos, dentro de um contexto de condições e ações que propiciam o alcance de uma alta funcionalidade com qualidade de vida. Em resumo, o indivíduo envelhecerá de maneira saudável quando sua capacidade funcional se mantiver o mais 
alta possível, com auxílio de ações promotoras de saúde, mesmo que o acúmulo de doenças e déficits prejudique sua capacidade intrínseca no envelhecimento.

\subsection{Medidas de Envelhecimento Saudável como marcadores biológicos sistêmicos prognósticos do envelhecimento}

A heterogeneidade do envelhecimento traz a necessidade da busca por medidas objetivas que identifiquem marcadores biológicos de declínios da saúde. Esses biomarcadores do envelhecimento são importantes para que possamos identificar os indivíduos que envelhecem de maneira diferente do esperado pelo processo fisiológico, e, a partir disso, possamos criar estratégias de cuidado e intervenções precoces que aumentem a capacidade funcional e promovam saúde (Slagboom et al., 2018).

De maneira intuitiva, mas também científica, sabe-se que a idade cronológica não consegue ser isoladamente um bom marcador do processo fisiológico nas idades mais avançadas, como ocorre na infância. Muitos fatores biológicos, sociodemográficos e de escolhas individuais interferem ao longo da vida nesse processo, trazendo a complexidade e heterogeneidade do envelhecimento (Santoni et al., 2017).

Por outro lado, conhecemos o que define um processo fisiológico de envelhecimento?

Existem muitas teorias celulares e sistêmicas que tentam explicar a senescência, mas, até o momento, o que podemos deduzir de todas é que o 
processo de envelhecimento é sempre decorrente, em última instância, de falhas nos mecanismos fisiológicos de reparo a danos múltiplos ao longo da vida (López-Otín et al., 2013). Portanto, se não há um mecanismo fisiológico único que explique a senescência, pode-se imaginar quão árdua é a tarefa de separar marcadores verdadeiros deste processo.

Alguns marcadores moleculares isolados têm sido investigados em estudos experimentais que avaliam, por exemplo, intervenções que sabidamente melhoram saúde e reduzem a velocidade de envelhecimento celular, como a restrição calórica e atividade física. Nenhum deles se apresenta como um bom marcador de evolução de envelhecimento individual (López-Otín et al., 2013; Slagboom et al., 2018).

O envelhecimento saudável, no qual indivíduos se diferenciam por apresentarem alta capacidade de lidar com fatores estressores durante a vida, sem grandes acúmulos de incapacidades com a idade, pode ser um bom modelo para o estudo desses biomarcadores. Medidas da capacidade funcional e da magnitude de controle de doenças são bastante utilizadas nesse sentido, como indicadores da saúde e de evolução do envelhecimento (Kulminski et al., 2006; Mitnitski et al., 2013; Marengoni et al., 2016; Santoni et al., 2017). 


\subsubsection{O acúmulo de doenças e a multimorbidade como marcadores prognósticos do envelhecimento}

O acúmulo de doenças ao longo da vida é inevitável e, como já exposto, é grande a preocupação atual em capacitar sistemas de saúde para os cuidados aos indivíduos com múltiplas doenças crônico-degenerativas. No contexto do envelhecimento, como vimos, uma das condições para a manutenção da saúde, é a existência de doenças controladas e não incapacitantes.

Em 1970, Feinstein primeiramente chamou a atenção para a condição de várias doenças no mesmo indivíduo, o que chamou de comorbidade, definida por ele como "qualquer entidade distinta que surge durante o curso clínico de um paciente que tem o seu índice de doenças sob estudo". $\mathrm{Na}$ ocasião, ele chamava a atenção para a necessidade em pesquisa clínica, de não se desprezar o impacto que outras doenças traziam no estudo de uma doença principal (Feinstein, 1970).

O conceito de multimorbidade foi proposto inicialmente por van den Akker et al., em 1996, como "a ocorrência simultânea de múltiplas doenças ou condições médicas num mesmo indivíduo, com suas inter-relações e implicações na saúde" (van den Akker, 1996). Mais tarde, Fortin et al. redefiniram a multimorbidade como "a coexistência de duas ou mais condições crônicas, onde uma não é necessariamente mais importante do que a outra" (Fortin et al, 2005). A grande importância desse conceito é a do entendimento de que a presença de duas ou mais doenças num indivíduo 
tem um impacto maior do que a ocorrência de somente uma delas isoladamente, ou seja, existe um efeito sinérgico, com consequências maiores do que o esperado somente pelo efeito aditivo das duas doenças (Rijken et al., 2005). Em conceito redefinido, o grupo de van den Akker, afirmou a importância da correta diferenciação entre multimorbidade e comorbidade, onde na primeira, nenhuma doença ou condição é prioritária em relação às outras; e reforçou que, para ser incluída na multimorbidade, uma doença ou condição deve ter caráter permanente, ser causada por alterações patológicas irreversíveis, ou requerer reabilitação por longo período de tempo (Nicholson et al., 2018).

A multimorbidade é bastante prevalente, ocorre em 55 a $98 \%$ da população idosa (Wolff et al., 2002; Fortin et al., 2005; Marengoni et al., 2011; Fortin et al., 2012), e acompanha o fenômeno global de aumento de condições crônicas de saúde e de aumento de carga de doenças já exposto no início. Dados publicados recentemente de um estudo transversal da avaliação inicial (2015 e 2016) de 9.412 indivíduos do ELSI-Brasil (Estudo Longitudinal da Saúde dos Idosos Brasileiros), mostram prevalência nacional de multimorbidade de $73,4 \%$ para os 60 anos, e de $82,4 \%$ para os 80 anos, considerando a presença de duas ou mais condições crônicas de saúde (Nunes et al., 2018).

Do ponto de vista fisiopatológico, a multimorbidade aumenta o risco de alterações no sistema fisiológico secundárias às interações entre as doenças e seus tratamentos, adicionando chance de complicações e incapacidades ao indivíduo (Nunes et al., 2016). Desse modo, as principais complicações 
da multimorbidade são o prejuízo funcional, a piora da qualidade de vida, a grande utilização de recursos de saúde e seus custos, e a alta mortalidade (Marengoni, 2011; Nunes, 2016). Rizzuto et al conseguiram comprovar o efeito sinérgico da multimorbidade através do seu impacto no índice YLL (Years of Life Lost), onde a presença de todas as doenças causou 7,5 anos de vida perdida com incapacidade, índice maior do que o calculado para cada uma das doenças analisadas separadamente. Além disso, encontraram alta mortalidade $(69,3 \%)$ relacionada à multimorbidade (Rizzuto et al, 2017).

Apesar da crescente importância dos estudos em multimorbidade, ainda existem problemas metodológicos em relação à tentativa de quantificação do fenômeno. Não há consenso nos índices que medem multimorbidade, tanto em relação ao número e tipo de doenças incluídas, quanto ao peso dado a elas de acordo com a severidade ou o impacto que as mesmas promovem no indivíduo. Podemos detectar algumas razões para a falta de consenso entre os índices de multimorbidade, a mais importante delas é a complexidade do próprio fenômeno, que dificilmente pode ser traduzido numa simples lista de doenças, outras razões dizem respeito aos diferentes objetivos propostos pelos diferentes índices, como mortalidade, incapacidade, e qualidade de vida. Além disso, diferentes níveis de assistência e populações diversas requerem foco em diferentes tipos e pesos de doenças (Diederichs et al., 2011).

Nos estudos de multimorbidade em populações de idosos, além da simples lista de doenças, os índices mais utilizados são o Charlson Comorbidity Index (CCI), de 1987, o Index of Co-Existent Diseases (ICED), 
de 1993, e o Cumulative IIIness Rating Scale (CIRS), de 1968 (Marengoni et al., 2011; Marengoni et al., 2016).

Em 1987, Charlson et al. publicaram um índice de comorbidade (Charlson comorbidity index) com o objetivo de estimar o risco de morte em 1 ano de pacientes acompanhadas por neoplasia de mama, com base em suas comorbidades. Nesse primeiro estudo, a idade não foi preditora de mortalidade em 1 ano (Charlson et al., 1987). Esse mesmo grupo, ao analisar o seguimento de 10 anos da mesma população notou que, além das comorbidades, a idade tinha impacto importante na mortalidade. Isso motivou a inclusão dessa variável no índice e nova validação do mesmo em 1994 (Charlson et al., 1994).

O Charlson comorbidity index (CCl) foi extensivamente validado como medida de impacto prognóstico de múltiplas doenças, incluindo mortalidade. Quando ajustado para idade, o Charlson comorbidity index (CCI) consegue estimar mortalidade em 5 anos de uma população. Em 2014, o próprio autor demonstrou que o Charlson comorbidity index (CCl) apresentou utilidade também na predição de custos em saúde (Charlson et al., 2014).

A crítica que se faz ao Charlson comorbidity index (CCl), quando utilizado em geriatria, é a de que as doenças incluídas no índice em geral não refletem as doenças mais prevalentes da das populações geriátricas estudadas, além disso, não é um índice bom quando se quer avaliar severidade de doenças e grau de incapacidades. Por outro lado, é uma ferramenta de fácil e rápida aplicabilidade, como se pode ver no ANEXO B, 
além de continuar contribuindo com correlações interessantes em mortalidade e medidas de prognóstico nos estudos com idosos.

O índice Cumulative IIIness Rating Scale (CIRS) foi desenvolvido por Linn et al., em 1968, inicialmente como uma intuitiva e prática maneira de revisar problemas médicos por sistemas orgânicos, gerando uma escala cumulativa. Essa escala foi revisada para refletir os problemas mais comuns do idoso, e foi renomeada de Cumulative Illness Rating Scale for Geriatrics (CIRS-G), que pode ser visto no ANEXO B (Parmelee et al., 1995). O índice é composto de 14 categorias divididas por sistemas de órgãos, e para cada categoria é pontuado um nível de severidade. O índice é, então, calculado conforme a soma dos níveis de severidade (pontuados de 0 a 4 , sendo $0=$ ausência de problemas e 4 = presença do problema em nível extremamente severo) de cada categoria. Dessa forma, a variação de pontuação do índice é de 0 a 56 (Linn et al., 1968; Parmelee et al., 1995).

A princípio, o índice CIRS-G pode ser aplicado por médicos e enfermeiros, desde que treinados para tal. Existe um manual completo e validado, disponível para o treinamento da aplicação do índice (Miller et al., 1992; Salvi et al., 2008). É recomendável a aplicação do CIRS-G em consultas presenciais com o paciente, para o correto esclarecimento das doenças e melhor classificação nos níveis de severidade, porém os autores não invalidam a sua utilização na forma retrospectiva, através de prontuários e registros dos pacientes. Os estudos que aplicaram o CIRS-G utilizando registros em prontuários de forma retrospectiva confirmaram o seu poder preditivo para mortalidade, hospitalização prolongada, readmissão 
hospitalar, avaliação cognitiva e funcional, deterioração funcional e carga de doença física (Miller et al., 1992; Conwell et al., 1993; Zekry et al., 2010; Beloosesky et al., 2011; Huntley et al., 2012).

A multimorbidade é considerada um bom indicador de saúde, bastante estudada em pesquisa epidemiológica e clínica. Índices de multimorbidade, e não apenas a contagem de doenças, conseguem melhor identificar risco de piora de saúde e prognóstico de uma população, para melhores estratégias de intervenção e políticas públicas (Marengoni et al., 2016).

Os índices de multimorbidade Cumulative Illness Rating Scale for Geriatrics (CIRS-G) e Charlson comorbidity index (CCI) podem ser interessantes para o estudo do envelhecimento, como marcadores de acúmulo de doenças ao longo do tempo e seus impactos em funcionalidade, bem-estar e mortalidade.

\subsection{2 Índices de fragilidade ou acúmulo de déficits na avaliação do prognóstico do envelhecimento}

O acúmulo de déficits é um dos componentes bem estudados para a identificação de idosos frágeis, em risco para situações de maior gravidade em saúde. A partir do estado clínico de fragilidade, considerada uma importante síndrome geriátrica, um grupo canadense, liderado por Rockwood, idealizou um índice (Frailty index, FI) que pudesse medir o estado de vulnerabilidade de uma pessoa a partir do acúmulo de déficits em sua saúde (Rockwood et al., 2000). Através do Frailty index (FI), pessoas 
com poucos déficits seriam consideradas mais saudáveis, e as portadoras de muitos déficits, mais frágeis. No ano seguinte, Mitnitski et al., do mesmo grupo, sugeriram que esse mesmo índice fosse utilizado para comparar individualmente o envelhecimento, e demonstraram o poder do índice em separar idosos frágeis e saudáveis, através de distribuições e curvas de sobrevida diferentes. Esses autores concluíram que índices de fragilidade poderiam ser utilizados como uma medida representativa de todos os déficits acumulados com o envelhecimento, refletindo melhor o que acontece ao longo da vida, onde problemas de saúde se acumulam e modificam a saúde de quem envelhece (Mitnitski et al., 2001). O Frailty index, proposto por Rockwood et al., contém 32 diferentes déficits que se relacionam com o envelhecimento, dentre eles atividades de vida diária, doenças ou problemas prevalentes nos idosos, e autoavaliação da saúde.

Índices de fragilidade ou, também chamados, índices de déficits cumulativos combinam variáveis biológicas e clínicas, incluindo as auto relatadas, que se relacionam com a saúde da população em estudo. São definidos como a proporção entre a contagem simples de déficits de saúde de um indivíduo e o número total de todos os potenciais déficits considerados para aquele indivíduo naquele estudo. Estão fortemente associados com mortalidade, apresentam aumento exponencial com a idade (Figura 4), e efeito "teto", onde a partir do valor de 0.7 em geral existe incompatibilidade com a vida (Mitnitski et al., 2013). As propriedades significativamente preditoras que os índices de fragilidade apresentam dependem mais do número de déficits incluídos, do que da natureza dos 
mesmos, mostrando que as variáveis de saúde raramente independem umas das outras. A taxa de acúmulo de déficits em média cresce $3 \%$ ao ano, independentemente da idade, do número de déficits utilizado no índice, ou de quais déficits são escolhidos (Mitnitski et al., 2001).

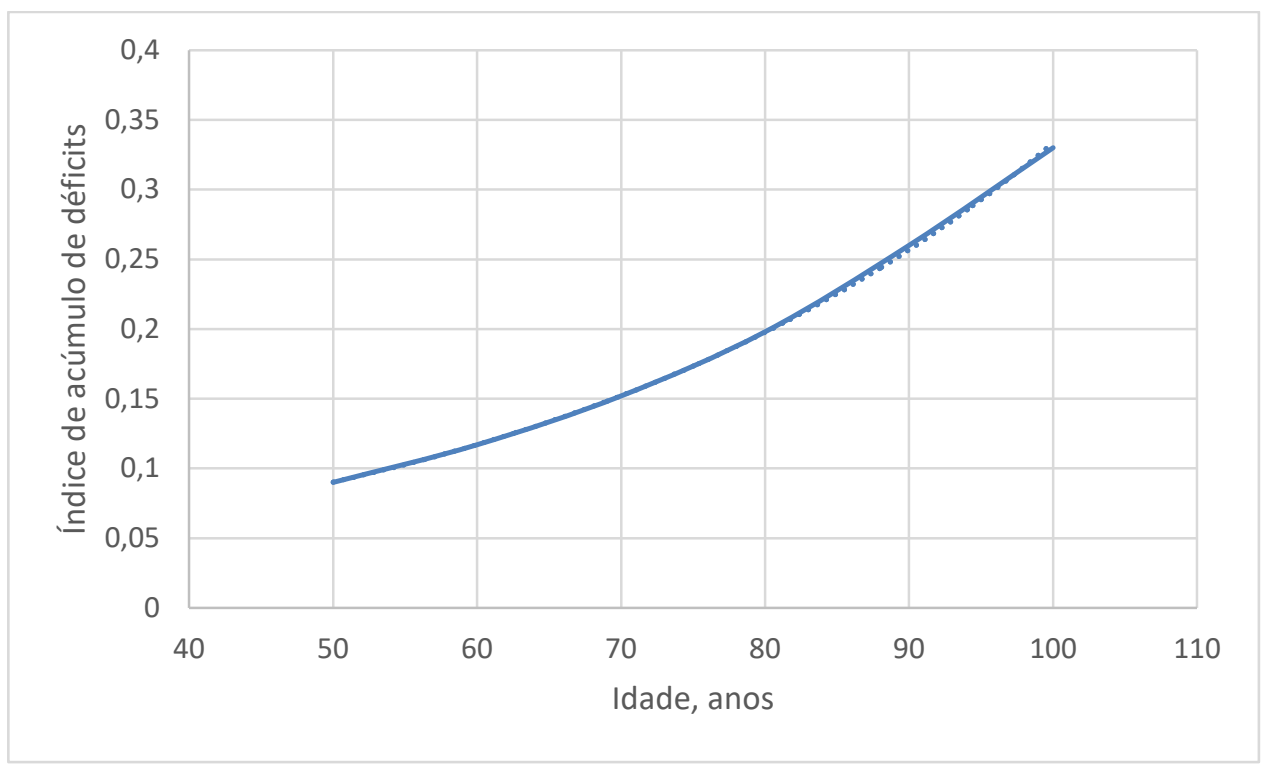

FONTE: Mitnitski et al., 2001. Adaptado de Mitnitski AB, Mogilner AJ, Rockwood K. Accumulation of Deficits as a Proxy Measure of Aging. Scientific World Journal. 2001;1:32336.

Figura 4 - Aumento exponencial do Índice de acúmulo de déficits relacionado à idade cronológica

Kulminski et al. utilizaram o Frailty index (FI), na coorte americana National Long-Term Care Survey (NLTCS), para avaliar a capacidade desse índice em diferenciar fenótipos de longevidade em associação com acúmulos de déficits. O Fl associou-se com tempo de vida, e foi capaz de capturar melhor do que a idade cronológica os anos entre o declínio da performance fisiológica e a morte, uma medida indireta do conceito de 
compressão da morbidade, proposto por Fries em 1980. Além disso, observaram diferenças relacionadas ao sexo, homens tiveram $\mathrm{Fl}$ mais baixos no início do estudo, porém viveram menos, demonstrando talvez maior adaptabilidade das mulheres aos déficits cumulativos, mecanismo fisiológico conhecido como alostase ou capacidade de resistência ao estresse (Fries, 1980; Kulminski et al., 2006; Kulminski et al., 2007). O Frailty index, parece ser, portanto, um índice que traduz comportamentos fisiológicos relacionados ao envelhecimento.

Em recorte populacional da mesma coorte National Long-Term Care Survey (NLTCS), Kulminski et al. avaliaram posteriormente, cerca de 5.000 participantes com potencial de longevidade no início do estudo longitudinal, e aplicaram índices de acúmulo de déficits construídos a partir 85 variáveis. Aplicaram também índices derivados das 85 variáveis, sendo que 0 subgrupo com menos variáveis foi o de 27 déficits, composto de 21 doenças e 6 incapacidades funcionais. Observaram o mesmo poder de discriminação entre os índices, demonstrando a pouca especificidade dos déficits. 0 aumento exponencial do índice de acúmulo de déficits foi mais expressivo quando incluídas variáveis que medem funcionalidade, como no índice de 27 variáveis. Portanto, o acréscimo de variáveis de funcionalidade às variáveis relacionadas a doenças, agrega maior poder ao índice. Foi observado ainda, acúmulo de déficits ao longo dos anos para a população avaliada como saudável no início do estudo (sem multimorbidade e sem incapacidades), na mesma velocidade, ou em alguns momentos até maior, do que a observada para a população não saudável (Kulminski et al., 2011). 
Apesar de ainda pouco numerosos, os estudos demonstram que índices que avaliam acúmulo de déficits (chamados de índices de acúmulo de déficits ou índices de fragilidade) são ferramentas convenientes para a descrição de propriedades estáticas e dinâmicas do processo de envelhecimento, com capacidade de avaliação ao longo do tempo de medidas importantes da saúde do idoso, como a deterioração da saúde global, a sobrevivência, o risco de hospitalização, a chance de longevidade, e o declínio da saúde relacionada à idade (Kulminski et al., 2011).

\subsubsection{A composição dos Índices de Multimorbidade e Fragilidade para o estudo do prognóstico do envelhecimento}

Especialistas nas áreas de interesse em multimorbidade e fragilidade têm apontado, nos últimos anos, a necessidade de estudos que tragam efetividade na promoção de saúde no envelhecimento, principalmente na formação de modelos de cuidados a pacientes complexos (Cesari et al., 2017; Vetrano et al., 2018a).

Até o momento, vários instrumentos e critérios foram desenvolvidos para a avaliação do impacto da multimorbidade e do acúmulo de déficits no indivíduo que envelhece. Isoladamente, nenhum instrumento conseguiu acurácia em detectar o momento a partir do qual o declínio fisiológico sistêmico ultrapassa o limiar de saúde no envelhecimento. Instrumentos que associam medidas de multimorbidade e fragilidade, esta última entendida como um estado fisiológico de maior vulnerabilidade a eventos estressores, 
parecem ser promissores biomarcadores do estado fisiológico de envelhecimento, a exemplo do Frailty index proposto por Rockwood et al (Rockwood et al., 2000; Kulminski et al., 2006), e de outros índices compostos (Santoni et al., 2015; Onder et al., 2015; Marengoni et al., 2016; Santoni et al., 2017) .

Novos instrumentos que associem medidas de fragilidade e multimorbidade (impactos funcionais de acúmulos de doenças), que sejam avaliados de forma contínua em estudos longitudinais e de fácil aplicação na prática clínica, são necessários para avaliar, em termos prognósticos, evoluções individuais do envelhecimento. Dessa forma, o achado de preditores associados a desfechos negativos poderão guiar intervenções individuais e populacionais na promoção do tão almejado envelhecimento saudável (Vetrano et al., 2018a; 2018b).

\subsection{Fatores preditores do envelhecimento saudável - genéticos e epigenéticos}

O conhecimento dos fundamentos para se atingir a longevidade com saúde no envelhecimento está entre os principais anseios e desafios das ciências médicas e biológicas (Brooks-Wilson, 2013). A busca pela longevidade e por um modelo de envelhecimento saudável somente tem sentido se pudermos descobrir os fatores que influenciam esse caminho. Inúmeras variáveis têm sido estudadas nos âmbitos biomédico e psicossocial. 
A longevidade e o envelhecimento saudável são fenótipos, resultados da interação entre o potencial genético e o ambiente, configurando uma plasticidade no envelhecimento. Ou seja, fatores culturais e psicossociais podem modular o processo biológico do envelhecimento, como demonstrado no primeiro estudo longitudinal de Duke, quando se observou que fatores não-genéticos poderiam contribuir com até 16 anos para a longevidade dos homens e até 23 anos das mulheres (Palmore, 1982). Desse modo, se corrigirmos os efeitos em função de doenças e de eventos socioculturais desfavoráveis, podemos imaginar indivíduos que permaneçam na senescência por mais tempo e tornem-se longevos com menos incapacidades funcionais (a esperada "compressão da morbidade" proposta por Fries).

Estudos em populações de centenários mostram que a longevidade excepcional é determinada menos pela hereditariedade genética (25 a 30\%) e mais por fatores ambientais, culturais, sociais e psíquicos construídos ao longo da vida, como estímulos intelectuais, sono e nutrição adequados, boa atividade física e social, medidas de redução do estresse, estabilidade emocional, e adequado enfrentamento psicológico e espiritual diante das dificuldades da vida (Brooks-Wilson, 2013). Estudos de associação genética (do inglês GWAS - Genome-Wide Association Studies) confirmam essa modesta a moderada contribuição da herança genética para a longevidade (20 a 50\%) (Walter et al., 2011).

Sowa et al. estudaram preditores de estilo de vida e psicossociais do envelhecimento saudável (definido no estudo como auto avaliação da saúde 
pontuada como boa ou muito boa, ausência de limitações nas atividades de vida diária, e presença de relato de algum sentido para a vida) em mais de 11.048 idosos participantes de um braço do estudo SHARE (Survey of Health, Ageing and Retirement in Europe, onda de 2010-2011). Os fatores preditores psicossociais e de estilo de vida encontrados foram: atividade física vigorosa ou moderada, consumo alto de vegetais e frutas, nutrição equilibrada, alto consumo de líquidos, estar empregado, participar de atividades sociais fora de casa, realizar-se com atividades dentro de casa, e estar satisfeito com a vida. O nível educacional e a renda foram preditores em alguns dos seis países europeus desse estudo (Sowa et al., 2016).

O MEDIS (Mediterranean Islands Study) é um estudo multicêntrico e observacional que estuda idosos que moram na região do Mediterrâneo, com objetivo de explorar associações de hábitos de vida e características psicossociais e ambientais com fatores cardiometabólicos. Dados recentes do corte transversal da coorte demonstraram associações de idade avançada com fumar menos, fazer menos atividade física, ter menor participação social, menor número de amigos, maior chance de morar sozinho, e visitar menos os serviços de saúde. Não há como estabelecer relação de causa e efeito, e provavelmente exista o efeito da mortalidade seletiva (Foscolou et al., 2018). Na avaliação longitudinal de uma das fases do estudo, o engajamento em atividade física e atividades sociais, além de hábitos dietéticos apresentaram associação positiva com envelhecimento saudável (Mariolis et al., 2016). 
Em revisão de 28 artigos, Depp e Jeste classificaram os preditores do envelhecimento saudável em três níveis de evidência: forte, moderado e limitado, como podemos ver no Quadro 1. Aqueles considerados fortes foram apontados em quatro ou mais estudos e apresentaram associação significativa em $75 \%$ ou mais dos estudos. Os moderados foram definidos como tendo associação significativa em 50 a $75 \%$ dos estudos, e os limitados, os que tiveram associação em menos de 50\% dos estudos (Depp; Jeste, 2006).

Quadro 1 - Preditores do envelhecimento bem-sucedido. Adaptado de Depp CA e Jeste DV. Definitions and Predictors of Successful Aging: A Comprehensive Review of Larger Quantitative Studies. Am J Geriatr Psychiatric 2006;14:6-20

\begin{tabular}{|c|c|c|}
\hline $\begin{array}{c}\text { Preditores fortes } \\
\text { ( } \geq 75 \% \text { dos estudos) }\end{array}$ & $\begin{array}{l}\text { Preditores moderados } \\
\text { (50 a } 75 \% \text { dos estudos) }\end{array}$ & $\begin{array}{l}\text { Preditores fracos } \\
\text { (<50\% dos estudos) }\end{array}$ \\
\hline Idade jovem & Alto nível de atividade física & Elevada renda \\
\hline Ausência de artrite & $\begin{array}{l}\text { Auto avaliação positiva da } \\
\text { saúde }\end{array}$ & Melhor educação \\
\hline $\begin{array}{l}\text { Ausência de problemas } \\
\text { auditivos }\end{array}$ & $\begin{array}{l}\text { Pressão arterial sistólica } \\
\text { baixa }\end{array}$ & Estar casado (a) \\
\hline $\begin{array}{l}\text { Ausência de prejuízo } \\
\text { nas AVDs }\end{array}$ & Poucas condições médicas & Etnia branca \\
\hline Não tabagismo & $\begin{array}{l}\text { Função cognitiva global } \\
\text { preservada }\end{array}$ & \\
\hline & Ausência de depressão & \\
\hline
\end{tabular}

Podemos observar que fatores relacionados às doenças e à multimorbidade, que tenham impacto positivo em capacidade funcional e 
percepção subjetiva, aliados a fatores psicossociais e de estilo de vida, são os principais determinantes do envelhecimento saudável.

Enquanto esse entendimento dos fatores ambientais e de estilo de vida pode otimizar nossa habilidade em prevenir doenças e melhorar a saúde populacional, estudos das bases genéticas da longevidade e do envelhecimento saudável em indivíduos com longevidade excepcional têm contribuído com importantes percepções biológicas. Através desses estudos, entendemos que a sobrevida humana é também influenciada por mecanismos genéticos de garantia de longevidade e proteção à susceptibilidade a doenças, além da influência do ambiente, das interações gene-ambientais e do acaso (Brooks-Wilson, 2013). O conhecimento dos genes que influenciam o curso da vida, preservando a saúde e a sobrevida esperada, ou abreviando seu percurso através do acúmulo de doenças, pode auxiliar na elucidação dos mecanismos biológicos envolvidos no envelhecimento e sugerir novas estratégias terapêuticas que promovam saúde e reduzam acúmulo de déficits ao longo da vida.

A genética claramente contribui, embora de maneira moderada, para a longevidade excepcional e o envelhecimento saudável em humanos (Murabito et al., 2012). Entretanto, a identificação dos genes envolvidos permanece um desafio. Um dos principais contribuintes para essa dificuldade é a heterogeneidade dos fenótipos, que, como citado, são influenciados por fatores não genéticos e ambientais. Desse modo, a escolha de fenótipos alternativos, mais homogêneos do envelhecimento (como exemplo: presença de doença específica; multimorbidade; presença 
de fragilidade e acúmulo de doenças; sobrevivência livre de doenças; preservação de altos níveis de funcionalidade; envelhecimento saudável; envelhecimento bem-sucedido), pode resultar em maior sucesso na descoberta de associação de genes (Murabito et al., 2012; Yashin et al., 2018).

$\mathrm{Na}$ busca de determinantes genéticos da longevidade e de outros fenótipos do envelhecimento, inicialmente os estudos testaram genes candidatos, originários de modelos animais, em populações de famílias longevas e pares de irmãos longevos. Mais recentes, os estudos de associação genômica ampla (GWAS - genome wide association studies), nos quais as variantes genéticas de todo o genoma são testadas para determinados fenótipos, tiveram mais êxito nessa busca (Murabito et al., 2012; Slagboom et al., 2018). Além disso, para melhorar a qualidade da estimativa dos dados genéticos, pesquisadores optam por desenhos de estudos longitudinais que contemplem dados incompletos, ou por metaanálises de dados, apesar das limitações e riscos no sentido de aumento de falsos negativos e erros de viés de seleção para associações positivas (Sebastiani et al., 2017; Yashin et al., 2018).

Os estudos de associação genômica ampla (GWAS - genome wide association studies) conseguiram identificar algumas variáveis genéticas associadas à longevidade e a fenômenos ou doenças complexas. Dentre vários genes candidatos, o locus APOE (que codifica uma apolipoproteína relacionada ao metabolismo de lípides e importante carreadora de colesterol no cérebro) e o locus FOXO3A (que codifica um fator de transcrição ligado a 
regulação do ciclo, autofagia e extensão de vida útil celular) foram os genes que tiveram associação mais robusta com longevidade (Broer et al., 2015; Slagboom at al., 2018). Um terceiro locus apresentou associação mais recente com longevidade, um locus intergênico no cromossomo 5q55.3, associado também a fenótipos de adipogênese, doença cardiovascular, funcionalidade física e estresse psicológico crônico (Deelen et al., 2014; Nygaard et al., 2017; Slagboom et al., 2018).

A primeira grande meta-análise de nove estudos de associação genômica ampla (GWAS - genome wide association studies) para longevidade, realizado em coortes do consórcio CHARGE (Cohorts for Heart and Aging Research in Genomic Epidemiology Consortium) reunindo mais de 25.000 pacientes com idades iguais ou superiores a 55 anos, foram encontrados 14 polimorfismos genéticos de nucleotídeo único (SNPS single nucleotide polymorphism) associados com mortalidade, e 8 associados com sobrevivência livre de doenças, todos altamente expressos no cérebro e envolvidos no desenvolvimento de função neurais, sugerindo portanto que processos neurais possam ser importantes na regulação do processo de envelhecimento (Walter et al., 2011). Outro estudo de associação genômica ampla (GWAS) comparou 763 indivíduos com longevidade excepcional na Alemanha com controles idosos mais jovens, e estudou 664.472 polimorfismos autossômicos. A única variante considerada determinante genética maior de sobrevivência com o avançar da idade foi o gene APOE, sendo que indivíduos longevos apresentaram o alelo $\varepsilon 2$ em maior frequência e o alelo $\varepsilon 4$ em menor frequência do que controles mais 
jovens (Nebel et al., 2011). Em meta-análise de 14 estudos de associação genômica ampla (GWAS) de descendentes europeus longevos ( $\geq 85$ anos) comparados com controles jovens ( $<65$ anos), Deelen et al. encontraram associação de longevidade com o locus TOMM40/APOE/APOC1, no cromossomo 19q13.32, e primeiro identificaram associação com locus rs149954 do cromossomo 5q13.32 (Deelen et al., 2014). Mais recentemente, o maior estudo tipo GWAS para associação genética e longevidade, a partir de biobanco de 75.244 descendentes europeus de longevos, mais uma vez demonstrou associações mais robustas do gene APOE com longevidade, especificamente variantes no locus TOMM40/APOE, sendo que outros genes candidatos apresentaram associações modestas (Pilling et al., 2016).

Além da longevidade, muitos fenótipos ligados a doenças relacionadas ao envelhecimento já têm associações genéticas estabelecidas. Alguns locus foram confirmados em estudos de associação genômica ampla (GWAS), como variantes ligadas a fenótipos relacionados ao tabagismo (câncer de pulmão, doença pulmonar obstrutiva crônica, doença arterial periférica), dependência de álcool, esquizofrenia, doença arterial coronariana, hipertensão arterial sistêmica, obesidade, alterações no metabolismo dos lípides, e doença de Alzheimer. As variantes genéticas do gene APOE estão fortemente associadas, nos diversos estudos, a doenças prevalentes relacionadas ao avanço da idade, especialmente doenças cardiovasculares e doença de Alzheimer (Rosvall et al., 2009; Slagboom et al., 2018; Liehn et al., 2018). 
No entanto, para um entendimento mais amplo do processo de envelhecimento, fenótipos como sobrevivência livre de doenças, idade parental de morte, envelhecimento saudável e idade biológica reduzida, aguardam confirmação de achados em estudos de associação genômica ampla (GWAS) para que possam ser replicados (Slagboom et al., 2018; Sebastiani et al., 2018). Essa dificuldade demonstra a complexidade dos fenótipos relacionados ao envelhecimento biológico em humanos e a necessidade de novos e mais amplos estudos genéticos que busquem novas associações e promovam estratégias de promoção do envelhecimento saudável.

Podemos assim dizer que, até o momento, o gene APOE é um importante, senão o principal, determinante genético de longevidade e de alguns fenótipos de doenças relacionados ao envelhecimento, e que outros fenótipos complexos ligados ao envelhecimento merecem atenção especial na busca de determinantes genéticos.

\subsection{O papel dos genes na longevidade humana e no envelhecimento}

Existem razões que justificam o fato de vivermos com longevidade após a idade maturativa, já que acumulamos fisiologicamente declínio funcional e ficamos cada vez mais longe da possibilidade reprodutiva?

Desde a teoria da seleção natural proposta por Darwin, em 1859, existem evidências de que biologicamente as espécies evoluem para propósitos essencialmente de sobrevivência e reprodução, ou seja, 
características selecionadas que favorecem à sobrevivência da espécie são passadas à prole ao longo de gerações. A partir da descoberta da dupla hélice (Watson; Crick,1953) como estrutura do Ácido Desoxirribonucleico (DNA), que já se sabia estar relacionado com a herança entre gerações, ficou claro o conceito de que as informações eram armazenadas e transmitidas a partir de cópias de sequências de nucleotídeos que contêm as bases nitrogenadas (adenina $-A$, guanina $-G$, citosina $-C$, timina $-T$ ) ligadas a um açúcar (pentose) e um grupo fosfato. Os genes são sequências de nucleotídeos do DNA que determinam o comando de alguma atividade celular e a transmissão de características hereditárias. Nos seres humanos, considerados complexos na evolução das espécies, esse código genético encontra-se nos cromossomos, compostos de fitas de DNA e proteínas estabilizadoras (histonas). O ser humano possui 23 cromossomos. Somente a partir de 2001, a partir do Projeto Genoma Humano, o conteúdo genético humano foi sequenciado em sua totalidade (Goldsmith, 2014).

A hipótese de que o envelhecimento e a longevidade sejam características geneticamente programadas vem sendo defendida desde 1891 por Weismann e seguidores. Ou seja, existiria um propósito evolucionista em se manter o indivíduo até idades mais avançadas que provavelmente beneficiaria futuras gerações, mesmo sendo prejudicial para o próprio indivíduo. Um exemplo seria a característica humana do altruísmo, benéfica para a preservação do grupo, porém deletéria para o indivíduo. Porém, o processo de envelhecimento celular e orgânico se mostra tão individual, complexo e variável, que seria difícil explicar algo totalmente 
programado por um ou alguns genes. Além disso, animais, em sua grande maioria, morrem até hoje em fases precoces da vida, não atuando em benefício do grupo se imaginarmos esse hipotético benefício do envelhecimento, e nem contribuindo para a seleção de genes relacionados ao envelhecimento (Kirkwood, 2002; Gladyshev, 2013; Goldsmith, 2014).

Portanto, seria improvável a existência de genes que programem o envelhecimento. A não programação do processo de envelhecimento e morte, portanto, traz o conceito de que organismos nascem com programações celulares apenas para viverem e se dividirem, e que mecanismos deletérios ocorrem durante a vida e fazem com que o declínio funcional os leve para a morte. Aprofundando esse conceito, a partir dos anos de 1940, os evolucionistas Fisher, Haldane, Medawar e Williams propuseram que a força de seleção dos genes deletérios num organismo decai após a idade reprodutiva, ou seja, esses genes expressam mais tarde seus fenótipos deletérios ao organismo, quando este já se reproduziu, e portanto, não são genes eliminados pela evolução nas gerações. Desse modo, com a idade avançando após a reprodução, a tendência do indivíduo é a de acumular mutações genéticas (teoria do acúmulo de mutações) que expressem características fenotípicas do envelhecimento, explicando, por exemplo, o aparecimento de doenças prevalentes só em fases mais avançadas da vida. Williams ainda postulou que é possível que a alta força de seleção até a fase reprodutiva selecione genes com efeitos benéficos para a sobrevivência e reprodução, mesmo que esses genes selecionados tenham efeitos deletérios em fases mais tardias da vida (teoria do 
antagonismo pleiotrópico) (Fabian; Flatt, 2011). Kirkwood acrescentou mais um conceito a essas teorias não programadas do envelhecimento, o de que conforme observamos uma redução na mortalidade extrínseca de uma população (advinda de menores condições inóspitas ou agressivas do ambiente), a seleção direciona para genes que investem na construção e manutenção do 'soma' (células e tecidos não relacionados com a reprodução), mais adaptados à melhor capacidade de reparo molecular e de resiliência celular a estresses bioquímicos (teoria do soma disponível) (Kirkwood, 2002).

A partir da exposição dessas teorias, Kirkwood predisse em 2002 que: seria improvável a existência de genes específicos para o envelhecimento; os genes importantes para o envelhecimento e a longevidade seriam aqueles selecionados para a manutenção do soma após a idade reprodutiva; seria provável a existência de pontes geneticamente determinadas entre benefícios para idades precoces e viabilidade em fases tardias da vida; e seria provável a existência de uma variedade de mutações genéticas com efeitos deletérios que contribuíssem para características fenotípicas do envelhecimento.

Em teoria mais recente, o geneticista e evolucionista Gladyshev trouxe nova e importante contribuição para o entendimento do processo biológico de envelhecimento, onde a base do envelhecimento seria a imperfeição existente em todos os mecanismos celulares, genéticos, transcripcionais, proteicos, metabólicos, etc. Todos os processos biológicos produzem imperfeições, que podem ser de origem estocástica (aleatória), ou 
determinística (relacionadas a determinadas programações genéticas de células/organismos particulares frente a determinadas exposições ambientais). Essas imperfeições são propriedade de todos os organismos vivos, fazem parte da origem e manutenção da vida, já que a sua existência causa variações que possibilitam organismos mais adaptados de serem selecionados, e são também a verdadeira causa do envelhecimento, na medida em que ajustes no grau de imperfeições definem ajustes no grau de envelhecimento, incluindo o controle da longevidade. Os efeitos de todas as imperfeições dos processos biológicos estão presentes desde o início da vida, se acumulam com o envelhecimento e se tornam deletérias em algum momento. A soma desses efeitos deletérios, definida pelo autor com o termo 'deleterioma', seria uma função do genótipo e do ambiente. Segundo o autor, qualquer fator que ajuste o processo de envelhecimento (em geral, ambiente, genes, mutações, alelos pleiotrópicos, processos estocásticos) pode modificar a longevidade ou tempo de vida, mas não modifica a causa desse processo, que é a existência de imperfeições biocelulares. As doenças relacionadas ao envelhecimento são resultantes de desvios na perfeita sincronização dos processos deletérios ('deleterioma') causados por fatores predisponentes genéticos, ambientais, e estocásticos, estreitando a relação entre envelhecimento e doenças relacionadas a ele (Gladyshev, 2013 e 2016).

A partir dessa última contribuição para o estudo das teorias do envelhecimento, entendemos que quando um gene particular é alterado, afetando a trajetória da longevidade de um indivíduo, isso causa alterações 
moleculares e metabólicas que resultam em diferentes conjuntos de processos deletérios (diferentes 'deleteriomas'). O impacto do processo original deve ser pensado em termos de efeitos cumulativos e sincronizados com contribuições de todos os genes e processos, e não de um gene ou processo únicos. Isso explica a dificuldade em estudarmos um gene particular que determine uma característica fenotípica do envelhecimento. Mutações ou polimorfismos alélicos contribuem para o envelhecimento, mas são apenas uma questão de ajustes na longevidade ou tempo de vida, como um rio que pode modificar o percurso por condições alternativas, mas que em nada modifica a verdadeira causa de sua descida da montanha até o mar, em analogia do próprio autor Gladyshev. A lei da gravidade, a verdadeira causa que levou o rio a descer a montanha e chegar no mar, são as imperfeições que ocorrem em todos os processos biocelulares do ser vivo e que não deixarão de existir (Gladyshev, 2013 e 2016).

É mais racional, portanto, que imaginemos alguns genes envolvidos em processos celulares complexos relacionados à manutenção da vida do organismo, que possam ainda ter variações genéticas e expressões fenotípicas diferentes (pleiotropismo), e que sofram ao longo da vida influências de mutações e fatores epigenéticos que modifiquem individualmente sua expressão fenotípica e interfiram no tempo de vida daquele organismo. Esses seriam considerados os "gerontogenes" ou genes relacionados ao envelhecimento. 


\subsection{Influência do gene da apolipoproteína E (APOE) nos fenótipos do envelhecimento}

\subsubsection{Apresentação do gene APOE, sua variação genética e associações fenotípicas significativas (longevidade e traços fenotípicos de doenças)}

O gene que codifica a proteína apolipoproteína E (proteína envolvida no metabolismo dos lípides e em alguns processos do metabolismo celular, produzida em hepatócitos, macrófagos e astrócitos), gene APOE, é localizado no cromossomo 19 em humanos (Bos et al., 2018). A variação de sua sequência de bases nas posições 112 e 158 resulta em três alelos: APOE $\varepsilon 2\left(\right.$ Cys $^{112}$, Cys $\left.^{158}\right)$, APOE $\varepsilon 3\left(\right.$ Cys $\left.^{112}, \operatorname{Arg}^{158}\right)$ e APOE $\varepsilon 4\left(\operatorname{Arg}^{112}\right.$, $\left.A r{ }^{158}\right)$. O alelo $\varepsilon 4$ da APOE é um gene ancestral entre os primatas (encontradas similaridades com a APOE de primatas), o alelo $\varepsilon 3$ foi derivado do $\varepsilon 4$ durante estágios recentes da evolução humana, e uma subsequente troca de base a partir do $\varepsilon 3$ deu origem ao $\varepsilon 2$. Provavelmente a mudança de dieta dos primatas para os humanos, na evolução, de amplamente baseada em plantas (baixo colesterol) para baseada em carnes (rica em colesterol), propiciou a seleção de alelos dos genes mais adaptativos, como o APOE $\varepsilon 3$ (Chaves; Narayanaswami, 2008).

A frequência dos alelos do gene APOE em amostras populacionais varia com a raça, a idade e o sexo. A frequência média global dos alelos $\varepsilon 2$, $\varepsilon 3$ e $\varepsilon 4$, respectivamente, é de cerca de $7 \%$ (variação de 0 a $20 \%$ ), $79 \%$ 
(variação de 50 a 90\%) e 14\% (variação de 10 a 20\%) (Corbo; Scacchi, 1999; Singh; Singh, 2006; Bos et al., 2018).

Entre as faixas etárias, a frequência do alelo $\varepsilon 2$ aumenta e a do $\varepsilon 4$ diminui com o avançar dos anos, sugerindo efeito protetor do alelo $\varepsilon 2$ na longevidade, e não se deve esperar alteração na frequência do alelo $\varepsilon 3$ com o avançar da idade (Panza, 2009; Kulminski et al., 2014; Sebastiani et al., 2018). No maior estudo populacional brasileiro sobre a distribuição do polimorfismo da APOE, dados de uma amostra de 1.408 idosos do município de Bambuí, Minas Gerais, sugerem frequência dos alelos similar à de outras populações ocidentais (frequências de $\varepsilon 2$, $\varepsilon 3$ e $\varepsilon 4$ respectivamente: 6,5\%, $80 \%$ e $13,5 \%$ ). Os autores relatam influência da raça na prevalência do alelo $\varepsilon 4$ (brasileiros afrodescendentes apresentaram frequência maior do alelo $\varepsilon 4$ ), e ausência de associação entre $\varepsilon 4$ e aumento da idade (Fuzikawa et al., 2007).

Globalmente, a frequência dos alelos do gene APOE é bastante variável, refletindo diferenças raciais, ancestralidade e interferência ambiental na seleção genética (Figura 5). Para todas as raças, a frequência do $\varepsilon 3$ varia de 50 a 90\% (africanos apresentam frequências mais baixas, $54 \%$ em pigmeus africanos e $69 \%$ em população de Ghana; e nativos americanos de origem maia e italianos do sul e da Sardenha, as maiores frequências, ao redor de $90 \%$ ). O alelo $\varepsilon 4$ é menos frequente nos povos do oeste e sul da Europa (frequências ao redor de 5 a 9\%), enquanto que povos do norte da Europa (Finlândia e Suécia) apresentam frequências de 20 a $24 \%$, e pigmeus africanos apresentam a maior frequência $(40,7 \%)$. Essa 
variação na frequência do alelo $\varepsilon 4$ reflete diferenças em hábitos dietéticos e expectativa de vida das populações. As menores frequências do alelo $\varepsilon 2$ (até $2 \%$ encontram-se em populações de siberianos, coreanos e esquimós inuits. Alguns nativos continente americano (indígenas brasileiros das tribos Yanomami e Xavante, mexicanos descendentes dos maias, equatorianos, e aborígenes australianos) não apresentam o alelo $\varepsilon 2$. No restante das populações do globo, a frequência do alelo $\varepsilon 2$ flutua, sem nenhuma tendência particular, entre $2 \%$ e $14,5 \%$, sendo que encontramos as mais altas frequências em países da África e da Oceania (Corbo; Scacchi, 1999; Singh; Singh, 2006; Sebastiani et al., 2018; Bos et al., 2018). 


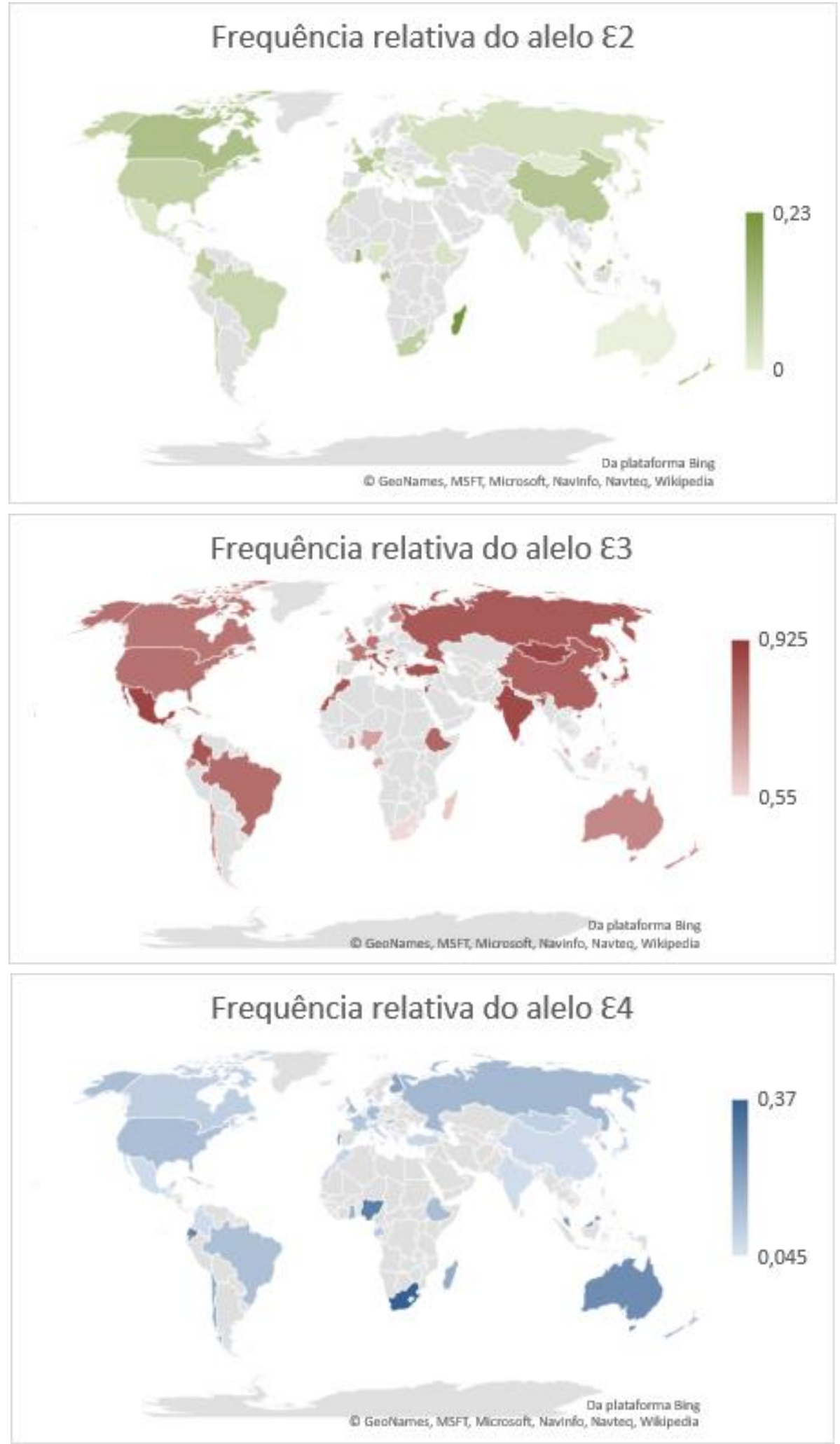

FONTE: Corbo e Scacchi, 1999; Singh, 2006

Figura 5 - Frequências dos alelos $\varepsilon 2$, $\varepsilon 3$ e $\varepsilon 4$ no mundo 
Em relação ao sexo, os dados de associações de gênero com as frequências alélicas e diferenças de expressão fenotípica são pouco consistentes (Kolovou et al., 2009). Até o momento, estudos longitudinais encontraram associação ligada ao gênero significativa da expectativa de vida com os alelos $\varepsilon 2$ e $\varepsilon 4$, sendo o efeito negativo do alelo $\varepsilon 4$ sobre a expectativa de vida mais expressivo em homens e o efeito protetor do alelo $\varepsilon 2$ mais expressivo em mulheres (Rosvall et al., 2009; Kulminski et al., 2014).

Além de polimórfico (a frequência de sua variação alélica atinge mais de $1 \%$ dos alelos da população), o gene APOE é um clássico exemplo de gene pleiotrópico, pois se expressa de diferentes maneiras em funções celulares diversas: metabolismo lipoproteico plasmático, processos oxidativos, inflamação, homeostase dos macrófagos, células gliais e neuronais, função adrenal e processos fisiológicos do sistema nervoso central. Muitos desses processos podem contribuir para a fisiopatologia do envelhecimento e de traços fenotípicos relacionados à idade, e em muitos deles, a expressão do gene da APOE pode ter implicações fenotípicas diferentes nas diversas fases da vida, algumas vezes beneficiando fases mais precoces e trazendo malefícios em fases mais avançadas da vida, configurando um antagonismo pleiotrópico (Kulminski et al., 2016). Com o avançar da idade, para fenótipos do envelhecimento, o alelo $\varepsilon 2$ é considerado protetor, o alelo $\varepsilon 4$ deletério e o alelo $\varepsilon 3$ neutro.

De forma robusta, estudos demonstram efeito protetor do alelo $\varepsilon 2$ para sobrevivência e longevidade, além de associação com redução de níveis de 
colesterol e doenças cardiovasculares, neuroproteção contra doença de Alzheimer e morte neuronal, redução de risco de acidente vascular cerebral em homens, redução de câncer gástrico e algumas doenças infecciosas, proteção celular do estresse oxidativo e morte celular, além de melhora de reparo ao DNA celular. Por outro lado, exemplificando o efeito pleitrópico do gene APOE, dados menos consistentes sugerem associação da presença do alelo ع2 com aumento de incidência de pneumonia, redução de densidade óssea e aumento de osteoporose, e risco aumentado de câncer de cólon (Rosvall et al., 2009; Kulminski et al., 2016; Souza et al., 2017; Sebastiani et al., 2018; Bos et al., 2018).

O alelo APOE $\varepsilon 4$, por sua vez, está fortemente relacionado a fenótipos de doenças relacionadas ao envelhecimento, especialmente doença de Alzheimer e doenças cardiovasculares. Estudos demonstram associação positiva com aumento de mortalidade e redução de expectativa de vida, aumento de colesterol total e LDL-colesterol, risco aumentado de doença ateromatosa (de grandes vasos, doença coronariana e cerebrovascular), de hipertensão arterial sistêmica, de diabetes não insulino-dependente, de progressão de nefropatia diabética e glomerulopatias, de arritmias cardíacas e de demências, em especial doença de Alzheimer (Rea et al., 2001; Bahia et al., 2008; Kulminski et al., 2016; Tindale et al., 2017; Bos et al., 2018; Shi et al., 2018; Sebastiani et al., 2018; Liehn et al., 2018). No metabolismo celular, APOE $\varepsilon 4$ está associado com aumento de estresse oxidativo, disfunção de macrófagos e inflamação, menor retirada de colesterol dos neurônios, aumento de neuroinflamação e de morte celular (Dose et al., 
2016; Bos et al., 2018). Confirmando o papel de pleiotropismo antagônico, o alelo $\varepsilon 4$ está positivamente associado a menor risco de fraturas e perda de densidade óssea, maior proteção contra a degeneração macular relacionada a idade, e aumento de fertilidade em populações jovens com altos índices de mortalidade por doenças infecciosas, como na África (Souza et al., 2017; Xiying et al., 2017; van Exel et al., 2017).

\subsubsection{Associações do gene APOE com outros fenótipos relacionados ao envelhecimento (funcionalidade, sobrevivência livre de doenças, multimorbidade e envelhecimento saudável)}

Associações do gene APOE com outros fenótipos do envelhecimento (sobrevivência livre de doenças; incapacidade física e declínio funcional; severidade de incapacidade; prejuízo multidimensional; fragilidade; velocidade de marcha; força de preensão palmar; função pulmonar; estresse oxidativo celular; auto avaliação da saúde; fatores socioambientais, como fatores estressantes de vida; atividade física; e envelhecimento saudável) ainda apresentam resultados pouco consistentes (Badera et al., 1998; Franceschi et al., 2007; Kulminski et al., 2008; Marcourakis et al., 2008; Rockwood et al., 2008; Zhang et al., 2008; Pilotto et al., 2009; Lan et al., 2009; Murabito et al., 2012; Vasunilashorn et al., 2013; Megale et al., 2016; Tindale et al., 2017; Bos et al., 2018).

Poucos estudos se ocuparam em buscar associação entre o polimorfismo do gene APOE e o envelhecimento saudável, representado 
pela alta funcionalidade e baixa morbidade. A prevalência da hereditariedade dos fenótipos relacionados ao envelhecimento saudável, incluindo funcionalidade, nos estudos de irmãos centenários, é semelhante à encontrada nos estudos de longevidade, cerca de 40\% (Murabito et al., 2012).

O primeiro estudo que procurou associação do genótipo da APOE com funcionalidade, em 218 idosos de comunidade americana, encontrou razão de chance de 2,2 de carreadores do alelo APOE ع4 apresentarem algum prejuízo nas AVD (Albert et al., 1995). Na mesma época, estudo italiano separou idosos octogenários e nonagenários saudáveis (definido como ausência de incapacidades e doenças crônicas severas, especialmente doença cardiovascular e demência) de idosos incapacitados, e não obteve diferenças na distribuição dos alelos do gene APOE entre os dois grupos, contrastando com os achados de menor frequência do $\varepsilon 4$ em longevos saudáveis em estudos de longevidade. Porém, a amostra, além de pequena (100 saudáveis e 62 incapacitados), apresentava baixa prevalência de $\varepsilon 4$ $(5,1 \%)$ e forte influência de fatores dietéticos protetores (Badera et al., 1998). Dados provenientes de 1.529 idosos, estudados na coorte prospectiva americana Duke EPESE, não mostraram associação do alelo APOE $\varepsilon 4$ com declínio funcional, medido por combinação de escalas de atividade de vida diária e saúde física. Houve interação significativa com o gênero, mulheres funcionais carreadoras do alelo APOE $\varepsilon 4$ na avaliação inicial apresentaram mais declínio funcional (Blazer et al., 2001). No estudo longitudinal da coorte de Framingham, foi encontrada hereditariedade em 44\% de 2614 
participantes para o fenótipo incapacidade física, dados condizentes com outra grande coorte dinamarquesa (Murabito et al., 2012). A partir dos dados de estudos de associação ampla com o genoma (GWAS) relacionados à longevidade e sobrevivência livre de doenças ou morte, foi realizada metaanálise com mais de 25.000 indivíduos acima de 55 anos e nenhuma associação teve significância genômica, apesar de 8 polimorfismos terem sido apontados como associados com sobrevivência livre de doenças (Walter et al., 2011; Murabito et al., 2012). No estudo SEBAS, em Taiwan, foram avaliados indicadores de funcionalidade física, incluindo capacidade de realização de atividades de vida diária, em cerca de 1000 indivíduos com idade média de 66 anos, e não foi encontrada associação com o gene APOE na avaliação transversal (Vasunilashorn et al., 2013). Em análise longitudinal da mesma coorte, o alelo APOE $\varepsilon 4$ associou-se com maior dificuldade na realização de atividades de vida diária (ADL) nos 6 anos de seguimento (razão de incidências acumuladas; $I R R=1,87$ ) (Chen et al., 2017). Outro estudo de amostra populacional americano de 1805 idosos (NLTCS, National Long-Term Care Survey), com idade média ao redor de 75 anos, demonstrou significativo aumento de risco de incapacidades nos portadores do alelo APOE $\varepsilon 4$, embora de maneira paradoxal tenha observado menores chances de desenvolvimento de incapacidades mais sérias nos homozigotos para $\varepsilon 4$ do sexo feminino (mulheres não carreadoras tiveram 5,3 vezes mais chance de evoluir com prejuízos severos de ADL), além de efeito protetor em homens com homozigose do $\varepsilon 3$ (Kulminski et al., 2008). Em estudo brasileiro, da coorte da cidade de Bambuí, em Minas Gerais (Bambuí Health 
and Aging Study), a presença do alelo APOE $\varepsilon 4$ foi associada a menor perda funcional $(\mathrm{OR}=0,65 ; 95 \% \mathrm{IC}: 0,47-0,92)$ em análise transversal de 1.496 idosos. Autores sugerem efeito pleiotrópico do alelo APOE $\varepsilon 4$ para eventual proteção da população contra infecções e situações de desnutrição, como encontrado em outras populações de risco no Brasil e na África (Megale et al., 2016).

Como visto nesses estudos, os resultados relativos a efeitos protetores ou deletérios da variação genética do APOE em fenótipos importantes do envelhecimento, especialmente funcionalidade, são pouco consistentes e contraditórios. Nos escassos estudos, o alelo APOE ع4 é considerado promotor em alguns dados, e em outros, protetor de perda de funcionalidade. Apesar disso, o gene APOE é considerado o gene mais relacionado com os outros fenótipos do envelhecimento além da longevidade, e merece atenção e aprofundamento no estudo de suas correlações (Brooks-Wilson, 2013; Tindale et al., 2017).

Não existem estudos até o momento que tenham avaliado associações do gene APOE com medidas de multimorbidade, como fenômeno mais amplo, ou com conceitos multidimensionais de envelhecimento saudável.

A análise dos mecanismos pleiotrópicos que relacionem genes a esses traços fenotípicos relacionados à idade (funcionalidade, grau de incapacidades ou acúmulo de déficits, sobrevivência livre de doenças, multimorbidade, e envelhecimento saudável) tem como importantes objetivos translacionais: determinar grupos populacionais de risco para esses traços; auxiliar no entendimento dos mecanismos fisiológicos 
mediados pelos genes; e propor estratégias de prevenção e novos modelos terapêuticos para um envelhecimento saudável (Kulminski et al., 2016). 
2 Hipóteses de Pesquisa 


\section{HIPÓTESES DE PESQUISA}

Fatores genéticos estão associados com fenótipos do envelhecimento. Estudos transversais em populações longevas, longitudinais e estudos de associação genômica ampla (GWAS), têm apontado como único gene associado de maneira consistente à longevidade e a alguns fenótipos do envelhecimento (demência e doença cardiovascular), o gene da Apolipoproteína E (APOE). Fenótipos mais sistêmicos e homogêneos, como o do envelhecimento saudável, podem sofrer menos influências dos fatores epigenéticos (comportamentais e ambientais) quando se buscam associações genéticas. Até o momento, entretanto, a associação do gene APOE com fenótipos alternativos, como o envelhecimento saudável, não tem sido demonstrada de maneira consistente. Nossa hipótese é que seja possível que o polimorfismo do gene APOE, através dos seus três alelos $\varepsilon 2$, $\varepsilon 3$ e $\varepsilon 4$, determine padrões diferentes de evolução de funcionalidade e morbidade ao longo do tempo, já que sabidamente são determinantes de doenças e de menor sobrevida, influenciando o prognóstico do envelhecimento. 
3 Objetivos 


\section{OBJETIVOS}

\subsection{Objetivo geral}

Determinar a influência do polimorfismo do gene APOE (alelos $\varepsilon 2$, $\varepsilon 3$ e ع4) nos índices prognósticos do envelhecimento (multimorbidade, funcionalidade e acúmulo de déficits) em dez anos da vida de idosos ambulatoriais.

\subsection{Objetivos específicos}

Determinar a influência de fatores epigenéticos (sociodemográficos, clínicos, hábitos de vida, e auto avaliação da saúde) nos índices prognósticos de envelhecimento (multimorbidade, funcionalidade e acúmulo de déficits) em dez anos da vida de idosos ambulatoriais.

Investigar se, o polimorfismo do gene APOE, fatores epigenéticos (sociodemográficos, clínicos, hábitos de vida, e auto avaliação da saúde) e o índice de acúmulo de déficits (DI), determinam diferenças na mortalidade em dez anos. 
4 Métodos 


\section{MÉTODOS}

\subsection{Delineamento da pesquisa}

Trata-se de um estudo longitudinal de dez anos de uma coorte retrospectiva de idosos ambulatoriais.

A avaliação inicial foi realizada em 2004 com a coleta de sangue para a análise do polimorfismo do gene APOE e entrevista clínica para obtenção de dados sociodemográficos, clínicos e de autoavaliação da saúde.

A avaliação longitudinal foi realizada após dez anos, através da análise retrospectiva de prontuários e coleta de dados clínicos para a análise dos desfechos.

\subsection{Recrutamento, local e participantes da pesquisa}

O estudo foi realizado no Hospital das Clínicas da Faculdade de Medicina da Universidade de São Paulo (HC-FMUSP), no ambulatório do Serviço de Geriatria do hospital, onde foram recrutados, em 2004, idosos de 60 anos ou mais de idade, provenientes do Grupo de Assistência Multidisciplinar ao Idoso Ambulatorial (GAMIA).

O GAMIA é um ambulatório assistencial, dentro do Serviço de Geriatria do hospital, fundado em 1984, cujo enfoque é o cuidado integral e multidisciplinar dos pacientes, com preocupação em estratégias de 
promoção de saúde, incluindo o controle de doenças. Anualmente são selecionados 30 idosos da comunidade, através de procura espontânea, sendo que, muitos comparecem à triagem anual por indicação de idosos já participantes do grupo. Essa seleção é realizada por uma equipe multidisciplinar composta pelos médicos do serviço e equipe de gerontologia (enfermagem, psicologia, serviço social, odontologia, nutrição, fisioterapia, fonoterapia e farmácia), utilizando-se de critérios de escolha de pacientes que possam se beneficiar do programa, em especial que necessitem de socialização e promoção de saúde, tenham poucas e bem controladas doenças, e sejam independentes.

Aliada à assistência diferenciada, incluindo consultas ambulatoriais mais regulares, esse ambulatório também é responsável por atividades de ensino aos alunos de graduação da Faculdade de Medicina e aos médicos residentes em Geriatria, com supervisão dos médicos assistentes do serviço.

\subsection{Avaliação inicial da amostra no ano de 2004}

Entre março e junho de 2004, idosos do GAMIA foram recrutados de maneira aleatória no momento de suas consultas de rotina e convidados a participar de um estudo de bases genéticas realizado na ocasião pelo Laboratório de Investigação Médica em Neurologia do Hospital das Clínicas da FMUSP (LIM/15).

Um total de 162 idosos aceitou de maneira esclarecida e voluntária, e após observados critérios de inclusão e exclusão dos participantes (Quadro 
2), técnicos e pesquisadores do LIM/15 coletaram amostras de sangue periférico que incluíam a determinação do genótipo da apolipoproteína $E$ (gene APOE) através da extração do DNA de leucócitos.

No mesmo momento, por nossa iniciativa, foram realizadas entrevistas clínicas com obtenção de dados sociodemográficos (idade, sexo, cor da pele, escolaridade, estado civil, arranjo domiciliar de moradia), questionamento sobre atividades funcionais (índice de atividades básicas de vida diária de Katz - ABVD, e escala de atividades instrumentais de vida diária de Lawton - AIVD) (Katz e Akpom, 1976; Duarte et al., 2007; Lawton e Brody, 1969; Lopes dos Santos e Virtuoso Junior, 2008), atividades cognitivas e físicas (escala desenvolvida por Verghese et al., 2003), e autoavaliação da saúde (Pagotto et al., 2013). ANEXO B.

Quadro 2 - Critérios de inclusão e exclusão da população na avaliação inicial

\section{Critérios de inclusão para a avaliação inicial da população}

1. Ser inscrito no atendimento ambulatorial do GAMIA (Grupo de Atendimento Multidisciplinar ao Idoso Ambulatorial) do Serviço de Geriatria do HC-FMUSP, ou seja, que preencheram critérios de escolha para tal (idade de 60 anos ou mais; ter poucas doenças e não incapacitantes na entrada; ter benefício de atendimento multidisciplinar na entrada, que incluem ações promotoras de saúde e de socialização).

2. Aceitar participar da entrevista e coleta de material genético, através de termo de consentimento livre e esclarecido (ANEXO A)

\section{Critérios de exclusão para a avaliação inicial da população}

1. Recusa ao convite para participação da pesquisa

Os dados da avaliação inicial utilizados para a análise (tempo zero) foram colhidos nessa entrevista clínica inicial, e complementados, na etapa 
de coleta retrospectiva após dez anos, com os hábitos de vida (tabagismo e etilismo), e informações das doenças e medicamentos da data da avaliação inicial.

Os critérios descritivos dos dados utilizados para a análise da avaliação inicial do estudo encontram-se detalhados no quadro a seguir (Quadro 3):

Quadro 3 - Descrição das características sociodemográficas e clínicas, hábitos de vida, auto avaliação da saúde, e características genéticas da avaliação inicial

\section{Características sociodemográficas}

Idade

Sexo

Cor

Escolaridade

Arranjo domiciliar

\section{Características Clínicas}

Atividades de Básicas de Vida Diária (ABVD)*

Atividades Instrumentais de Vida Diária (AIVD)*

Índice de multimorbidade CIRS$G^{*}$

Índice de multimorbidade CIRSG CM2*

Índice de multimorbidade $C C{ }^{*}$ Índice de acúmulo de déficits, $D l^{*}$

Número de medicamentos*
Número de anos completos

Masculino ou feminino

Branca ou não-branca

Número de anos de estudo conforme última série escolar completa

Mora com alguém ou mora sozinho

Número de atividades básicas de vida diária conforme índice proposto por Katz ( 0 a 6)

Número de atividades instrumentais de vida diária conforme escala proposta por Lawton (0 a 8)

Número total (0 a 56)

Número de categorias marcadas com nível de gravidade $\geq 2$ ( 0 a 14)

Número total (0 a 33)

Número calculado pelo CIRS-G CM2 (0 a 14) somado a $A B V D$, exceto continência urinária (0 a 5) e AIVD (0 a 8) dividido por 27

Número total de medicamentos que está prescrito no prontuário 
Quadro 3 - Descrição das características sociodemográficas e clínicas, hábitos de vida, auto avaliação da saúde, e características genéticas da avaliação inicial (conclusão)

\begin{tabular}{|ll|}
\hline $\begin{array}{l}\text { Hábitos de vida } \\
\text { Tabagismo* }\end{array}$ & $\begin{array}{l}\text { Uso atual ou prévio de fumo de tabaco, } \\
\text { independentemente da carga tabágica }\end{array}$ \\
Etilismo* & $\begin{array}{l}\text { Uso atual ou prévio de álcool no mínimo } \\
4 \times / \text { semana }\end{array}$ \\
Atividade Física & $\begin{array}{l}\text { Faz ou não alguma atividade física pelo } \\
\text { menos 1 vez na semana (ANEXO B) }\end{array}$ \\
Atividade Cognitiva & $\begin{array}{l}\text { Faz ou não alguma atividade cognitiva pelo } \\
\text { menos 1 vez na semana (ANEXO B) }\end{array}$ \\
Atividade Social & $\begin{array}{l}\text { Participa de grupos de discussão pelo menos } \\
\text { Atividade Metabólica }\end{array}$ \\
Faz ou não atividades de impacto metabólico \\
(subir 2 lances de escada e/ou serviço de \\
casa) pelo menos 4 vezes na semana \\
(ANEXO B) \\
Auto avaliação da saúde
\end{tabular}

ABVD = Atividades Básicas de Vida Diária (Katz e Akpom, 1976) ; AIVD = Atividades Instrumentais de Vida Diária (Lawton e Brody, 1969); CIRS-G = Cumulative Illness Rating Scale for Geriatrics (Linn et al., 1968); CIRS-G CM2 = CIRS-G de categorias marcadas com nível de gravidade $\geq 2 ; \mathrm{CCl}=$ Charlson comorbidity index (Charlson et al., 1987).

* Características obtidas na fase de coleta retrospectiva dos dados do estudo, descritas no item 4.3. 


\subsection{Avaliação longitudinal retrospectiva da amostra - seguimento de dez anos (2004 a 2014)}

Após dez anos do momento inicial (tempo zero = coleta do material genético e entrevista clínica), foi realizada coleta de dados retrospectivos com o intuito de responder aos objetivos propostos.

As fontes dos dados retrospectivos foram:

- prontuários hospitalares institucionais fornecidos pelo Serviço de Arquivo Médico (SAME) do HC-FMUSP;

- prontuário eletrônico desenvolvido pelo Serviço de Geriatria do HC-FMUSP (PRONTMED);

- dados coletados e arquivados no próprio ambulatório pela equipe médica do GAMIA;

- sistema de prescrição eletrônica de medicamentos do hospital (Sistema de Prescrição Eletrônica Ambulatorial de Medicamentos - SIGH-FAR, desenvolvido pela Prodesp para o HC-FMUSP);

- sistema eletrônico de resultados de exames do hospital (HC-LAB, Divisão de Laboratório Central HC-FMUSP);

- site de busca de falecidos, disponível em https://www.falecidosnobrasil.org.br/. [acesso em 21/11/2018]

A avaliação retrospectiva foi obtida para cada um dos participantes escolhendo-se registros em prontuário de uma consulta em cada ano, a partir da avaliação inicial de 2004 até 2014, sendo que cada consulta 
subsequente deveria estar no período de 9 a 15 meses de intervalo da consulta precedente (Quadro 4).

Dessa maneira, obtivemos dez avaliações de cada paciente, uma por ano, além da avaliação inicial. As avaliações foram assim identificadas para a confecção da planilha base da análise: tempo zero, t0 (ano 2004); tempo 1, t1 (ano 2005), e assim por diante, até o tempo 10, t10 (ano 2014).

Quadro 4 - Critérios de inclusão e exclusão - Avaliação retrospectiva

\section{Critérios de inclusão para a avaliação retrospectiva}

1. Ter realizado a avaliação inicial completa no ano de 2004 , que constava de entrevista clínica e genotipagem da apolipoproteína E (APOE)

2. Apresentar funcionalidade total na avaliação inicial de 2004 (pontuação de total de ABVD e AIVD)

3. Manter acompanhamento no GAMIA (Grupo de Atendimento Multidisciplinar ao Idoso Ambulatorial) a partir da avaliação inicial, por pelo menos 9 meses

\section{Critérios de exclusão para a avaliação retrospectiva}

2. Perda de qualquer dado da avaliação inicial, genético ou da entrevista clínica

3. Presença de qualquer incapacidade para atividades de vida diária (ABVD e/ou AIVD)

4. Perda de acompanhamento no GAMIA após 9 meses da avaliação inicial

Dos 162 participantes da avaliação inicial, 139 apresentavam dados completos na avaliação inicial (genéticos, sociodemográficos e clínicos), destes, 8 foram excluídos por apresentarem perda de funcionalidade na avaliação inicial. Dos 131 participantes que restaram, 6 perderam seguimento antes de 9 meses do tempo zero, restando, portanto, 125 participantes, amostra essa que utilizamos para a avaliação retrospectiva de todos os dados que discriminaremos a seguir (Figura 6). 


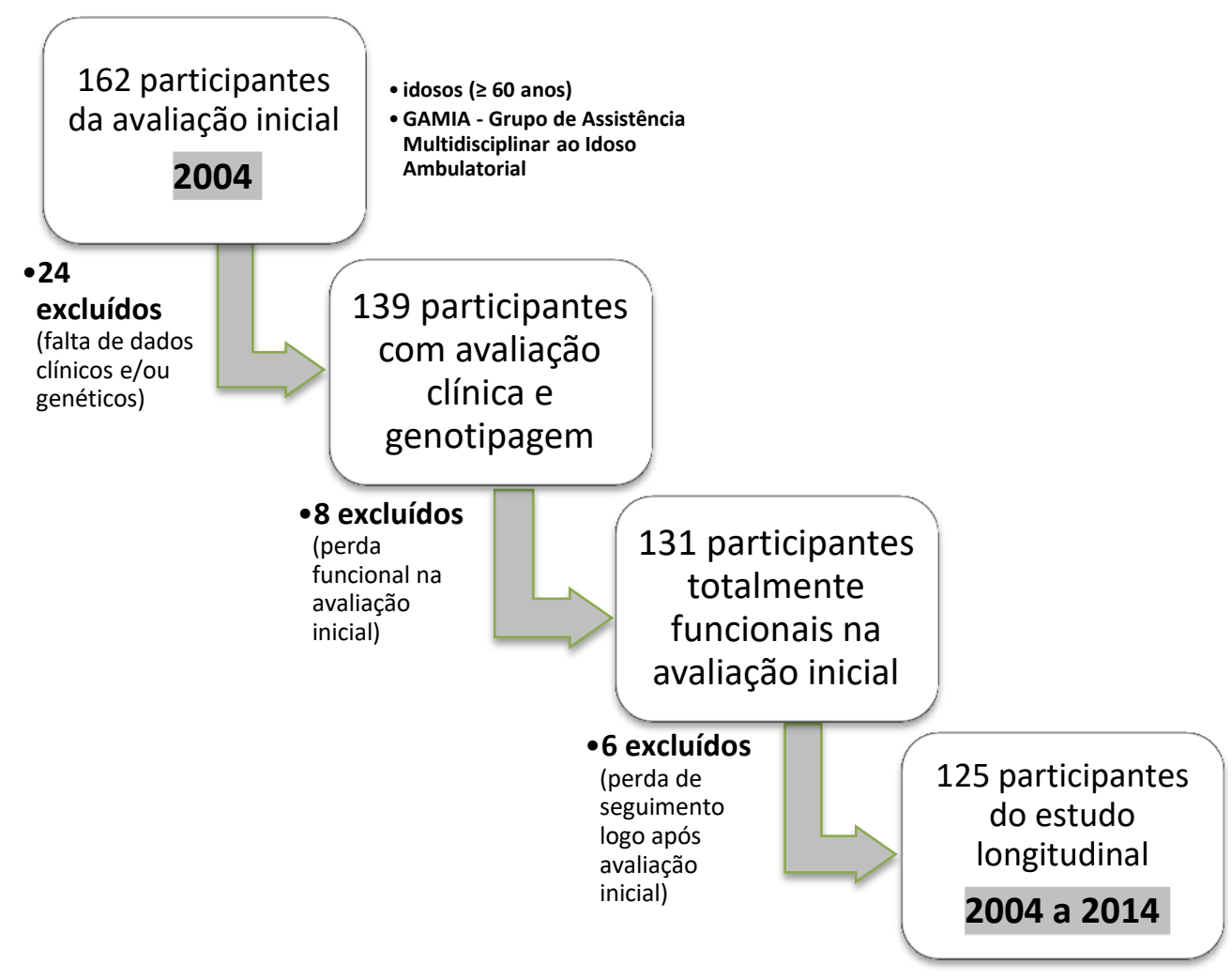

Figura 6 - Processo de recrutamento da amostra; ambulatório de geriatria do HC-FMUSP - 2004

Os dados genéticos permaneceram fechados para o examinador, até a finalização da coleta de dados da fase retrospectiva, e foram abertos apenas após a finalização total da coleta, quando foram calculadas a distribuição e frequência dos alelos do gene APOE.

Ao final, para cada ano, de 2004 a 2014, cada um dos 125 participantes do estudo apresentava dados de doenças e medicamentos, utilizados para o cálculo dos índices de multimorbidade, CIRS-G, CIRS-G CM2, e CCl. Porém, para a funcionalidade, as atividades de vida diária nem 
sempre foram relatadas em todas as consultas analisadas, e, somente foram considerados os relatos de ABVD e AIVD quando pontuados de forma completa, ou quando explicitado no texto da consulta como "totalmente funcional para ABVD e AIVD".

\subsubsection{Avaliação de multimorbidade}

A multimorbidade foi medida através dos índices Cumulative Illness Rating Scale for Geriatrics (CIRS-G) (Parmelee et al., 1995), e Charlson comorbidity index (CCI) (Charlson et al., 1987), aplicado para cada tempo de avaliação, desde a avaliação inicial (t0 a t10) (ANEXO B).

O CIRS-G é uma escala idealizada para medir problemas médicos por sistemas de órgãos, como já explicado na introdução, com ênfase em problemas médicos crônicos comuns no idoso, e que gera um índice cumulativo baseado na presença e nível de gravidade de cada categoria sistêmica (14 categorias sistêmicas; 0 a 4 de severidade para cada categoria). A escala permite várias maneiras de medir a multimorbidade: por número total ( 0 a 56); por número total de categorias pontuadas ( 0 a 14); por índice de gravidade - pontuação total/número de categorias pontuadas; ou por número de categorias pontuadas conforme nível 2, 3 ou 4 de gravidade. 
Quadro 5 - Índice Cumulative IIIness Rating Scale for Geriatrics (CIRS-G)

\begin{tabular}{|c|c|}
\hline & ÍNDICE CIRS-G \\
\hline & 0 - Nenhum problema \\
\hline o & 1 - Problema leve atual ou significativo no passado \\
\hline 芯 & 2 - Incapacidade moderada ou terapia inicial necessária \\
\hline 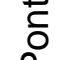 & 3 - Incapacidade grave ou constante, problema crônico incontornável \\
\hline & $\begin{array}{l}4 \text { - Acometimento grave, tratamento imediato necessário, incapacidade } \\
\text { completa }\end{array}$ \\
\hline & Coração \\
\hline & Vascular \\
\hline & Hematopoiético \\
\hline & Respiratório \\
\hline & Olhos, ouvidos, nariz, faringe, laringe \\
\hline & Digestório alto \\
\hline & Digestório baixo \\
\hline & Fígado \\
\hline & Renal \\
\hline & Genitourinário \\
\hline & Musculoesquelético/tegumentar \\
\hline & Neurológico \\
\hline & Endocrinometabólico/mamas \\
\hline & Psiquiátrico \\
\hline & Número de categorias pontuadas \\
\hline & Total geral \\
\hline & Número de categorias com nível de gravidade $\geq 2$ \\
\hline
\end{tabular}

Adaptado do artigo original do autor: Parmelee PA. J Am Geriatr Soc 1995;43:130-137

Aplicamos para cada participante, em cada um dos dez tempos (t0 a t10): o número total do CIRS-G (0 a 56) e o número de categorias de morbidade pontuadas como nível de gravidade $\geq 2$, que nomeamos de CIRS-G CM2 (0 a 14), conforme visto no Quadro 5. 
Foi necessário um treinamento do pesquisador principal para a melhor aplicação da escala, orientado por um manual de acesso aberto ao público (Miller, 1992; Salvi et al., 2008). Os autores sugerem a aplicação em pacientes vivos, de forma presencial, porém declaram que não se opõem à sua aplicação em dados retrospectivos provenientes de prontuários. Todos os dados da fase longitudinal, principalmente a aplicação do índice CIRS-G, foram realizados por um único pesquisador, no caso, o principal, o que trouxe uma uniformização na interpretação da coleta de dados, fundamental, em nosso entendimento, para a utilização do CIRS-G de forma retrospectiva.

Além do CIRS-G, utilizamos também o Charlson comorbidity index (CCl) original, conforme visto no Quadro 6. 
Quadro 6 - Charlson comorbidity index (CCl)

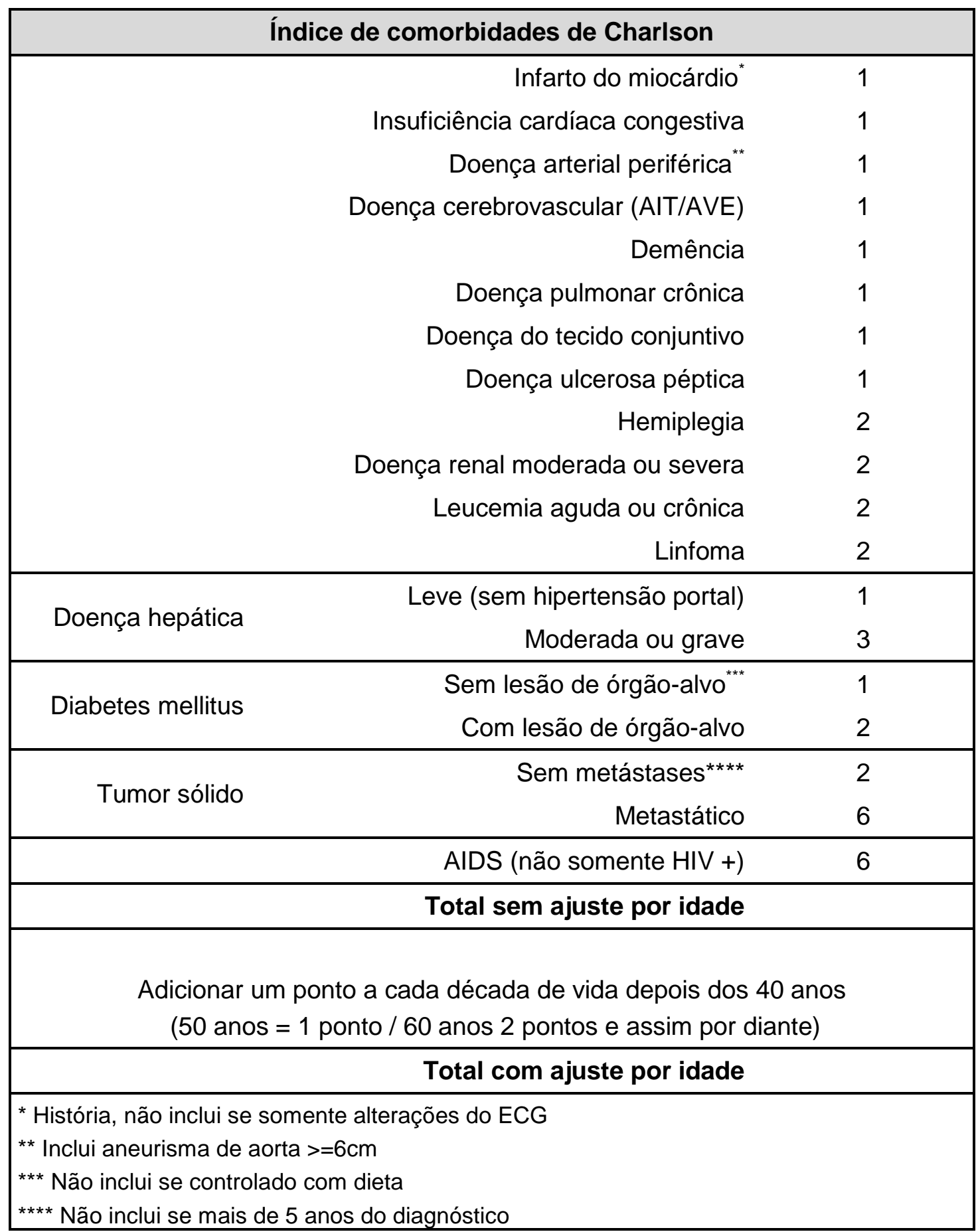

Adaptado do artigo original do autor: Charlson ME. J Clin Epidemiol. 1994;47:1245-51. 
Para a análise estatística das características basais da avaliação inicial, categorizamos os índices de multimorbidade CIRS-G e CCI, em três níveis: leve, moderado e grave, mediante divisão da distribuição dos valores contínuos por tercis.

Na análise do seguimento longitudinal, utilizamos os índices CIRS-Ge CCl como variáveis contínuas para a análise de predição dos fatores genéticos e não-genéticos (sociodemográficos, clínicos, hábitos de vida e autoavaliação da saúde).

O índice CIRS-G CM2, sensibilizado para nível de gravidade, foi utilizado na confecção do índice de acúmulo de déficits (DI), como será explicado a seguir.

\subsubsection{Avaliação de funcionalidade}

A funcionalidade de cada participante foi avaliada através das escalas de atividades básicas e instrumentais de vida diária (ABVD e AIVD) registradas nos dez anos de avaliação (t0 a t10) (Lawton; Brody, 1969; Katz; Akpom, 1976). Como são medidas importantes de serem obtidas com a presença do participante, e a coleta foi retrospectiva, consideramos somente os dados de funcionalidade quando o médico que atendeu a consulta descreveu no prontuário a funcionalidade através de pontuação das escalas de ABVD e AIVD, ou quando descreveu como "totalmente funcional nas ABVD/AIVDs". 
Para a avaliação da funcionalidade no seguimento, foi considerada perda de funcionalidade quando ocorreu perda de pelo menos uma das atividades básicas de vida diária (ABVD) de 5 categorias (excluindo-se a continência urinária), ou perda de pelo menos uma das atividades instrumentais de vida diária (AIVD) em relação às atividades que tinha no tempo precedente. Esse tempo de perda de funcionalidade, avaliado em anos, foi utilizado para a análise de sobrevida para a predição de fatores genéticos e não-genéticos no seguimento de dez anos.

\subsubsection{Avaliação de acúmulo de déficits}

O acúmulo de déficits, entendido como a somatória de variáveis biológicas e clínicas que têm impacto na saúde da população em estudo, é uma medida importante para a avaliação do prognóstico do envelhecimento. Ou seja, dos 125 participantes, queríamos dimensionar quais evoluíram ao longo dos dez anos com preservação de saúde no envelhecimento, e quais se desviaram da perda fisiológica esperada para aquele período.

O índice utilizado para essa medida de acúmulo de déficits foi por nós idealizado, baseando-se em critérios permitidos em estudos da literatura médica pertinente, para os quais o índice é a proporção entre a contagem simples de déficits de saúde de um indivíduo e o número total de todos os potenciais déficits considerados para aquele indivíduo naquele estudo. Segundo os critérios propostos, o índice deverá ser de no mínimo 20 categorias utilizadas, escolhidas pelo pesquisador de maneira a melhor 
representarem a saúde da população naquele estudo, sem especificidade de quais, sendo que o acréscimo de variáveis de funcionalidade às variáveis escolhidas relacionadas a doenças agrega maior poder ao índice.

Utilizamos como modelo, o índice proposto por Kulminski et al., em 2011, composto por 27 categorias que agregavam 21 doenças e 6 incapacidades funcionais, através do qual conseguiu avaliar prognóstico do envelhecimento em coorte de cerca de 5000 indivíduos da coorte National Long-Term Care Survey (NLTCS) (Kulminski et al., 2011).

Nosso índice de acúmulo de déficits (DI ou Déficit Index) foi composto pela soma do CIRS-G CM2 (categorias do CIRS-G pontuadas com nível de gravidade $\geq 2$ ), de 0 a 14 , com as medidas de funcionalidade avaliadas pelas atividades de vida diária (ABVD de cinco categorias, excluída a incontinência urinária, pois esta já é medida pelo CIRS-G, e AIVD de oito categorias). Portanto o número máximo de categorias do nosso índice é de 27 (14 categorias relacionadas a doenças, e 13 categorias relacionadas a funcionalidade), e a variação do índice é de 0 a 1.

O índice de acúmulo de déficits (DI) foi aplicado para todos os pontos de coleta de cada paciente, ao longo dos dez anos, que continham dados completos de funcionalidade, já que os dados de multimorbidade sempre estavam completos.

Consideramos avaliar a saúde no envelhecimento da nossa amostra ao longo do tempo (prognóstico do envelhecimento, ou relação entre o envelhecimento observado na população em estudo e o envelhecimento 
esperado pelos mecanismos naturais fisiológicos), através da utilização do índice de acúmulo de déficits (DI).

O índice de acúmulo de déficits (DI) é apropriado para a avaliação do prognóstico do envelhecimento, e espera-se que exista uma perda natural de $3 \%$ do DI para cada ano de evolução do envelhecimento (taxa extraída de curvas exponenciais de avaliações de vários estudos, e que segundo os autores desses estudos, sempre segue uma constante, derivada de uma equação logarítmica) (Mitnitski et al., 2001).

Para cada participante da amostra, ao longo dos dez anos de evolução, foi considerada perda de envelhecimento fisiológico quando o acúmulo de déficits calculado pelo Déficit Index (DI) passou a ser maior do que o esperado (aumento de $3 \%$ ao ano em relação ao DI inicial calculado no tempo zero). Esse tempo de perda de envelhecimento fisiológico, avaliado em anos, foi utilizado para a análise de sobrevida para a predição de fatores genéticos e não-genéticos no seguimento de dez anos.

\subsubsection{Avaliação de mortalidade}

A mortalidade total foi avaliada ao longo dos dez anos de evolução da amostra. O tempo para a morte de cada participante do grupo que morreu, avaliado em anos, foi utilizado para a análise de sobrevida para a predição de fatores genéticos e não-genéticos no seguimento de dez anos. 


\subsubsection{Desfechos e variáveis de interesse}

\subsubsection{Desfechos}

O desfecho primário selecionado foi:

- perda de envelhecimento fisiológico, medida pelo tempo até o aumento maior que o esperado ( $>3 \%$ ao ano) no índice de acúmulo de déficits (DI) em dez anos

Outros desfechos foram também selecionados para o estudo:

- perda de funcionalidade, medida pelo tempo até a ocorrência da primeira perda de uma das atividades de vida diária (ABVD ou AIVD) em dez anos;

- ganho de multimorbidade, em pontuação média de índices de mutlimorbidade, em dez anos;

- $\quad$ mortalidade, medida pelo tempo até o óbito (sobrevida) em dez anos.

\subsubsection{Variáveis preditoras}

A variável preditora primária de interesse foi o polimorfismo do gene APOE, através da:

- Presença do alelo ع2 (em homozigose ou heterozigose);

- Presença do alelo ع4 (em homozigose ou heterozigose).

Variáveis epigenéticas também foram de interesse na análise:

- Fatores sociodemográficos (idade, sexo, raça, escolaridade, e arranjo domiciliar); 
- Fatores clínicos (índice de multimorbidade CIRS-G; índice de multimorbidade $\mathrm{CCl}$; número de medicamentos prescritos)

- Hábitos de vida (tabagismo; etilismo; atividades físicas, cognitivas, sociais e metabólicas)

- Autoavaliação da saúde

\subsection{Considerações éticas da pesquisa}

$\mathrm{Na}$ fase inicial, a solicitação de projeto denominado "Envelhecimento Saudável - Correlações dentre alguns determinantes clínicos, funcionais e genéticos", onde constam a coleta do material genético e entrevista clínica para estudo de variáveis do envelhecimento saudável, e o Termo de Consentimento Livre e Esclarecido, foram aprovados pela CAPPesq do Hospital das Clínicas da FMUSP, sob o número de 451/05.

Quando se delineou a etapa de coleta retrospectiva dos dados da mesma amostra, dez anos depois, o projeto de pesquisa foi novamente submetido ao parecer do Comitê de Ética em Pesquisa (CEP) do HCFMUSP (registro número 13440), e como não se configuraram mudanças na proposta de se estudar associações entre o mesmo determinante genético, no caso, o gene APOE, com medidas de envelhecimento saudável, utilizando-se inclusive dos mesmos dados obtidos na avaliação inicial, como consta no Termo de Consentimento Livre e Esclarecido assinado individualmente por todos os pacientes na ocasião, foi aprovado pelo CEP em 08/04/2015. O projeto foi então submetido e aprovado pela 
CONEP/Plataforma Brasil (www.saude.gov.br/plataformabrasil), sob o número CAAE 43239015.7.0000.0068.

Observações éticas relacionadas a este estudo genético (conforme orientações contidas na resolução no 340 de 08 de julho de 2004 do Conselho Nacional de Saúde):

- Quanto ao destino: o material genético somente foi utilizado para os objetivos propostos e com consentimento prévio na ocasião. O DNA extraído foi guardado, porém somente seria utilizado para novas pesquisas com novo consentimento do paciente e da Comissão de Ética do Hospital, o qual não é a proposta desse novo delineamento, conforme esclarecido acima;

- A presente pesquisa enquadra-se na definição II.1 c) pesquisa em genética de populações: estudo da variabilidade genética normal de alguns polimorfismos de DNA em idosos e de sua relação com parâmetros clínicos e funcionais de saúde;

- Os dados genéticos dos participantes somente serão utilizados para esclarecimentos científicos populacionais, e não individuais, com a finalidade de relacionar possíveis determinantes genéticos de envelhecimento saudável populacional;

- Os dados serão de conhecimento somente dos pesquisadores e podem ser revelados somente aos próprios indivíduos se assim o quiserem;

- Não é o objetivo deste estudo aconselhamento genético dos participantes ou familiares, visto que não é uma pesquisa em genética clínica;

- Este estudo não tem fins de ordem terapêutica, incluindo a genética; 
- Os dados obtidos neste estudo somente serão objeto de estudos futuros com o consentimento prévio esclarecido dos seus participantes.

\subsection{Cálculo da Amostra}

Trata-se de um estudo de coorte retrospectivo com tamanho de amostra pré-definido pelos dados coletados em 2004.

Pelo teste de log-rank, com um erro alfa $<0,05$, o estudo terá um poder de $80 \%$ para detectar diferenças de $20 \%$ entre dois grupos de igual tamanho (65 participantes cada), considerando a taxa de desfecho no grupo de menor risco igual a aproximadamente $65 \%$ ao final do seguimento.

Esse cálculo foi realizado pelo programa StatsToDo para análise de sobrevida disponível online (<https://www.statstodo.com/SSizSurvival_Pgm.php>) e baseado na proposta de Machin et al., 1997.

Uma análise sobre o poder do estudo para predizer as associações encontradas será realizada durante a etapa final de análise dos dados.

\subsection{Análise Estatística}

As análises foram realizadas com o pacote estatístico Stata para Windows, versão14.0 (StataCorp, College Station, TX). Todas as hipóteses alternativas foram bicaudais e uma probabilidade de erro alfa menor o que $5 \%$ foi adotada para definir resultados estatisticamente significativos. 


\subsubsection{Análises descritivas e bivariadas}

As variáveis categóricas foram reportadas em número absoluto e porcentagem. As variáveis discretas e contínuas foram descritas através da sua média e desvio-padrão ou mediana e intervalo interquartil (IIQ) de acordo com a distribuição. A distribuição das variáveis foi checada por inspeção visual dos respectivos histogramas. Os coeficientes de Skewness e Kurtosis foram calculados para fornecer medidas objetivas do padrão de distribuição de cada variável. O teste de Shapiro-Wilk foi utilizado para avaliar se a distribuição preenchia critérios de normalidade, com valores de $p$ $<0,05$ rejeitando distribuição normal.

Para comparar duas médias utilizou-se $o$ teste $t$ de student para amostras independentes ou equivalente não paramétrico (teste de MannWhitney). Quando a comparação ocorreu entre variáveis com três categorias utilizou-se o one-way analysis of variance (ANOVA) ou equivalente não paramétrico (teste de Kruskal-Wallis). Para comparar duas ou mais proporções independentes utilizou-se o teste de qui-quadrado $\left(x^{2}\right)$. Nas ocasiões em que havia uma ordem inerente entre três ou mais grupos, foram reportados os valores do teste de qui-quadrado de tendência. Em situações em que a comparação entre duas proporções envolveu categorias com contagem absoluta em valor igual ou menor a cinco, preferiu-se utilizar o teste exato de Fisher. 


\subsubsection{Análise de Sobrevida}

Esse estudo de coorte realizou o seguimento dos participantes durante 10 anos. As medidas de desfecho foram coletadas anualmente com base em revisão de prontuários do GAMIA. Além da ocorrência dos desfechos, houve interesse em analisar a probabilidade dos eventos ao longo do tempo de seguimento. Sobrevida foi considerada como o tempo entre a entrada do participante no estudo até a ocorrência do desfecho ou até a censura, ocasionada por perda de seguimento, óbito ou término do período de acompanhamento.

A variável independente principal desse estudo, alelos do gene da APOE, foi analisada separadamente da seguinte forma:

a) Presença do alelo $\varepsilon 4$ vs. ausência do alelo $\varepsilon 4$, tendo como controle o grupo alelo $\varepsilon 3 \varepsilon 3$.

b) Presença do alelo $\varepsilon 2$ vs. ausência do alelo $\varepsilon 2$, tendo como controle o grupo alelo $\varepsilon 3 \varepsilon 3$.

O desfecho de maior interesse foi tempo até perda do envelhecimento fisiológico, definido como aumento maior do que 3\% em um ano no déficit index (medida calculada pela média de déficits em 27 variáveis representando comorbidades e funcionalidade do paciente). Como desfechos secundários foram analisados individualmente o tempo até perda de ABVD, tempo até perda de AIVD e tempo até o óbito.

As curvas de Kaplan-Meier foram utilizadas para representação gráfica da ocorrência desses desfechos ao longo do seguimento de acordo 
com a variável independente principal (presença vs. ausência dos alelos APOE - $\varepsilon 4$ e $\varepsilon 2$ em comparação ao grupo controle alelo $\varepsilon 3 \varepsilon 3)$. O teste de log-rank foi aplicado para a comparação das curvas de sobrevivência.

Modelos de riscos proporcionais de Cox em modelo bruto e ajustado avaliaram a associação dos alelos APOE com os desfechos. O modelo ajustado contemplou a inclusão de variáveis sociodemográficas (idade, sexo, raça, escolaridade) e multimorbidade pelo CIRS-G. A medida de risco que mensura a associação dos preditores com os desfechos nesse tipo de regressão é o hazard ratio $(\mathrm{HR})$.

A verificação da adequação da proporcionalidade dos riscos ao longo do tempo foi realizada por meio da análise de resíduos de Schoenfeld. Valores de $\mathrm{p}$ acima de 0,05 confirmaram que a suposição de proporcionalidade foi respeitada em todos os modelos de regressão de Cox.

Foram avaliadas também como variáveis independentes alternativas os seguintes preditores epigenéticos: fatores sociodemográficos (idade, sexo, raça, escolaridade, arranjo de moradia), variáveis clínicas (multimorbidade pelo CIRS-G e CCI, número de medicamentos em uso), autoavaliação da saúde e hábitos de vida (tabagismo, etilismo, atividades físicas, cognitivas, metabólicas e sociais). Os modelos de Cox univariados e multivariados investigaram a associação desses fatores com os desfechos de sobrevida. $\mathrm{Na}$ análise multivariada, houve ajuste para os fatores sociodemográficos (idade, sexo, raça e escolaridade) e para os preditores epigenéticos que atingiram nível de significância $<0,05$ para o desfecho estudado. 


\subsubsection{Regressão linear}

Para análise do desfecho multimorbidade, foram utilizados modelos de regressão linear simples e multivariada uma vez que os índices CIRS-G e $\mathrm{CCl}$ possuem formato de variáveis contínuas. A pontuação nesses índices ao final do seguimento de 10 anos foi considerada a variável de desfecho de interesse. Como os pacientes iniciaram o estudo apresentado graus diferentes de multimorbidade, mesmo nas análises simples foi realizado ajuste para o valor de multimorbidade da avaliação inicial. $\mathrm{O} \mathrm{CCl}$ por apresentar distribuição não normal foi avaliado após transformação logarítmica. Os mesmos preditores genéticos e epigenéticos avaliados nas análises de sobrevida foram considerados para o desfecho multimorbidade, tendo novamente dado ênfase aos alelos do gene da APOE. As análises ajustadas incluíram obrigatoriamente no modelo as variáveis sociodemográficas (idade, sexo, raça, escolaridade e arranjo de moradia).

Modelos de regressão linear contemplando medidas anuais repetidas de déficit index, CIRS-G e $\mathrm{CCl}$ analisaram a evolução desses índices prognósticos ao longo de 10 anos considerando dois grupos distintos: (1) aquele formado pelos participantes que morreram em 10 anos e (2) aquele formado pelos que permaneceram vivos até o final do estudo. A inclusão de um termo de interação entre a presença do óbito e o tempo estimou se houve diferença na evolução destes índices ao longo de todo seguimento. Essas análises foram ilustradas em gráficos que demonstraram as médias 
anuais (com intervalo de confiança de 95\%) dos índices para os dois grupos de interesse. 
5 Resultados 


\section{RESULTADOS}

\subsection{Características da amostra na avaliação inicial (ano de 2004)}

$\mathrm{Na}$ avaliação inicial de 2004, como podemos ver na tabela 1, a amostra de 125 participantes apresentava média de idade de 74,9 anos (DP 7,1 anos), variando de 61 a 94 anos. Menos de um quarto da amostra (28; $22,4 \%$ ) era constituída de muito idosos ( $\geq 80$ anos). Em sua maioria eram indivíduos do sexo feminino $(96 ; 76,8 \%)$, de cor branca $(102 ; 81,6 \%)$, de nacionalidade brasileira (113; 90,4\%). Estudaram em média 5,6 anos (DP $3,8)$, sendo que a minoria era analfabeta $(7 ; 5,6 \%)$ ou de nível superior $(7$; $5,6 \%$ ). A maior parte desses idosos morava com alguém, em geral com familiares (83; 66,4\%), apesar de na maioria serem viúvos, solteiros ou separados $(84 ; 67,2 \%)$.

A grande maioria da amostra não consumia bebida alcoólica (116; $92,8 \%$ e não fumava $(90 ; 72 \%)$. Eram bastante ativos fisicamente (102; $81,6 \%$, e a maioria fazia atividades de consumo metabólico mais alto, como subir dois lances de escada ou cuidar da casa, pelo menos quatro vezes por semana $(114 ; 91,2 \%)$. Dois em cada três idosos praticava atividades semanais de estímulo cognitivo, como leitura, palavras cruzadas, jogos de carta ou tabuleiro $(75 ; 60 \%)$. Porém, a minoria participava de grupos sociais semanais de discussão (45; 36\%). Não houve associação entre fazer atividade física e fazer atividade social $(p=0,11)$ 
Tabela 1 - Características da amostra na avaliação inicial do estudo ( $\mathrm{N}=125)$; ambulatório de geriatria do HC-FMUSP - 2004

\begin{tabular}{|c|c|c|c|}
\hline & Categorias & Número & $\begin{array}{c}\text { Proporção } \\
\text { (\%) }\end{array}$ \\
\hline \multicolumn{4}{|l|}{ Característica Sociodemográfica } \\
\hline \multirow[t]{5}{*}{ Idade } & Idade (anos), média (DP) & $74,9(7,1)$ & \\
\hline & 60 a 69 anos & 29 & 23,2 \\
\hline & 70 a 79 anos & 68 & 54,4 \\
\hline & 80 a 89 anos & 22 & 17,6 \\
\hline & $\geq 90$ anos & 6 & 4,8 \\
\hline \multirow[t]{2}{*}{ Sexo } & Feminino & 96 & 76,8 \\
\hline & Masculino & 29 & 23,2 \\
\hline \multirow[t]{2}{*}{ Cor } & Branca & 102 & 81,6 \\
\hline & Não Branca & 23 & 18,4 \\
\hline \multirow[t]{2}{*}{ Nacionalidade } & Brasileira & 113 & 90,4 \\
\hline & Estrangeira & 12 & 9,6 \\
\hline Escolaridade Média, anos (DP) & & $5,6(3,8)$ & \\
\hline \multirow[t]{2}{*}{ Estado civil } & Viúvo, solteiro ou separado & 84 & 67,2 \\
\hline & Casado & 41 & 32,8 \\
\hline \multirow[t]{2}{*}{ Arranjo domiciliar } & Mora com alguém & 83 & 66,4 \\
\hline & Mora sozinho & 42 & 33,6 \\
\hline \multicolumn{4}{|l|}{ Característica Clínica } \\
\hline \multicolumn{2}{|c|}{ Número de medicamentos, média (DP) } & $4,8(2,6)$ & \\
\hline Tabagismo & Atual ou prévio & 35 & 28 \\
\hline Etilismo & Atual ou prévio & 9 & 7,2 \\
\hline Atividade Física & Regular ( $\geq 1 \mathrm{x} /$ semana) & 102 & 81,6 \\
\hline Atividade Cognitiva & Regular ( $\geq 1 \mathrm{x} /$ semana) & 75 & 60 \\
\hline Atividade Social & Regular ( $\geq 1 \mathrm{x} /$ semana) & 45 & 36 \\
\hline Atividade Metabólica & Regular ( $\geq 4 x /$ semana) & 114 & 91,2 \\
\hline \multirow[t]{2}{*}{ Autoavaliação da saúde } & Muito boa/Boa & 65 & 52 \\
\hline & Regular/Ruim/Muito Ruim & 60 & 48 \\
\hline \multirow[t]{2}{*}{ Funcionalidade } & ABVD preservadas & 125 & 100 \\
\hline & AIVD preservadas & 125 & 100 \\
\hline Índice CIRS-G, média (DP) & & $10,24(4,6)$ & \\
\hline \multirow[t]{3}{*}{ Nível de multimorbidade (CIRS-G) } & Leve $(\leq 8)$ & 44 & 35,2 \\
\hline & Moderado (8,1 a 11) & 45 & 36 \\
\hline & Grave (> 11) & 36 & $\begin{array}{l}28,8 \\
\text { contin }\end{array}$ \\
\hline
\end{tabular}


Tabela 1 - Características da amostra na avaliação inicial do estudo $(\mathrm{N}=125)$; ambulatório de geriatria do HC-FMUSP - 2004 (conclusão)

\begin{tabular}{|c|c|c|c|}
\hline & Categorias & Número & $\begin{array}{c}\text { Proporção } \\
(\%)\end{array}$ \\
\hline Índice $C C I$, média (DP) & & $0,9(1,2)$ & \\
\hline \multirow[t]{3}{*}{ Nível de multimorbidade ( $C C I)$} & Leve (0) & 68 & 54,4 \\
\hline & Moderado (1) & 27 & 21,6 \\
\hline & Grave (> 1) & 30 & 24 \\
\hline $\begin{array}{l}\text { Índice de acúmulo de déficits } \\
\text { (DI), média (DP) }\end{array}$ & & $\begin{array}{c}0,11 \\
(0,06)\end{array}$ & \\
\hline \multicolumn{4}{|l|}{ Característica Genética } \\
\hline \multicolumn{4}{|l|}{ Polimorfismo do gene APOE } \\
\hline$\varepsilon 2 \varepsilon 2$ & & 0 & 0 \\
\hline$\varepsilon 2 \varepsilon 3$ & & 5 & 4 \\
\hline$\varepsilon 2 \varepsilon 4$ & & 20 & 16 \\
\hline$\varepsilon 3 \varepsilon 3$ & & 26 & 20,8 \\
\hline$\varepsilon 3 \varepsilon 4$ & & 70 & 56 \\
\hline$\varepsilon 4 \varepsilon 4$ & & 4 & 3,2 \\
\hline \multicolumn{4}{|l|}{ Frequência dos alelos } \\
\hline$\varepsilon 2$ & & 25 & 10 \\
\hline$\varepsilon 3$ & & 127 & 50,8 \\
\hline$\varepsilon 4$ & & 98 & 39,2 \\
\hline \multicolumn{4}{|l|}{ Presença dos alelos } \\
\hline Presença $\varepsilon 2(\varepsilon 2 \varepsilon 2, \varepsilon 2 \varepsilon 3, \varepsilon 2 \varepsilon 4)$ & & 25 & 20 \\
\hline Presença $\varepsilon 4(\varepsilon 2 \varepsilon 4, \varepsilon 3 \varepsilon 4, \varepsilon 4 \varepsilon 4)$ & & 94 & 75,2 \\
\hline
\end{tabular}

ABVD = Atividades Básicas de Vida Diária (Katz e Akpom, 1976) ; AIVD = Atividades Instrumentais de Vida Diária (Lawton e Brody, 1969); CIRS-G = Cumulative IIIness Rating Scale for Geriatrics (Linn et al., 1968); $C C l=$ Charlson comorbidity index (Charlson et al., 1987); APOE = gene da apolipoproteína E.

Quanto às características clínicas, eram pacientes totalmente funcionais para as atividades básicas e instrumentais da vida diária no início do estudo, condição de inclusão no estudo. Apesar de funcionais, faziam uso de 4,8 medicamentos em média, e apresentavam multimorbidade, com 
índices CIRS-G de 10,24 (DP 4,6), com variações de pontuação de 1 até máximo de 23 e $\mathrm{CCl}$ de 0,9 (DP 1,2), variando de 0 a 6 . Conforme observamos na Figura 7, as principais doenças crônicas em prevalência que acompanhavam essa população eram: hipertensão arterial sistêmica (70,4\%), distúrbios dos lípides $(72 \%)$, osteoartrose $(62,4 \%)$, doenças do trato gastrointestinal alto (37,6\%), insuficiência venosa crônica (37,6\%), osteoporose (28\%), e depressão/transtorno de ansiedade generalizada $(24,8 \%)$. Em relação às deficiências sensoriais, 28\% tinham algum grau funcional de deficiência auditiva e $16 \%$ de deficiência visual. As outras condições crônicas de saúde encontravam-se em prevalências menores do que $20 \%$.

\section{Doenças na avaliação inicial da amostra $(\mathrm{N}=125)$}

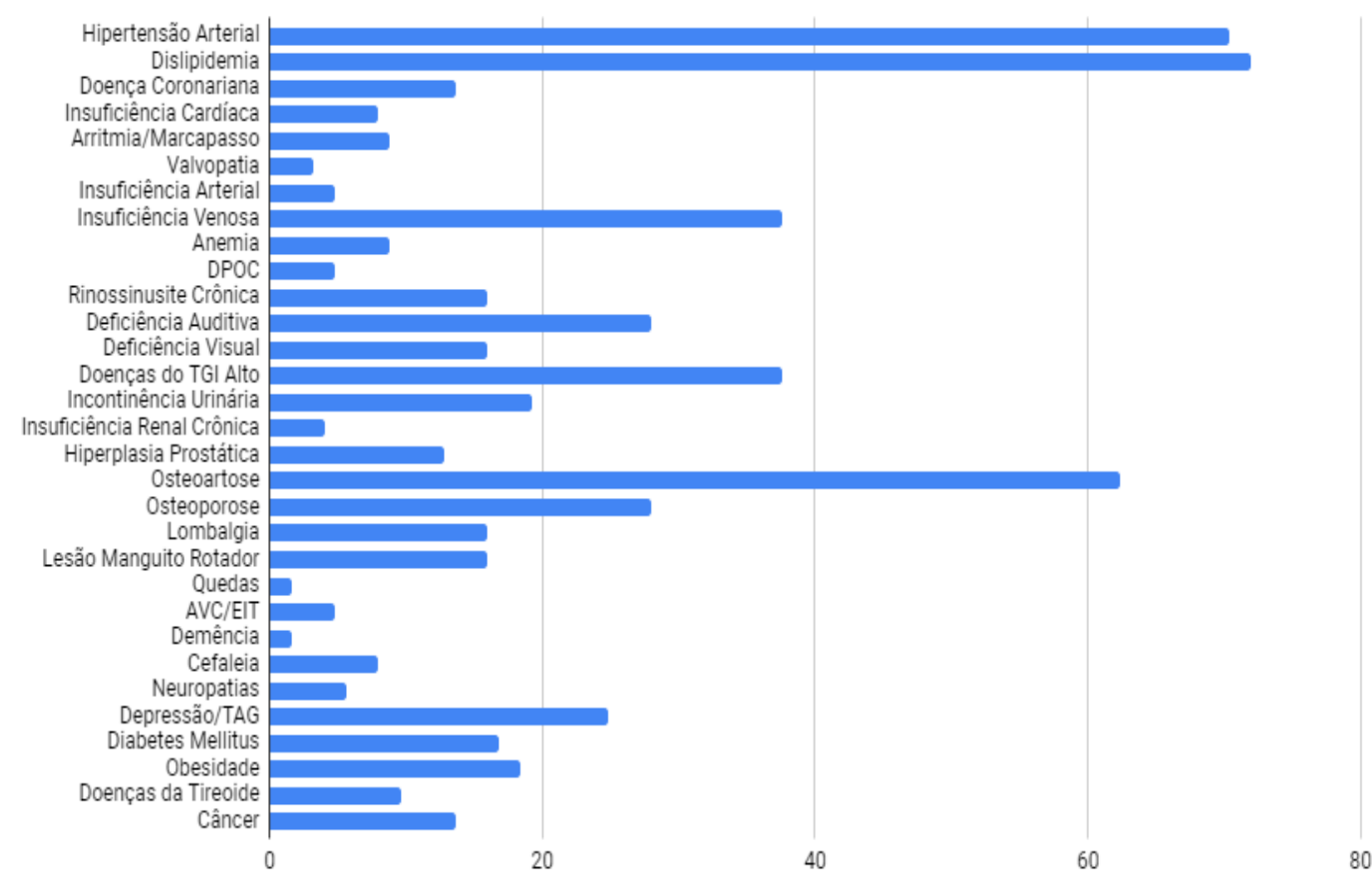

Figura 7 - Prevalência das principais doenças e condições crônicas de saúde da amostra no início do estudo; ambulatório de geriatria do HC-FMUSP - 2004 
Quando analisamos os dados da amostra inicial a partir da multimorbidade, dividida em níveis de gravidade por meio dos tercis inferior, médio e superior (multimorbidade leve, moderada e grave), percebemos que, a idade, sexo, raça, número de medicamentos, e a autoavaliação da saúde apresentaram associação significativa com a pontuação do CIRS-G (Tabela 2). A idade média foi cerca de 4 anos maior no nível grave; houve diminuição na proporção de mulheres e de não brancos em níveis mais graves de multimorbidade. O número de medicamentos se correlacionou fortemente com multimorbidade mais grave, e os participantes avaliaram pior sua saúde quando a multimorbidade foi maior. O etilismo apresentou tendência de associação com níveis de multimorbidade intermediários e graves pelo CIRS-G $(p=0,05)$. 
Tabela 2 - Características basais dos participantes de acordo com 0 Cumulative IIIness Rating Scale for Geriatrics (CIRS-G) no início do estudo; ambulatório geriatria do HC-FMUSP - 2004

\begin{tabular}{|c|c|c|c|c|}
\hline \multirow[b]{2}{*}{ Características } & \multicolumn{3}{|c|}{ CIRS-G } & \multirow[b]{2}{*}{$\mathbf{P}$ valor } \\
\hline & $\begin{array}{c}\text { Tercil } \\
\text { inferior } \\
(1-8) \\
(\mathrm{N}=44)\end{array}$ & $\begin{array}{c}\text { Tercil } \\
\text { Médio } \\
(9-11) \\
(\mathrm{N}=45)\end{array}$ & $\begin{array}{c}\text { Tercil } \\
\text { superior } \\
(12-23) \\
(\mathrm{N}=36)\end{array}$ & \\
\hline \multicolumn{5}{|l|}{ Fatores sociodemográficos } \\
\hline Idade (anos), média (DP) & $72,7(7,5)$ & $75,5(6,3)$ & $76,6(6,8)$ & 0,04 \\
\hline Sexo Feminino, N (\%) & $38(86,4)$ & $34(75,6)$ & $24(66,7)$ & 0,04 \\
\hline Raça branca, N (\%) & $32(72,7)$ & $36(80,0)$ & $34(94,4)$ & 0,01 \\
\hline Estado civil casado, $\mathrm{N}(\%)$ & $31(70,5)$ & $32(71,1)$ & $21(58,3)$ & 0,27 \\
\hline Mora sozinho, N (\%) & $19(43,2)$ & $12(26,7)$ & $11(30,6)$ & 0,21 \\
\hline Escolaridade, mediana (IIQ) & $4,0(4,0-8,0)$ & $4,0(3,8-8,0)$ & $4,0(3,0-9,5)$ & 0,59 \\
\hline \multicolumn{5}{|l|}{ Fatores genéticos } \\
\hline Presença do alelo APOE ع2, N (\%) & $8(18,2)$ & $12(26,7)$ & $5(13,9)$ & 0,38 \\
\hline Presença do alelo APOE $\varepsilon 4, \mathrm{~N}(\%)$ & $30(68,2)$ & $38(84,4)$ & $26(72,2)$ & 0,47 \\
\hline $\begin{array}{l}\text { Número de medicamentos em uso, } \\
\text { média (DP) }\end{array}$ & $3,0(2,0)$ & $5,1(2,0)$ & $6,7(2,4)$ & $<0,001$ \\
\hline $\begin{array}{l}\text { Autoavaliação da saúde boa/muito } \\
\text { boa, } N(\%)\end{array}$ & $27(61,4)$ & $25(55,6)$ & $13(36,1)$ & 0,03 \\
\hline \multicolumn{5}{|l|}{ Hábitos de vida } \\
\hline Tabagismo, N (\%) & $9(20,5)$ & $13(28,9)$ & $13(36,1)$ & 0,12 \\
\hline Etilismo, N (\%) & $0(0,0)$ & $5(11,1)$ & $4(11,1)$ & 0,05 \\
\hline Realiza atividades físicas, N (\%) & $38(86,4)$ & $38(84,4)$ & $26(72,2)$ & 0,11 \\
\hline Realiza atividades cognitivas, N (\%) & $28(63,6)$ & $26(57,8)$ & $21(58,3)$ & 0,61 \\
\hline Realiza atividades sociais, N (\%) & $18(40,9)$ & $13(28,9)$ & $14(38,9)$ & 0,79 \\
\hline Realiza atividades metabólicas, N (\%) & $43(97,7)$ & $39(86,7)$ & $32(88,9)$ & 0,14 \\
\hline
\end{tabular}

$\mathrm{DP}=$ desvio padrão; IIQ = intervalo interquartil; CIRS-G = Cumulative IIIness Rating Scale for Geriatrics (Linn et al., 1968)

Variáveis categóricas foram comparadas pelo teste do qui-quadrado; variáveis contínuas foram analisadas pelo teste de análise de variância (ANOVA) (quando média e DP) ou teste de KruskalWallis (quando mediana e IIQ). 
Associação de sexo, raça e número de medicamentos também foi encontrada de forma semelhante quando a multimorbidade foi graduada pelo $\mathrm{CCl}$, porém associações com idade e autoavaliação da saúde não foram encontradas com este índice (Tabela 3).

Tabela 3 - Características basais dos participantes de acordo com 0 Charlson comorbidity index (CCI) no início do estudo; ambulatório geriatria do HC-FMUSP - 2004

\begin{tabular}{|c|c|c|c|c|}
\hline \multirow[b]{2}{*}{ Características } & \multicolumn{3}{|c|}{$\mathrm{CCl}$} & \multirow[b]{2}{*}{$\mathbf{P}$ valor } \\
\hline & $\begin{array}{c}\text { Tercil } \\
\text { inferior } \\
(0-0) \\
(N=68)\end{array}$ & $\begin{array}{c}\text { Tercil } \\
\text { Médio } \\
(1-1) \\
(\mathrm{N}=27)\end{array}$ & $\begin{array}{c}\text { Tercil } \\
\text { superior } \\
(2-6) \\
(N=30)\end{array}$ & \\
\hline \multicolumn{5}{|l|}{ Fatores sociodemográficos } \\
\hline Idade (anos), média (DP) & $74,5(7,7)$ & $74,5(5,5)$ & $75,9(7,0)$ & 0,64 \\
\hline Sexo Feminino, N (\%) & $60(88,2)$ & $21(77,8)$ & $15(50,0)$ & $<0,001$ \\
\hline Raça branca, N (\%) & $51(75,0)$ & $23(85,2)$ & $28(93,3)$ & 0,03 \\
\hline Estado civil casado, N (\%) & $50(73,5)$ & $16(59,3)$ & $18(60,0)$ & 0,14 \\
\hline Mora sozinho, N (\%) & $26(38,2)$ & $6(22,2)$ & $10(33,3)$ & 0,46 \\
\hline Escolaridade, mediana (IIQ) & $4,0(4,0-8,0)$ & $4,0(3,0-4,0)$ & $4,0(3,0-8,0)$ & 0,09 \\
\hline \multicolumn{5}{|l|}{ Fatores genéticos } \\
\hline Presença do alelo APOE ع2, N (\%) & $11(16,2)$ & $8(29,6)$ & $6(20,0)$ & 0,64 \\
\hline Presença do alelo APOE $\varepsilon 4, N(\%)$ & $52(76,5)$ & $20(74,1)$ & $22(73,3)$ & 0,94 \\
\hline $\begin{array}{l}\text { Número de medicamentos em uso, } \\
\text { média (DP) }\end{array}$ & $4,2(2,5)$ & $5,4(2,5)$ & $5,7(2,5)$ & 0,01 \\
\hline $\begin{array}{l}\text { Autoavaliação da saúde boa/muito } \\
\text { boa, } N(\%)\end{array}$ & $38(55,9)$ & $16(59,3)$ & $11(36,7)$ & 0,12 \\
\hline \multicolumn{5}{|l|}{ Hábitos de vida } \\
\hline Tabagismo, N (\%) & $18(26,5)$ & $5(18,5)$ & $12(40,0)$ & 0,27 \\
\hline Etilismo, N (\%) & $3(4,4)$ & $2(7,4)$ & $4(13,3)$ & 0,12 \\
\hline Realiza atividades físicas, N (\%) & $55(80,9)$ & $23(85,2)$ & $24(80,0)$ & 0,99 \\
\hline Realiza atividades cognitivas, $\mathrm{N}(\%)$ & $39(57,4)$ & $16(59,3)$ & $20(66,7)$ & 0,40 \\
\hline Realiza atividades sociais, N (\%) & $26(38,2)$ & $10(37,0)$ & $9(30,0)$ & 0,46 \\
\hline Realiza atividades metabólicas, N (\%) & $64(94,1)$ & $24(88,9)$ & $26(86,7)$ & 0,20 \\
\hline
\end{tabular}

$\mathrm{DP}=$ desvio padrão; IIQ = intervalo interquartil; $C C l=$ Charlson comorbidity index (Charlson et al., 1987)

Variáveis categóricas foram comparadas pelo teste do qui-quadrado; variáveis contínuas foram analisadas pelo teste de análise de variância (ANOVA) (quando média e DP) ou teste de Kruskal-Wallis (quando mediana e IIQ). 
Em relação aos dados genéticos, a distribuição dos alelos do gene APOE na amostra não apresentou o equilíbrio genético de distribuição dos alelos esperado para esta população, conforme método de Hardy-Weinberg (teste de Qui-quadrado X2 =69,8; $p<0,05$ para grau de liberdade 5). Em geral, foi observada alta frequência do alelo $\varepsilon 4$ (39,6\%), próxima à frequência do alelo $\varepsilon 3$ (50\%). Não temos nenhum representante do genótipo $\varepsilon 2$ em homozigose, e apenas 4 pacientes $(3,2 \%)$ do genótipo $\varepsilon 4$ em homozigose. Quando analisamos apenas a presença dos alelos, forma que será utilizada na análise dos dados, o alelo $\varepsilon 2$ está presente em $20 \%$ e o alelo $\varepsilon 4$ está presente na maioria (75,2\%) dos participantes (Figura 8).

Polimorfismo do gene APOE

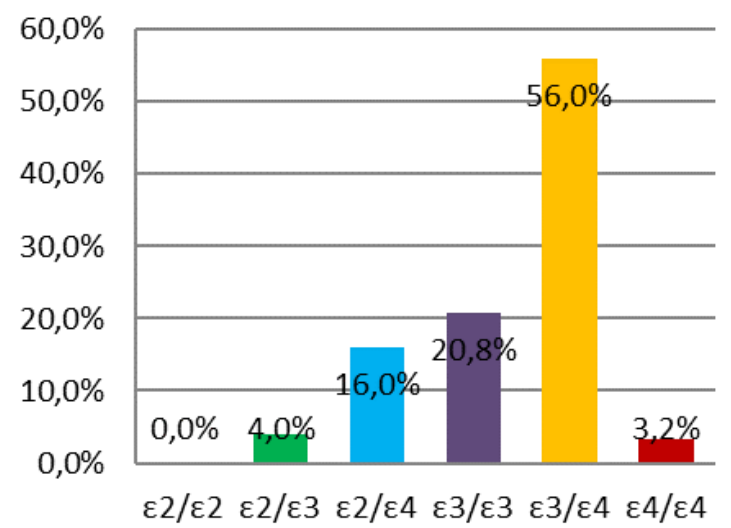

Frequência dos alelos do gene APOE

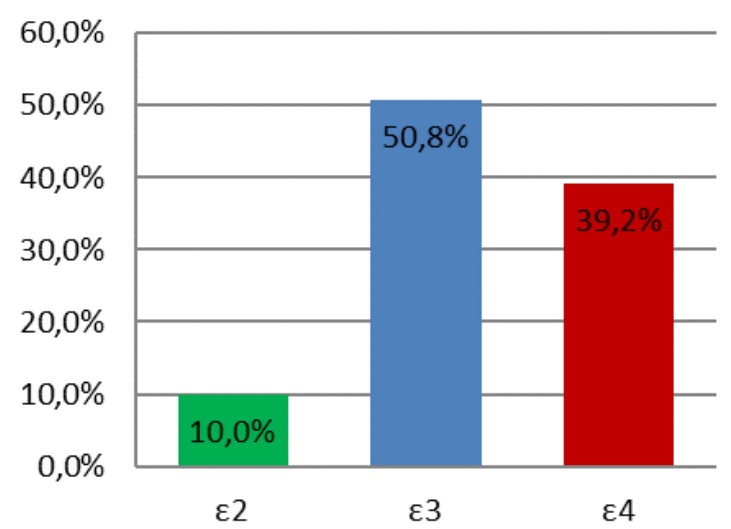

Figura 8 - Polimorfismo genético da apolipoproteína $E(A P O E)$ e frequência dos alelos na amostra total $(\mathrm{N}=125)$ 


\subsection{Avaliação longitudinal da amostra em relação aos desfechos}

$\mathrm{Na}$ avaliação longitudinal, 85 participantes completaram os dez anos de seguimento (houve 34 mortes e 6 perdas).

Em relação ao desfecho primário do estudo, apenas 17 pacientes (14\%) evoluíram com índice de acúmulo de déficits igual ao esperado para o envelhecimento fisiológico (3\% de perda ao ano em relação ao DI medido na avaliação inicial). Portanto, a maioria apresentou perda de envelhecimento fisiológico (DI observado na avaliação inicial $=0,11$; DI observado ao final dos dez anos $=0,28)$, como mostra a Figura 9.

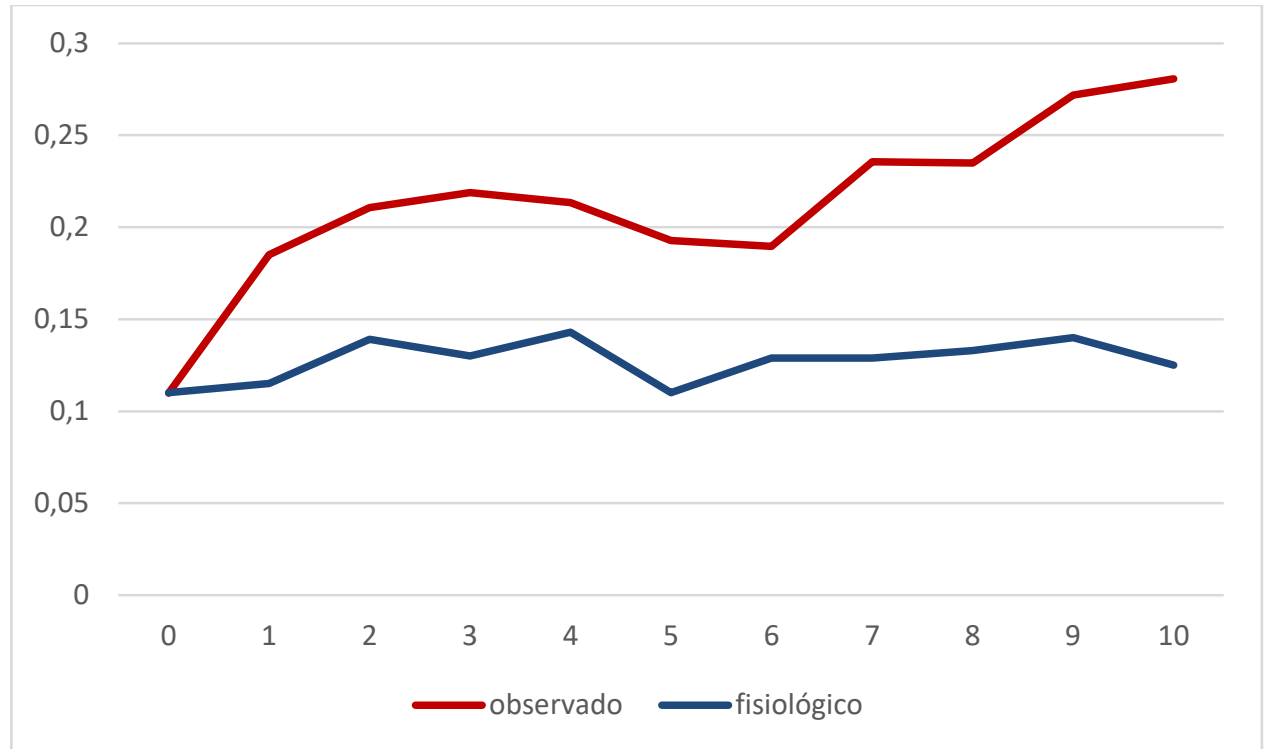

Figura 9 - Evolução do Índice de acúmulo de déficits (DI) na amostra ao longo dos dez anos de acompanhamento, DI observado e DI fisiológico $(\mathrm{N}=125)$ 
Não houve diferenças na evolução do DI ao longo do seguimento, quando comparamos faixas etárias, sexo e nível de multimorbidade do início do estudo.

No seguimento dos dez anos que se seguiram à avaliação inicial, a perda de funcionalidade ocorreu em menos da metade da amostra, tanto para ABVD (32 indivíduos, 25,6\%), quanto para AIVD (56 indivíduos, 44,8\%).

Em relação ao ganho de multimorbidade, a pontuação total do CIRS-G apresentou um ganho de 5,84 pontos na média ao longo dos dez anos (de 10,24 pontos no início para 16,08 pontos no décimo ano) (Figura 10). Ocorreu também incremento na média do índice CIRS-G CM2, ou seja, em média os participantes evoluíram com mais categorias de gravidade maior que 2 no CIRS-G ao longo dos dez anos (2,94 para 5,27).

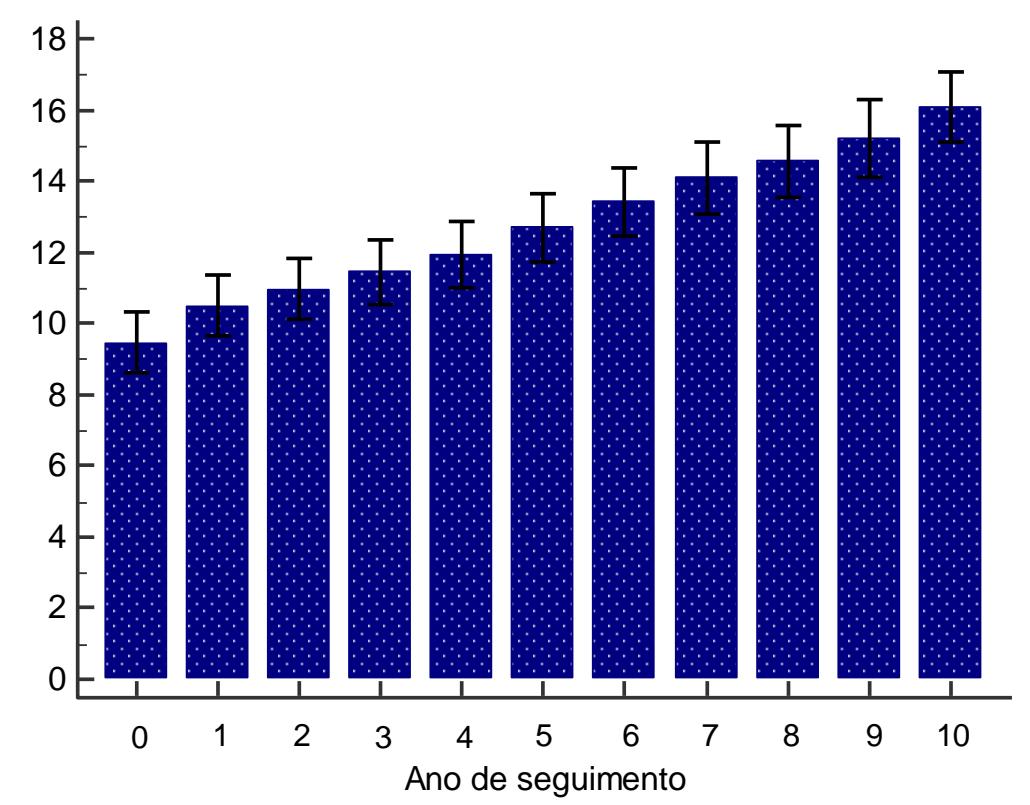

Figura 10 - Evolução da pontuação média do índice de multimorbidade CIRS-G na amostra ao longo do seguimento de dez anos $(\mathrm{N}=125)$ 
Quando foi utilizado o índice $\mathrm{CCl}$, observamos também o aumento da multimorbidade ao longo dos dez anos $(\mathrm{CCl}=0,872$ no início e 1,69 ao final dos dez anos), conforme visto na Figura 11.

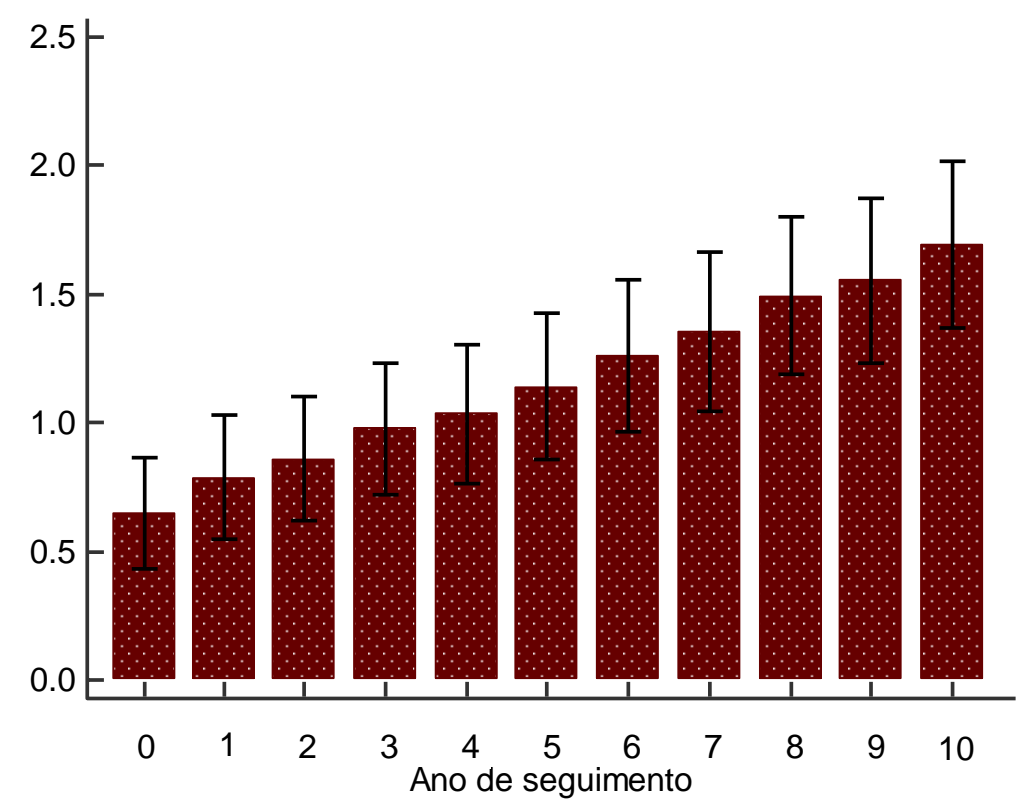

Figura 11 - Evolução da pontuação média do índice de multimorbidade Charlson comorbidity index $(\mathrm{CCl})$ ao longo do seguimento em dez anos $(\mathrm{N}=125)$ 
Prevalência de doenças na avaliação inicial $(\mathrm{N}=125)$ e final $(\mathrm{N}=85)$ da amostra

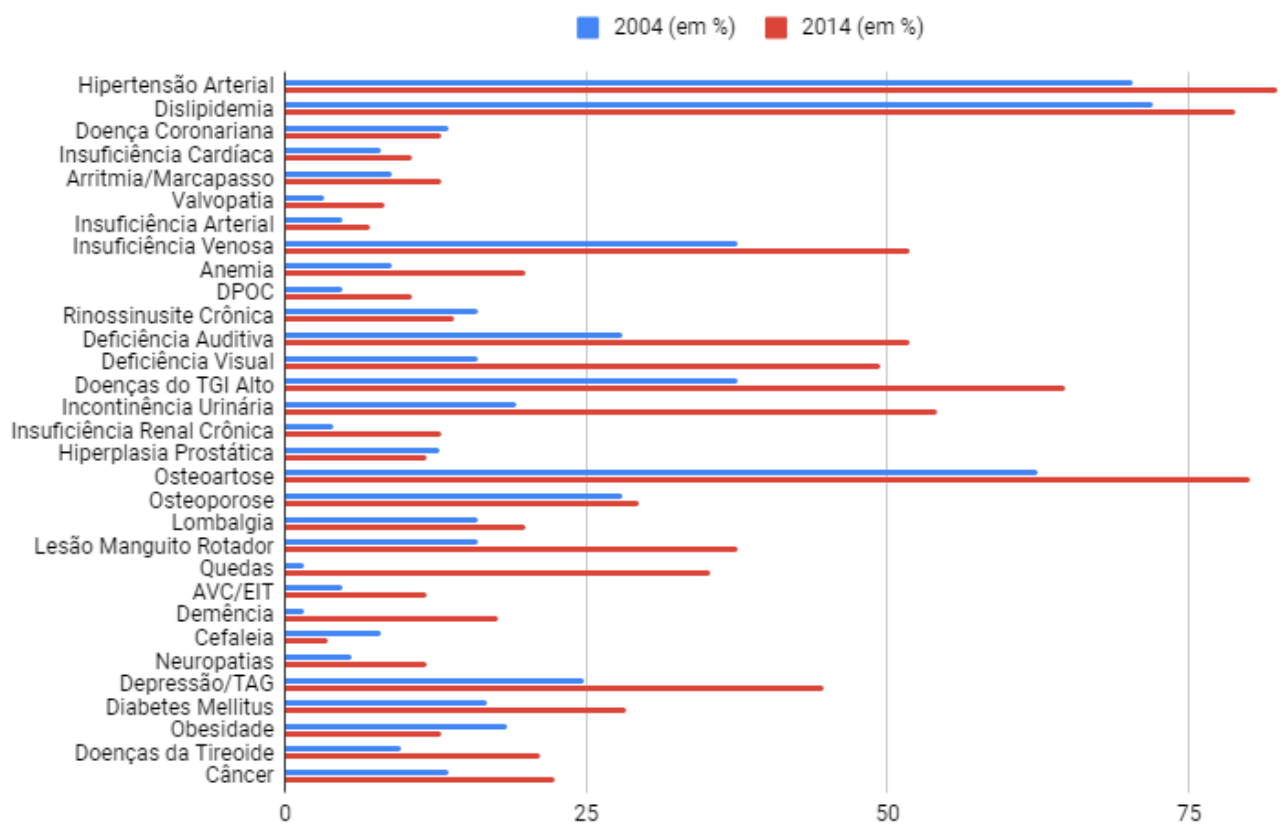

Figura 12 - Prevalência das principais doenças e condições crônicas de saúde da amostra no início e final do estudo; ambulatório de geriatria do HC-FMUSP - 2004

Várias doenças ou condições crônicas de saúde aumentaram significativamente em prevalência ao longo dos dez anos, como podemos observar na Figura 12. Mas principalmente houve um ganho expressivo de déficits sensoriais (mais da metade da amostra ao final apresentava deficiência visual e auditiva), e síndromes geriátricas relacionadas a piora de funcionalidade, como quedas e incontinência urinária.

Em relação ao desfecho óbito, 34 dos 125 participantes (27,2\%) morreram no período analisado. 


\subsection{Associação univariada dos fatores genéticos e epigenéticos com} os desfechos em 10 anos

Foram avaliadas as associações univariadas dos fatores epigenéticos e o gene APOE com os desfechos em 10 anos.

Não houve fatores associados em nível de significância menor que 0,05 com perda do envelhecimento fisiológico em 10 anos (Tabela 4). O fato de apenas 17 participantes terem apresentado envelhecimento fisiológico durante o seguimento diminuiu o poder da análise para detectar diferenças entre os grupos com envelhecimento fisiológico e não fisiológico. 
Tabela 4 - Associação das características dos participantes no início do estudo com perda do envelhecimento fisiológico em 10 anos; ambulatório geriatria do HC-FMUSP - 2004 a 2014

\begin{tabular}{|c|c|c|c|}
\hline \multirow{2}{*}{ Características } & \multicolumn{2}{|c|}{$\begin{array}{l}\text { Perda do envelhecimento } \\
\text { fisiológico* }\end{array}$} & \multirow{2}{*}{$P$ valor } \\
\hline & $\begin{array}{c}\text { Não } \\
(N=17)\end{array}$ & $\underset{(N=108)}{\operatorname{Sim}}$ & \\
\hline \multicolumn{4}{|l|}{ Fatores sociodemográficos } \\
\hline Idade (anos), média (DP) & $72,2(6,5)$ & $75,3(7,1)$ & 0,09 \\
\hline Sexo Feminino, N (\%) & $13(76,5)$ & $83(76,9)$ & 1,00 \\
\hline Raça branca, N (\%) & $14(82,4)$ & $88(81,5)$ & 1,00 \\
\hline Estado civil casado, N (\%) & $5(29,4)$ & $36(33,3)$ & 1,00 \\
\hline Mora sozinho, N (\%) & $8(47,1)$ & $34(31,5)$ & 0,21 \\
\hline Escolaridade, mediana (IIQ) & $4,0(4,0-8,0)$ & $4,0(3,5-8,0)$ & 0,94 \\
\hline \multicolumn{4}{|l|}{ Fatores genéticos } \\
\hline Presença do alelo APOE $\varepsilon 2, \mathrm{~N}(\%)$ & $9(13,0)$ & $16(28,6)$ & 0,09 \\
\hline Presença do alelo APOE $\varepsilon 4, N(\%)$ & $51(73,9)$ & $43(76,8)$ & 0,93 \\
\hline \multicolumn{4}{|l|}{ Fatores Clínicos } \\
\hline $\begin{array}{l}\text { Índice de comorbidades CIRS-G, mediana } \\
\text { (IIQ) }\end{array}$ & $10,0(5,8-11,0)$ & $10,0(7,0-12,0)$ & 0,43 \\
\hline $\begin{array}{l}\text { Índice de comorbidade de Charlson, mediana } \\
\text { (IIQ) }\end{array}$ & $0,0(0,0-1,0)$ & $1,0(0,0-1,0)$ & 0,60 \\
\hline $\begin{array}{l}\text { Número de medicamentos em uso, média } \\
\text { (DP) }\end{array}$ & $4,2(2,2)$ & $4,9(2,6)$ & 0,25 \\
\hline $\begin{array}{l}\text { Autopercepção da saúde muito boa ou boa, } \\
N(\%)\end{array}$ & $8(47,1)$ & $57(52,8)$ & 0,66 \\
\hline \multicolumn{4}{|l|}{ Hábitos de vida } \\
\hline Tabagismo, N (\%) & $2(11,8)$ & $33(30,6)$ & 0,15 \\
\hline Etilismo, N (\%) & $0(0,0)$ & $9(8,3)$ & 0,61 \\
\hline Realiza atividades físicas, N (\%) & $16(94,1)$ & $86(79,6)$ & 0,19 \\
\hline Realiza atividades cognitivas, N (\%) & $8(47,1)$ & $67(62,0)$ & 0,29 \\
\hline Realiza atividades sociais, N (\%) & $7(41,2)$ & $38(35,2)$ & 0,79 \\
\hline Realiza atividades metabólicas, N (\%) & $17(100,0)$ & $97(89,8)$ & 0,36 \\
\hline
\end{tabular}

$\mathrm{DP}=$ desvio padrão; $\mathrm{IIQ}=$ intervalo interquartil; CIRS-G = Cumulative IIIness Rating Scale for Geriatrics.

Variáveis categóricas foram comparadas pelo teste exato de Fischer, exceto os fatores genéticos que foram comparados pelo teste do qui-quadrado; variáveis contínuas foram analisadas pelo teste $t$ para amostras independentes (quando média e DP) ou teste de Mann-Whitney (quando mediana e IIQ).

* Perda de envelhecimento fisiológico caracterizada pelo acúmulo de déficits $>3 \%$ ao ano no Déficit Index, medida que engloba variáveis de funcionalidade e doenças crônicas (Mitnitski et al., 2001).

* Perda de funcionalidade para atividades básicas e/ou instrumentais da vida diária. 
Em relação à perda de funcionalidade para $A B V D$ ou AIVD, não houve associação significativa do gene APOE (Tabela 5).

Tabela 5 - Associação das características dos participantes no início do estudo com perda funcional em 10 anos; ambulatório de geriatria HC-FMUSP - 2004 a 2014

\begin{tabular}{|c|c|c|c|}
\hline \multirow[b]{2}{*}{ Características } & \multicolumn{2}{|c|}{ Perdeu funcionalidade $^{*}$} & \multirow[b]{2}{*}{$\mathbf{P}$ valor } \\
\hline & $\begin{array}{c}\text { Não } \\
(N=69)\end{array}$ & $\underset{(N=56)}{\operatorname{Sim}}$ & \\
\hline \multicolumn{4}{|l|}{ Fatores sociodemográficos } \\
\hline Idade (anos), média (DP) & $73,1(6,3)$ & $77,0(7,4)$ & 0,002 \\
\hline Sexo Feminino, N (\%) & $54(78,3)$ & $42(75,0)$ & 0,67 \\
\hline Raça branca, N (\%) & $56(81,2)$ & $46(82,1)$ & 0,89 \\
\hline Estado civil casado, N (\%) & $21(30,4)$ & $20(35,7)$ & 0,53 \\
\hline Mora sozinho, N (\%) & $30(43,5)$ & $12(21,4)$ & 0,01 \\
\hline Escolaridade, mediana (IIQ) & $4,0(4,0-8,0)$ & $4,0(3,0-4,5)$ & 0,04 \\
\hline \multicolumn{4}{|l|}{ Fatores genéticos } \\
\hline Presença do alelo APOE ع2, N (\%) & $9(13,0)$ & $16(28,6)$ & 0,09 \\
\hline Presença do alelo APOE $\varepsilon 4, \mathrm{~N}(\%)$ & $51(73,9)$ & $43(76,8)$ & 0,93 \\
\hline \multicolumn{4}{|l|}{ Fatores Clínicos } \\
\hline Índice de comorbidades CIRS-G, mediana (IIQ) & $9,0(6,8-11,3)$ & $11,0(9,0-13,0)$ & 0,02 \\
\hline $\begin{array}{l}\text { Índice de comorbidade de Charlson, mediana } \\
\text { (IIQ) }\end{array}$ & $0,0(0,0-1,0)$ & $1,0(0,0-1,5)$ & 0,23 \\
\hline Número de medicamentos em uso, média (DP) & $4,4(2,6)$ & $5,4(2,4)$ & 0,04 \\
\hline $\begin{array}{l}\text { Autopercepção da saúde muito boa ou boa, } \\
N(\%)\end{array}$ & $34(49,3)$ & $31(55,4)$ & 0,50 \\
\hline \multicolumn{4}{|l|}{ Hábitos de vida } \\
\hline Tabagismo, N (\%) & $18(26,1)$ & $17(30,4)$ & 0,60 \\
\hline Etilismo, N (\%) & $3(4,3)$ & $6(10,7)$ & 0,30 \\
\hline Realiza atividades físicas, N (\%) & $62(89,9)$ & $40(71,4)$ & 0,008 \\
\hline Realiza atividades cognitivas, N (\%) & $49(71,0)$ & $26(46,4)$ & 0,006 \\
\hline Realiza atividades sociais, N (\%) & $25(36,2)$ & $20(35,7)$ & 0,95 \\
\hline Realiza atividades metabólicas, N (\%) & $67(97,1)$ & $47(83,9)$ & 0,01 \\
\hline
\end{tabular}


Ao avaliar os fatores epigenéticos, o desfecho perda funcional foi o que mais se associou a variáveis preditoras em dez anos (Tabela 5). As variáveis na avaliação inicial da amostra que tiveram poder de associação à perda de funcionalidade por ABVD ou AIVD em dez anos foram: idade mais alta, escolaridade mais baixa, nível mais alto de multimorbidade medido pelo CIRS-G na entrada, número mais alto de medicamentos prescritos, sedentarismo, falta de atividade cognitiva, e falta de atividade metabólica. Os participantes do estudo que moravam sozinhos, apresentaram proteção contra a perda funcional ao longo de dez anos (Tabela 5).

Em relação à mortalidade em dez anos, os fatores de risco do início do estudo que mais se destacaram foram idade mais alta, maior pontuação nos índices de multimorbidade CIRS-G e CCl e sedentarismo (Tabela 6).

Em relação à multimorbidade em 10 anos, consideramos ajuste para a carga de doenças no início do estudo uma vez que os participantes apresentavam pontuações diferentes no CIRS-G e CCI na avaliação inicial. A presença do alelo APOE $\varepsilon 2$ não se associou a maiores valores de CIRS-G $(p=0,61)$ e $C C I(p=0,86)$ em 10 anos. Também não houve associação da presença do alelo APOE \&4 com maior carga de doenças em 10 anos, tanto pelo CIRS-G $(p=0,31)$ como pelo $\mathrm{CCl}(p=0,73)$. Alguns fatores epigenéticos associaram-se significativamente com a pontuação do CIRS-G e CCI. Idosos que moravam sozinhos apresentaram uma média de 2,63 pontos a menos no CIRS-G em comparação aqueles que moravam acompanhados $(p=0,001)$. Já aqueles que realizavam atividades metabólicas chegaram ao final do seguimento de 10 anos com uma média 5 pontos menor no CIRS-G 
$(p=0,001)$ e 1 ponto menor no $\mathrm{CCl}(p=0,03)$ em comparação com aqueles que não faziam tais atividades. Houve ainda associação de etilismo com CIRS-G CM2, um índice que aumenta a gravidade do CIRS-G. Idosos com uso de álcool pelo menos quatro vezes por semana tiveram uma média de 1,86 pontos a mais no CIRS-G CM2 quando comparados aqueles com menor consumo de álcool $(p=0,02)$. 
Tabela 6 - Associação das características dos participantes no início do estudo com mortalidade em 10 anos; ambulatório de geriatria HC-FMUSP - 2004 a 2014

\begin{tabular}{|c|c|c|c|}
\hline \multirow[b]{2}{*}{ Características } & \multicolumn{2}{|c|}{ Óbito } & \multirow[b]{2}{*}{ P valor } \\
\hline & $\begin{array}{c}\text { Não } \\
(N=91)\end{array}$ & $\operatorname{Sim}_{(N=34)}$ & \\
\hline \multicolumn{4}{|l|}{ Fatores sociodemográficos } \\
\hline Idade (anos), média (DP) & $73,4(5,5)$ & $78,7(9,2)$ & $<0,001$ \\
\hline Sexo Feminino, N (\%) & $73(80,2)$ & $23(67,6)$ & 0,14 \\
\hline Raça branca, N (\%) & $72(79,1)$ & $30(88,2)$ & 0,10 \\
\hline Estado civil casado, N (\%) & $30(33,0)$ & $11(32,4)$ & 0,95 \\
\hline Mora sozinho, N (\%) & $34(37,4)$ & $8(23,5)$ & 0,15 \\
\hline Escolaridade, mediana (IIQ) & $4,0(3,3-8,0)$ & $4,0(4,0-8,0)$ & 0,53 \\
\hline \multicolumn{4}{|l|}{ Fatores genéticos } \\
\hline Presença do alelo APOE $\varepsilon 2, \mathrm{~N}(\%)$ & $21(23,1)$ & $4(11,8)$ & 0,10 \\
\hline Presença do alelo APOE $\varepsilon 4, \mathrm{~N}(\%)$ & $72(79,1)$ & $22(64,7)$ & 0,15 \\
\hline \multicolumn{4}{|l|}{ Fatores clínicos } \\
\hline Índice de comorbidades CIRS-G, mediana (IIQ) & $10,0(7,0-11,0)$ & $11,0(9,0-18,0)$ & 0,01 \\
\hline $\begin{array}{l}\text { Índice de comorbidade de Charlson, mediana } \\
\text { (IIQ) }\end{array}$ & $0,0(0,0-1,0)$ & $1,0(0,0-3,0)$ & 0,002 \\
\hline Número de medicamentos em uso, média (DP) & $4,6(2,6)$ & $5,4(2,5)$ & 0,11 \\
\hline $\begin{array}{l}\text { Autopercepção da saúde muito boa ou boa, } N \\
(\%)\end{array}$ & $48(52,7)$ & $17(50,0)$ & 0,79 \\
\hline \multicolumn{4}{|l|}{ Hábitos de vida } \\
\hline Tabagismo, N (\%) & $24(26,4)$ & $11(32,4)$ & 0,51 \\
\hline Etilismo, N (\%) & $5(5,5)$ & $4(11,8)$ & 0,25 \\
\hline Realiza atividades físicas, N (\%) & $78(85,7)$ & $24(70,6)$ & 0,05 \\
\hline Realiza atividades cognitivas, N (\%) & $54(59,3)$ & $21(61,8)$ & 0,81 \\
\hline Realiza atividades sociais, N (\%) & $33(36,3)$ & $12(35,3)$ & 0,92 \\
\hline Realiza atividades metabólicas, N (\%) & $85(93,4)$ & $29(85,3)$ & 0,16 \\
\hline
\end{tabular}

$\mathrm{DP}=$ desvio padrão; $\mathrm{IQ}=$ intervalo interquartil; CIRS-G = Cumulative IIIness Rating Scale for Geriatrics.

Variáveis categóricas foram comparadas pelo teste do qui-quadrado, exceto etilismo que foi comparado pelo teste exato de Fischer; variáveis contínuas foram analisadas pelo teste $t$ para amostras independentes (quando média e DP) ou teste de Mann-Whitney (quando mediana e IIQ). 


\title{
5.4 Análises de sobrevida para a perda de envelhecimento fisiológico, perda de funcionalidade em ABVD e AIVD, e mortalidade
}

\begin{abstract}
As análises de sobrevida investigaram a associação dos fatores genéticos e epigenéticos com tempo até perda do envelhecimento fisiológico, tempo até perda de ABVD e AIVD e tempo até o óbito.
\end{abstract}

\subsubsection{Avaliação do alelo $\varepsilon 4$ do gene APOE}

Pelas estimativas de Kaplan-Meier, a presença do alelo $\varepsilon 4$ não foi preditora de perda de funcional para ABVD (teste de log-rank, $p=0,63$ ) e AIVD (teste de log-rank, $p=0,95$ ). Também não houve associação com tempo até perda de envelhecimento fisiológico (Figura 13). Apesar dos indivíduos com a presença do alelo $\varepsilon 4$ terem apresentado menor incidência de morte quando comparados aqueles com alelo $\varepsilon 3 \varepsilon 3$ (grupo controle), a diferença não atingiu nível de significância estatístico (Figura 14). 


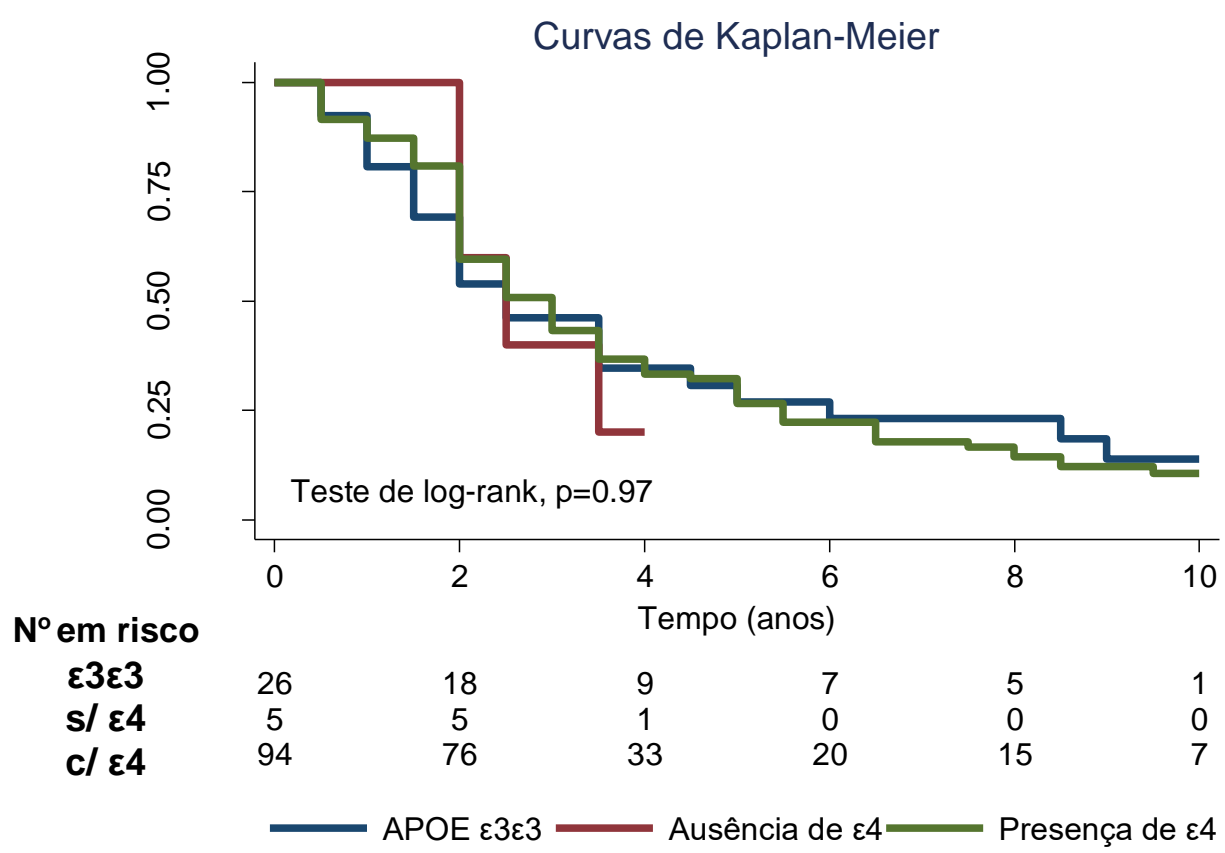

Figura 13 - Curvas de Kaplan-Meier para perda do envelhecimento fisiológico conforme a presença ou ausência do alelo $\varepsilon 4$ do gene APOE $(\mathrm{N}=125)$.

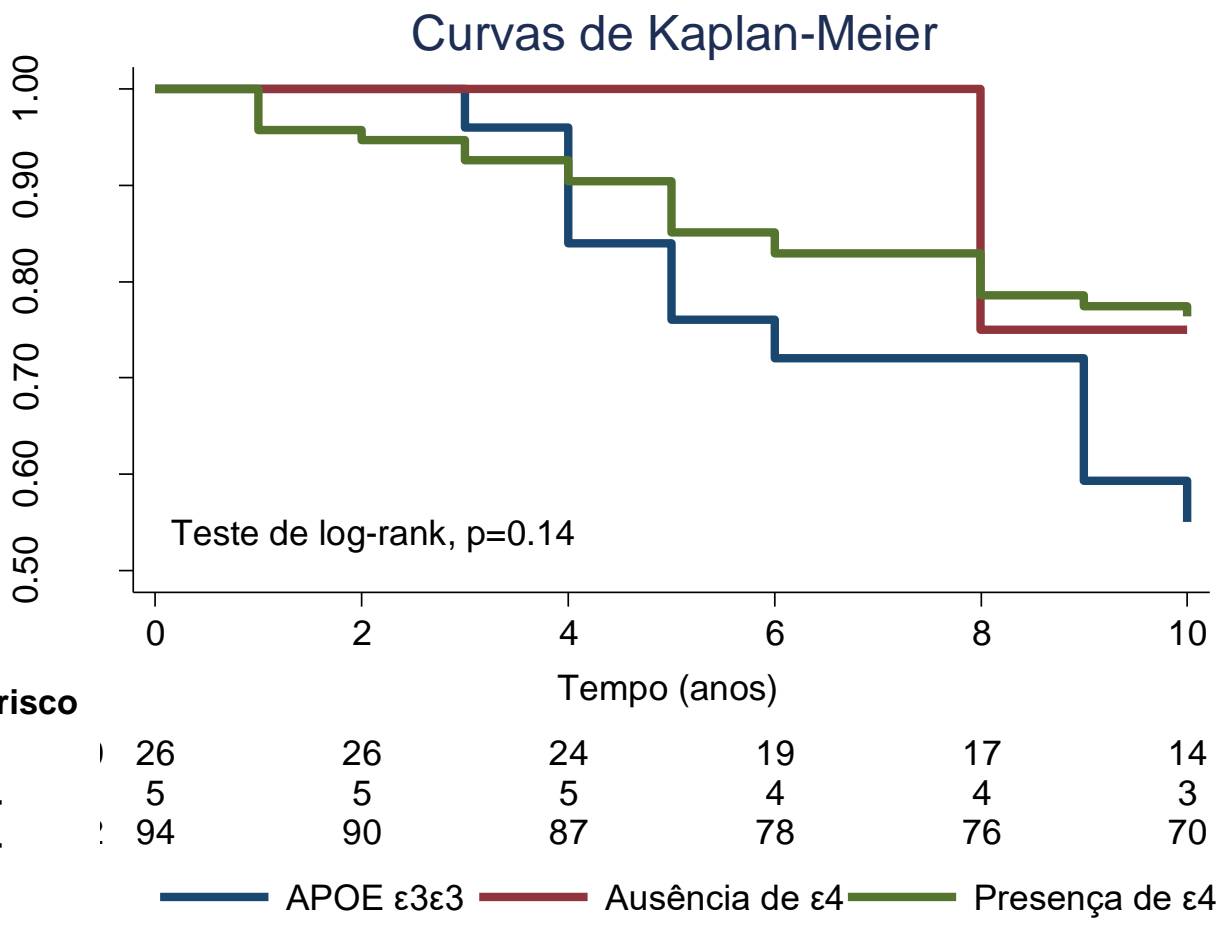

Figura 14 - Curvas de Kaplan-Meier para sobrevida conforme a presença ou ausência do alelo $\varepsilon 4$ do gene APOE $(\mathrm{N}=125)$ 
Nos modelos de regressão de Cox, a presença do alelo $\varepsilon 4$ também apresentou tendência de associação apenas com o desfecho tempo até a morte, porém sem atingir o nível de significância estatística (Tabela 7).

Tabela 7 - Modelos de regressão de Cox para associação da presença do alelo $\varepsilon 4$ do gene APOE com desfechos em 10 anos; ambulatório de geriatria HC-FMUSP - 2004 a 2014

\begin{tabular}{|c|c|c|c|}
\hline \multirow{2}{*}{\multicolumn{2}{|c|}{ Desfechos }} & \multicolumn{2}{|c|}{ Hazard Ratio (Intervalo de Confiança de $95 \%$ ) } \\
\hline & & Modelo Univariado & Modelo Ajustado* \\
\hline \multicolumn{2}{|c|}{$\begin{array}{l}\text { Perda de envelhecimento } \\
\text { fisiológico }\end{array}$} & $1,00(0,62-1,60 ; p=1,00)$ & $1,04(0,65-1,68 ; p=0,86)$ \\
\hline \multirow{2}{*}{$\begin{array}{l}\text { Perda de } \\
\text { funcionalidade }\end{array}$} & ABVD & $0,69(0,31-1,55 ; p=0,37)$ & $0,66(0,29-1,52 ; p=0,33)$ \\
\hline & AIVD & $0,90(0,46-1,75 ; p=0,76)$ & $0,67(0,34-1,33 ; p=0,25)$ \\
\hline \multicolumn{2}{|l|}{ Mortalidade } & $0,50(0,24-1,03 ; p=0,06)$ & $0,54(0,25-1,15 ; p=0,11)$ \\
\hline
\end{tabular}

$A B V D=$ atividades básicas de vida diária; AIVD = atividades instrumentais de vida diária. Grupo de referência $=$ indivíduos com alelo $\varepsilon 3 \varepsilon 3$.

${ }^{*}$ Ajustado para fatores sociodemográficos (idade, sexo, raça, escolaridade) e multimorbidade (CIRSG) 


\subsubsection{Avaliação do alelo ع2 do gene APOE}

Pelas estimativas de Kaplan-Meier, a presença do alelo $\varepsilon 2$ não foi preditora de perda de funcional para ABVD (teste de log-rank, $p=0,49$ ) e AIVD (teste de log-rank, $\mathrm{p}=0,19)$ ). Também não houve associação com tempo até perda de envelhecimento fisiológico (Figura 15). Os indivíduos com a presença do alelo $\varepsilon 2$ apresentaram uma tendência de melhor sobrevida quando comparados aqueles com alelo $\varepsilon 3 \varepsilon 3$ (grupo controle), com $\mathrm{p}=0,09$ (Figura 16). 


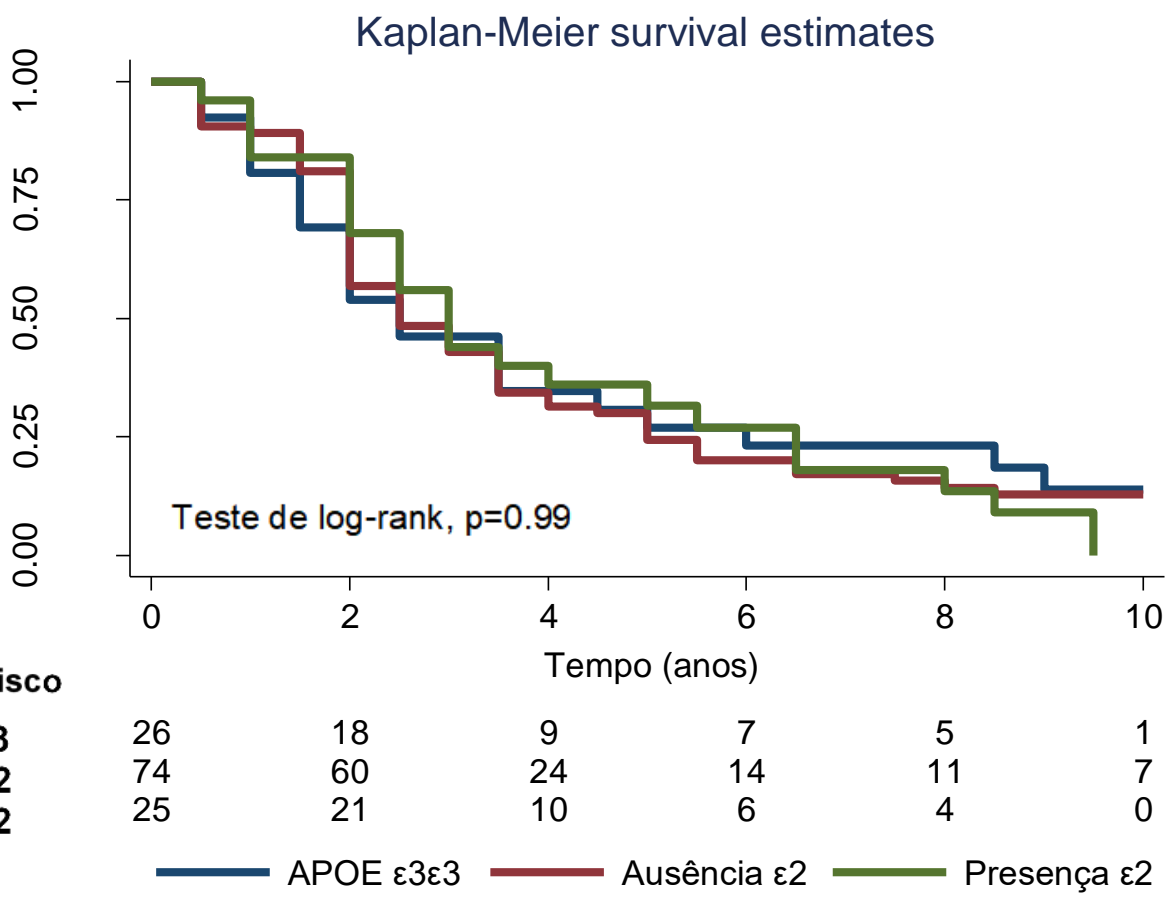

Figura 15- Curvas de Kaplan-Meier para perda de envelhecimento fisiológico conforme a presença ou ausência do alelo $\varepsilon 2$ do gene APOE $(\mathrm{N}=125)$

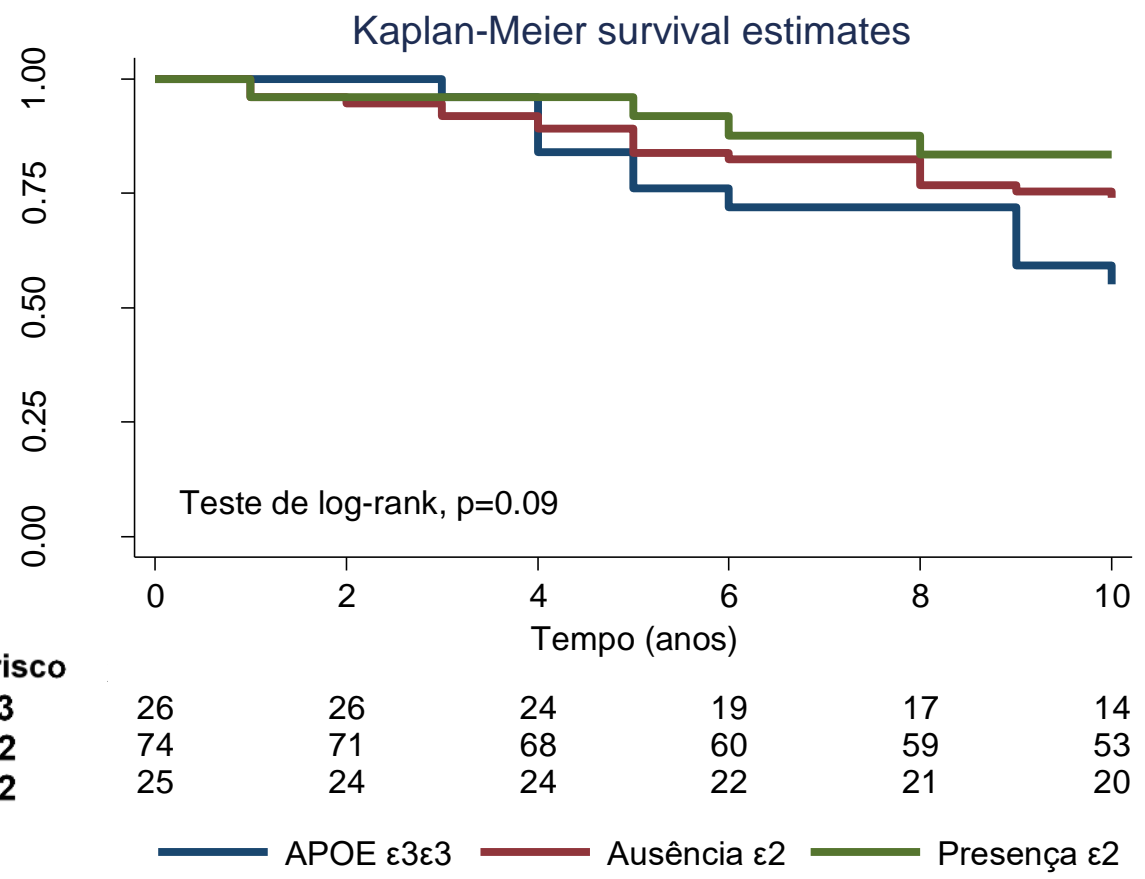

Figura 16 - Curvas de Kaplan-Meier para sobrevida conforme a presença ou ausência do alelo $\varepsilon 2$ do gene APOE $(\mathrm{N}=125)$ 
Nos modelos de regressão de Cox, a presença do alelo $\varepsilon 2$ também apresentou tendência de associação apenas com o desfecho tempo até a morte, porém sem atingir o nível de significância estatística (Tabela 8).

Tabela 8 - Modelos de regressão de Cox para associação da presença do alelo $\varepsilon 2$ do gene APOE com desfechos em 10 anos; ambulatório de geriatria HC-FMUSP - 2004 a 2014

\begin{tabular}{lccc}
\hline Desfechos & \multicolumn{2}{c}{ Hazard Ratio (Intervalo de Confiança de 95\%) } \\
& Modelo Univariado & Modelo Ajustado* \\
\hline $\begin{array}{l}\text { Perda de envelhecimento } \\
\text { fisiológico }\end{array}$ & $1,01(0,56-1,82 ; p=0,97)$ & $1,15(0,63-2,09 ; p=0,66)$ \\
$\begin{array}{l}\text { Perda de } \\
\text { funcionalidade }\end{array}$ & ABVD & $0,86(0,32-2,30 ; p=0,77)$ & $0,90(0,32-2,54 ; p=0,84)$ \\
Mortalidade & AIVD & $1,33(0,61-2,86 ; p=0,47)$ & $1,13(0,51-2,54 ; p=0,76)$ \\
\hline & $0,33(0,11-1,04 ; p=0,06)$ & $0,41(0,12-1,36 ; p=0,14)$ \\
\hline
\end{tabular}

ABVD = atividades básicas de vida diária; AIVD = atividades instrumentais de vida diária. Grupo de referência = indivíduos com alelo $\varepsilon 3 \varepsilon 3$.

${ }^{*}$ Ajustado para fatores sociodemográficos (idade, sexo, raça, escolaridade) e multimorbidade (CIRSG) 


\subsubsection{Avaliação dos fatores epigenéticos}

A tabela 9 apresenta os resultados significativos dos modelos de regressão de Cox uni e multivariados correspondentes à associação dos fatores epigenéticos com os desfechos tempo até perda de envelhecimento fisiológico, tempo até perda de ABVD e AIVD e tempo até o óbito.

Houve destaque para faixa etária $\geq 80$ anos que se associou com todos os desfechos e atividade física que se associou com todos os desfechos exceto tempo até o óbito na análise multivariada. 
Tabela 9 - Modelos de regressão de Cox para associação dos fatores epigenéticos com desfechos em 10 anos; ambulatório de geriatria HC-FMUSP - 2004 a 2014

\begin{tabular}{lcc}
\hline \multirow{2}{*}{ Desfechos } & \multicolumn{2}{c}{ Hazard Ratio (Intervalo de Confiança de 95\%) } \\
\cline { 2 - 3 } & \multicolumn{1}{c}{ Modelo Univariado } & Modelo Ajustado* \\
\hline Perda de envelhecimento fisiológico & \\
Idade entre 70 e 80 anos & $1,86(1,13-3,07 ; p=0,01)$ & $2,32(1,37-3,93 ; p=0,002)$ \\
Idade $\geq 80$ anos & $2,37(1,32-4,27 ; p=0,004)$ & $3,46(1,79-6,68 ; p<0,001)$ \\
Atividades físicas & $0,61(0,38-0,98 ; p=0,04)$ & $0,55(0,34-0,90 ; p=0,02)$ \\
Tabagismo & $1,54(1,02-2,32 ; p=0,04)$ & $1,89(1,13-3,15 ; p=0,02)$ \\
Etilismo & $2,08(1,04-4,17 ; p=0,04)$ & - \\
Perda de AIVD & & \\
Idade $\geq 80$ anos & $5,76(2,43-13,6 ; p<0,001)$ & $6,74(2,65-17,2 ; p<0,001)$ \\
Sexo feminino & $0,75(0,41-1,38 ; p=0,35)$ & $0,43(0,22-0,83 ; p=0,01)$ \\
Escolaridade $\leq 4$ anos & $1,82(0,99-3,33 ; p=0,05)$ & - \\
Morar sozinho & $0,45(0,24-0,85 ; p=0,01)$ & - \\
CIRS-G tercil médio (9-11 pts.) & $2,17(1,11-4,28 ; p=0,02)$ & \\
CIRS-G tercil superior $(\geq 12$ pts.) & $2,41(1,19-4,90 ; p=0,01)$ & \\
Atividades físicas & $0,43(0,24-0,76 ; p=0,004)$ & $0,47(0,25-0,87 ; p=0,02)$ \\
Atividades cognitivas & $0,52(0,31-0,87 ; p=0,01)$ & - \\
Atividades metabólicas & $0,35(0,17-0,72 ; p=0,004)$ & - \\
Perda de ABVD & & - \\
Idade $\geq 80$ anos & $13,3(3,02-58,3 ; p=0,001)$ & $11,9(2,57-55,6 ; p=0,002)$ \\
Sexo feminino & $0,56(0,27-1,19 ; p=0,13)$ & $0,34(0,15-0,77 ; p=0,01)$ \\
CIRS-G tercil médio (9-11 pts.) & $3,30(1,29-8,47 ; p=0,01)$ & $2,36(1,12-4,97 ; p=0,02)$ \\
Atividades físicas & $0,41(0,19-0,87 ; p=0,02)$ & $0,38(0,16-0,88 ; p=0,02)$ \\
Atividades metabólicas & $0,37(0,14-0,97 ; p=0,04)$ & - \\
Mortalidade & & - \\
Idade $\geq 80$ anos & $3,86(1,50-9,89 ; p=0,005)$ & $5,32(1,83-15,5 ; p=0,002)$ \\
Atividades físicas & $0,45(0,21-0,94 ; p=0,03)$ & - \\
CIRS-G tercil superior $(\geq 12$ pts.) & $2,82(1,20-6,66 ; p=0,02)$ & - \\
CCI tercil superior $(\geq 2$ pts.) & $3,46(1,66-7,21 ; p=0,001)$ & $3,36(1,62-6,96 ; p=0,001)$ \\
\hline & & \\
\hline
\end{tabular}

ABVD = atividades básicas de vida diária; AIVD = atividades instrumentais de vida diária; CIRS-G = Cumulative IIIness Rating Scale for Geriatrics; $\mathrm{CCl}=$ Charlson comorbidity index.

* Ajustado para os fatores sociodemográficos (faixa etária, sexo, raça, escolaridade) e para as outras variáveis significativas $(p<0,05)$ na análise univariada. 


\subsection{Avaliação do ganho de multimorbidade}

A multimorbidade foi avaliada por meio de modelos de regressão linear múltipla tendo como desfecho a pontuação do CIRS-G e CCI ao final do tempo de seguimento. Após ajuste para as variáveis sociodemográficas e clínicas (idade, sexo, raça, anos de escolaridade, arranjo de moradia e escore do CIRS-G no início do estudo), idosos que realizavam atividades metabólicas tiveram uma média de aproximadamente 4 pontos $(\beta=-4,37 ; p$ $=0,003)$ a menos no CIRS-G aos 10 anos de seguimento quando comparados aos pacientes que não realizavam atividades metabólicas. Participantes que moravam sozinho no início do estudo também se associaram com menor pontuação do CIRS-G ao fim de 10 anos de seguimento $(\beta=-2,28 ; p=0,005)$.

Quando testamos o índice de multimorbidade CIRS-G CM2, ou seja, um índice que aumenta a gravidade do CIRS-G, idosos que referiram etilismo apresentaram uma média de aproximadamente 2 pontos $(\beta=1,78 ; p$ $=0,045)$ a mais no CIRS-G CM2 aos 10 anos de seguimento quando comparados aos pacientes que não referiram etilismo, após ajuste para variáveis sociodemográficas e clínicas

Não houve associação significativa de nenhum preditor estudado com o índice CCl. 


\subsection{Análise da evolução anual dos índices prognósticos em relação à mortalidade}

Observamos associação da morte com os índices prognósticos do envelhecimento.

O grupo composto pelos idosos que faleceram apresentou maior quantidade de acúmulo de déficits, medido pelo DI $(p<0,001)$ (Figura 17), e maior carga de multimorbidade, medida pelo CIRS-G total $(p<0,001)$ (Figura 18) e CIRS-G CM2 ( $p<0,001)$ (Figura 19) no decorrer dos dez anos de seguimento, avaliado por análise de regressão de medidas repetidas a cada ano.

Não houve associação, porém, de maior carga de multimorbidade medida pelo $\mathrm{CCl}$ no grupo que faleceu ao longo dos dez anos $(p=0.32)$ (Figura 20). 


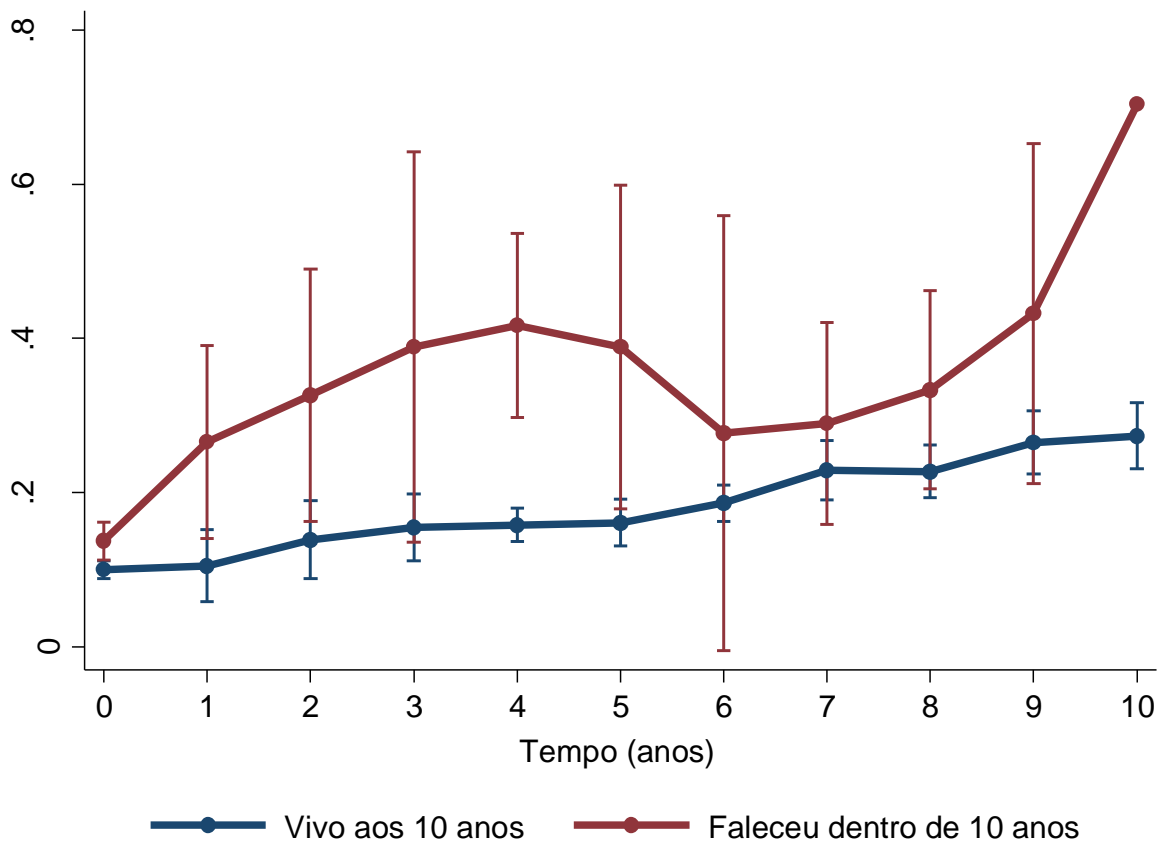

Figura 17 - Curva do índice de acúmulo de déficits (DI) dos participantes que morreram em relação aos que estavam vivos após dez anos de seguimento $(\mathrm{N}=125)$

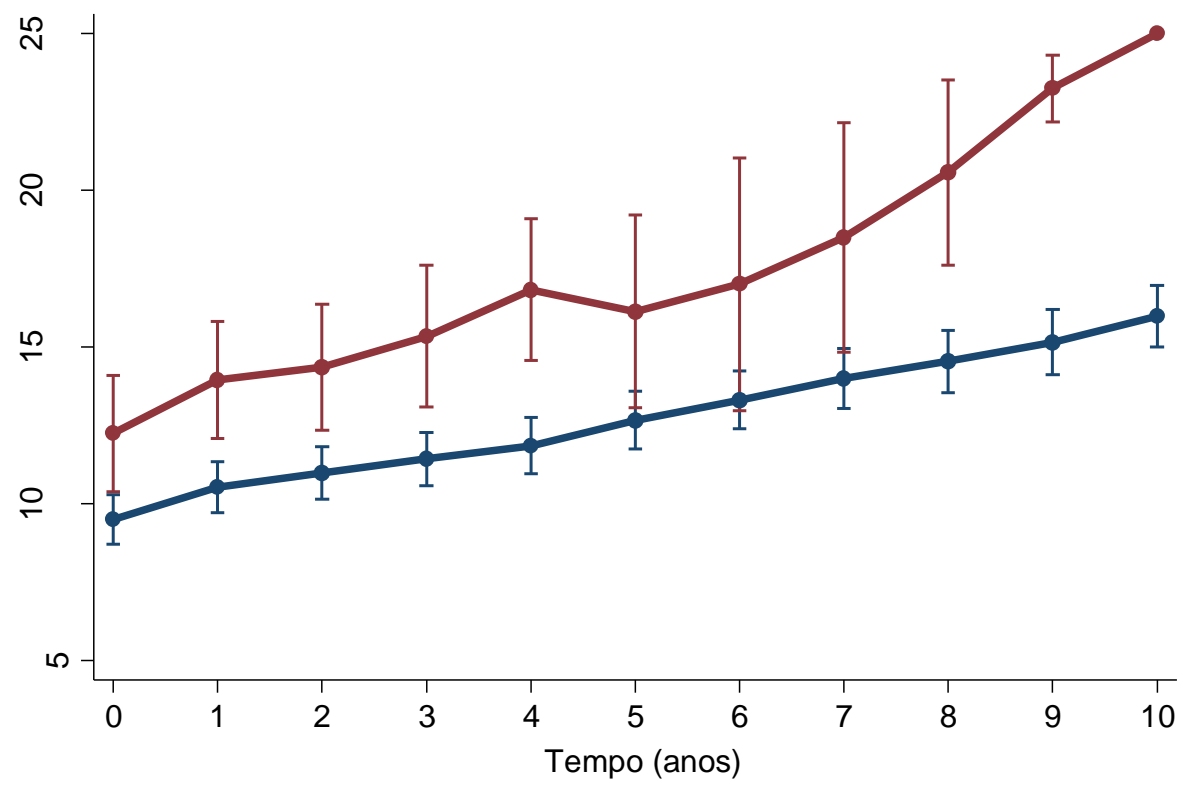

$\longrightarrow$ Vivo em 10 anos $\longrightarrow$ Faleceu dentro de 10 anos

Figura 18 - Curva do índice de multimorbidade CIRS-G dos participantes que morreram em relação aos que estavam vivos após dez anos de seguimento $(\mathrm{N}=125)$ 


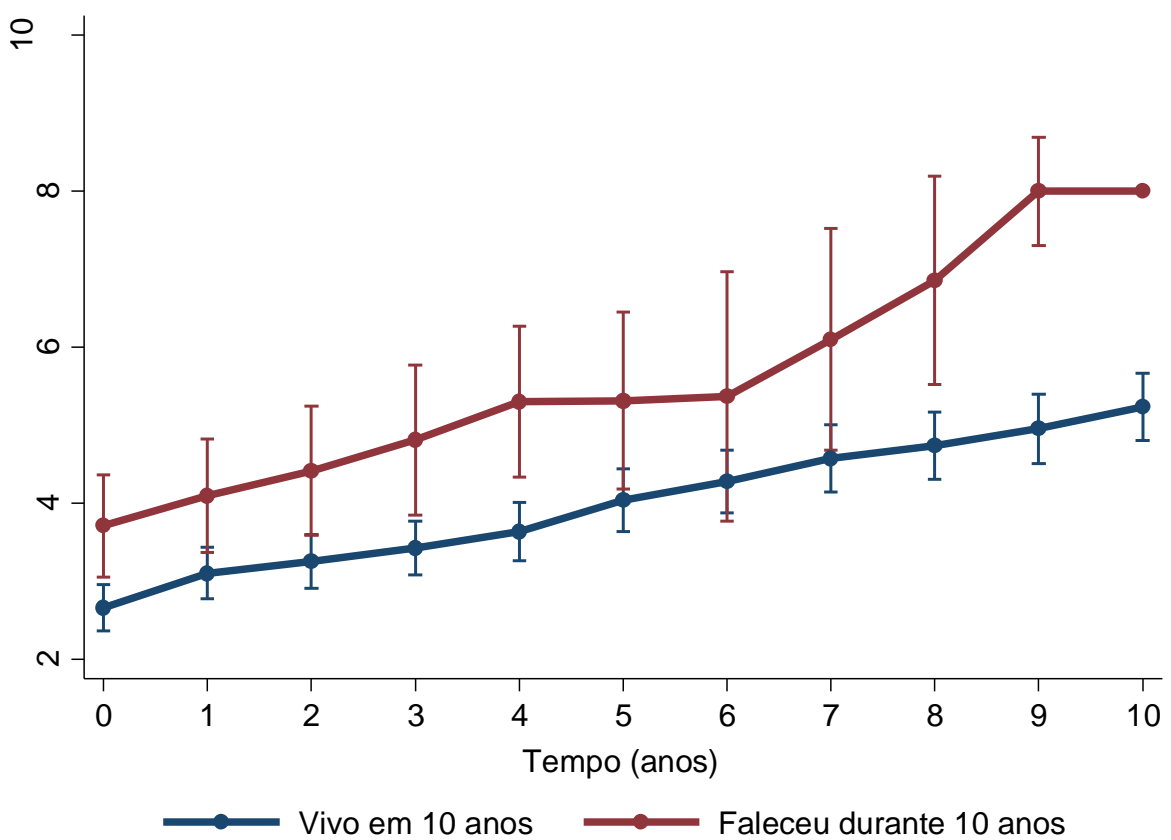

Figura 19- Curva do índice de multimorbidade CIRS-G CM2 dos participantes que morreram em relação aos que estavam vivos após dez anos de seguimento $(\mathrm{N}=125)$

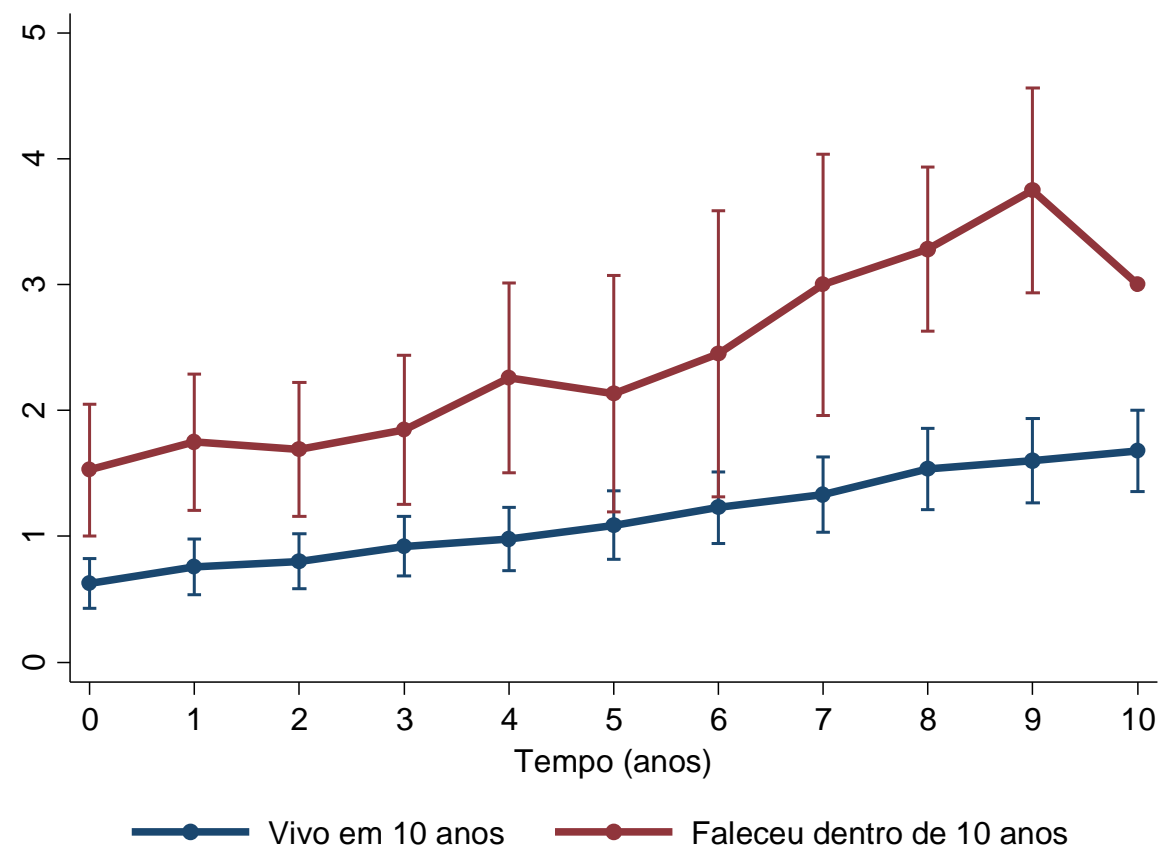

Figura 20 - Curva do índice de multimorbidade Charlson comorbidity index (CCl) dos participantes que morreram em relação aos que estavam vivos após dez anos de seguimento $(\mathrm{N}=125)$ 
6 Discussão 


\section{DISCUSSÃO}

Os fatores que contribuem para o envelhecimento com mínimas incapacidades no ser humano, ainda são pouco entendidos. Tanto a longevidade excepcional, quanto a sobrevivência com poucas doenças e alta funcionalidade, têm sido objeto de estudo especialmente nas últimas duas décadas. Objetivamos nesse estudo, contribuir para o entendimento dos fatores envolvidos no alcance desse modelo de envelhecimento, definido como saudável, e, especialmente, o papel de um dos poucos genes, reconhecidamente associado ao envelhecimento, o gene da apolipoproteína E (APOE).

Para que atingíssemos esse objetivo, inicialmente fez-se necessária a escolha de critérios que melhor traduzissem o conceito de saúde no envelhecimento para o nosso objeto de estudo. Entendendo que o envelhecimento é individual, heterogêneo e dinâmico, escolhemos como nosso norte, o conceito proposto pela Organização da Saúde (OMS) para o qual o indivíduo envelhece com saúde quando mantém a capacidade funcional para suas escolhas e objetivos que o encaminhem ao bem-estar em idade avançada (WHO World Report on Ageing and Health, 2015).

Diversas maneiras e critérios foram previamente propostos, e certamente, a escolha do critério utilizado para definir o envelhecimento saudável interfere diretamente nos achados dos estudos sobre esse tema. Depp e Jeste, em revisão de 28 estudos quantitativos publicados até o ano 
de 2006, encontraram 29 diferentes definições operacionais para o envelhecimento bem-sucedido ou saudável (Depp; Jeste, 2006). Mais recentemente, Cosco et al. apontou 105 definições diferentes em sua revisão sistemática sobre o assunto (Cosco et al., 2014).

A dificuldade em se definir critérios traduz a diversidade de dimensões que podem influenciar o modo como a qualificação do envelhecimento é vista. Para os olhos de Rowe e Kahn, que primeiro introduziram o conceito em 1999, o modelo deveria diferenciar o idoso que envelheceu com mínima deterioração fisiológica, de forma "bem-sucedida", daquele que envelheceu de forma "usual", com doenças acumuladas e perda de capacidade funcional. Seus estudos pioneiros através da MacArthur Research Network on Successful Aging propuseram três componentes para que um idoso pudesse ser bem-sucedido no seu envelhecimento: ter ausência ou conseguir evitar doenças e fatores de risco para elas; manter alta capacidade cognitiva; e engajar-se ativamente na vida. Apesar de incluir a necessidade do engajamento social, o modelo original de Rowe e Kahn era bastante fundamentado em componentes biomédicos (Rowe; Kahn, 1999). Outros autores, como Baltes e Smith, Vaillant e Mukamel, ampliaram esse conceito com uma perspectiva mais ecológica, onde o envelhecimento poderia ser bem-sucedido, mesmo que apresentasse doenças e limitações, onde o importante seria a habilidade em manter-se funcional nos domínios físico, cognitivo, emocional e social. Esses autores basearam suas observações através de seus estudos em fatores preditores de envelhecimento funcional (Curb et al., 1990; Baltes; Smith, 1997). 
Assim, modelos para se definir o envelhecimento saudável, que expressem a capacidade do idoso em se manter funcional, devem ser baseados em domínios objetivos biomédicos (essencialmente físicos e cognitivos) e psicossociais (essencialmente níveis educacionais, suporte social e familiar, e aspectos psicológicos de humor, capacidade de aceitação e satisfação com a vida).

Atualmente, um terceiro domínio tem sido bastante valorizado, o subjetivo, onde o próprio idoso define a qualidade do seu envelhecimento, através de auto percepções de aspectos de saúde e de envelhecimento. Quando critérios subjetivos são comparados a objetivos, percebe-se que idosos avaliam a qualidade do seu envelhecimento como positiva levando em consideração mais fatores, além da ausência de doenças ou limitações funcionais. Montross et al. avaliaram idosos americanos da comunidade, independentes na maioria, e mostraram que altos níveis de envelhecimento saudável subjetivo foram relacionados com a possibilidade de passar mais tempo em atividades prazerosas, como leitura, ouvir rádio e visitar familiares (Montross et al., 2006).

Apesar da necessidade de ampliação dos domínios a serem incluídos no estudo do envelhecimento saudável, Lowry et al. sugerem, a partir das evidências, que a presença de capacidade funcional e física devem ser os componentes principais de qualquer uma das definições de envelhecimento saudável ou bem-sucedido (Lowry et al., 2012).

A definição de envelhecimento saudável por domínio objetivo baseado em capacidade funcional e severidade de doenças (modelo biomédico), foi 
por nós escolhida por se adequar a uma necessidade de medidas objetivas, mais acessíveis em revisão retrospectiva de prontuários, e que traduzissem de forma adequada a evolução desses idosos ao longo do tempo mediante um preditor que sabidamente estava relacionado a presença de doenças físicas e incapacitantes no envelhecimento, no caso o gene APOE. Dessa forma, entendemos também que, apesar da possível simplificação e distanciamento da visão multidimensional do envelhecimento, ainda assim essa definição contempla a funcionalidade, que é base e tradução da evolução do envelhecimento ao longo do tempo.

Nossa casuística foi composta de idosos totalmente funcionais no início do estudo, o que possibilitou a utilização de modelos biomédicos baseados em capacidade funcional para a avaliação da evolução do envelhecimento ao longo dos dez anos, o que chamamos de prognóstico do envelhecimento. Apesar de total funcionalidade em atividades de vida diária, os idosos apresentavam multimorbidade com pontuações nos índices CIRS-G de 10,24, e CCl de 0,9, capazes de discriminar subgrupos de nível de multimorbidade para a identificação de desfechos em saúde em nível ambulatorial, conforme observado na Tabela 1 . Em revisão sistemática de estudos sobre o uso de instrumentos de avaliação de multimorbidade, o CIRS-G mostrou-se superior para avaliação de funcionalidade e qualidade de vida, enquanto que o $\mathrm{CCl}$ foi bom preditor de mortalidade (Huntley et al., 2012). Em relação ao CIRS-G, não existem notas de corte sugeridas para definir graus de multimorbidade, porém, uma média de 10 na pontuação total reflete doenças presentes em 4 ou 5 sistemas diferentes, e tem boa 
correlação com desfechos clínicos em idosos ambulatoriais (Fortin et al., 2005; Hudon et al., 2005).

Apesar de apresentarem correlações com alguns indicadores de saúde, índices de multimorbidade são insuficientes para capturar a complexidade da saúde do idoso, principalmente como índice prognóstico ao longo do tempo. Estudos mostram que índices que contemplem múltiplos indicadores passam a ser mais completos nesse objetivo, especificamente associando indicadores de funcionalidade aos índices de multimorbidade. A utilização desses novos índices agrega valor, na medida em que ajuda a identificar precocemente indivíduos que se desviam negativamente da trajetória esperada de saúde da população. São importantes para dar bases ao planejamento de estratégias de promoção de saúde e intervenções no envelhecimento.

Poucos índices baseados em indicadores objetivos múltiplos foram testados em ambientes ambulatoriais e comunitários. Em 2016, Marengoni et al. publicaram dados de um estudo transversal de 3363 idosos, utilizando um índice complexo para medir a prevalência de multimorbidade em quatro dimensões: multimorbidade por número de doenças; gravidade de multimorbidade pelo índice CIRS-G sensibilizado para níveis mais altos de categorias; polifarmácia; e problemas de saúde complexos, com prejuízos funcionais e/ou cognitivos. Os autores encontraram prevalência baixa de multimorbidade pelos quatro critérios juntos (1,6 a 14,9\%), sendo que essa variação esteve associada com idade elevada (para todos), sexo feminino (para todos, exceto a multimorbidad) e escolaridade baixa (para problemas 
de saúde complexos) (Marengoni et al., 2016). Em estudo longitudinal de 6 anos da coorte do Swedish National Study, autores acompanharam indicadores de saúde de 3363 idosos da comunidade, totalmente funcionais, utilizando um índice complexo chamado HAT (Health Assesment Tool), que contemplava 5 dimensões (velocidade de marcha; status cognitivo; multimorbidade pelo número de doenças; incapacidade pela perda de ABVD; e incapacidade por perda de AIVD). O HAT foi preditor de hospitalização e mortalidade (Santoni et al., 2017).

Procuramos também avaliar os desfechos relacionados ao envelhecimento de nossa amostra através de um índice composto de medidas de multimorbidade e funcionalidade. Construímos nosso índice a partir da somatória das categorias marcadas com nível de gravidade no mínimo 2 no CIRS-G, e das atividades de vida diária preservadas. Baseamos a construção desse índice nos índices que medem acúmulo de déficits ao longo do tempo, como o já conhecido Frailty index proposto (Rockwood et al., 2000). Esses índices de acúmulo de déficits refletem interações complexas de processos fisiológicos associados ao envelhecimento, portanto são instrumentos interessantes para prognóstico de evolução do envelhecimento, e podem ser construídos a partir de no mínimo 20 categorias escolhidas de forma aleatória, desde que relacionadas à saúde do idoso (Kulminski et al., 2011).

Conforme observado na figura 9, nosso índice de acúmulo de déficits (DI) mostrou distanciamento do envelhecimento fisiológico esperado na grande maioria da amostra (86\%). Houve aumento de 2,5 vezes no índice DI 
ao final dos dez anos de estudo $(\mathrm{DI}=0,28)$ em relação à avaliação inicial da amostra $(\mathrm{DI}=0,11)$, sendo que o esperado era de $3 \%$ ao ano. Ou seja, houve aumento de 8 vezes na taxa de acúmulo de déficits ao longo dos dez anos. Kulminski et al. observaram índice médio de 0,259 para mulheres e 0,274 para homens aos 75 anos no ano de início do estudo. As taxas de acúmulo de déficits também maiores do que o esperado em coorte longitudinal National Long Term Care Survey (NLTCS), em 17 anos, sendo que a taxa foi mais acelerada para mulheres mais próximas de idades mais avançadas e as curvas se convergiram em idades mais avançadas entre saudáveis e não saudáveis (demonstrando a compressão da morbidade) (Kulminski et al., 2006). Em outro estudo longitudinal (Long Life Family Study, LLFS), o mesmo autor encontrou aumento de mais de $5 \%$ na taxa de aumento de índice de acúmulo de déficits de 27 categorias para a população doente em relação à que considerou saudável (Kulminski et al., 2011).

Em relação à evolução da multimorbidade durante o seguimento dos dez anos, a maioria (57\% pelo CIRS-G e $94 \%$ pelo $\mathrm{CCl}$ ) dos idosos apresentou piora de multimorbidade, com ganho de 5,84 pontos na média do índice CIRS-G do início (de 10,24 para 16,08), e ganho de 0,82 no $\mathrm{CCl}$ (de 0,87 para 1,69). Essa é uma amostra de idosos em acompanhamento no GAMIA (Grupo de Assistência Multidisciplinar ao Idoso Ambulatorial), que apesar de ter como um dos critérios de elegibilidade para a entrada no grupo, o de ter poucas doenças e doenças controladas, alguns desses idosos já estavam em acompanhamento no GAMIA por anos. Por outro lado, a alta multimorbidade em nosso estudo reflete a realidade de idosos com 
idade média de 75 anos da população. Fortin utilizou em seu estudo canadense o CIRS-G para análise de multimorbidade em 980 indivíduos, e encontrou escore de CIRS-G acima de 10 pontos em $70 \%$ dos 320 indivíduos acima de 65 anos. A média da pontuação do CIRS-G foi de 13,1 para homens e 12,9 para mulheres acima de 65 anos. No estudo de Fortin, um escore de 10 no CIRS-G indicou doenças em pelo menos 4 ou 5 sistemas (Fortin et al., 2005). Em revisão sistemática de 41 estudos de multimorbidade em idosos acima de 60 anos, Marengoni encontrou prevalências de 55 a $98 \%$ de multimorbidade definida como presença de 2 ou mais doenças (Marengoni et al., 2011). Em nosso meio, Nunes encontrou prevalência de $57,9 \%$ de multimorbidade (2 ou mais doenças) em 666 idosos da cidade de Pelotas/RS (Nunes et al., 2016). A prevalência de multimorbidade varia conforme o critério que a define, como demonstrado em amostra representativa da população suíça, na qual o uso de um índice de multimorbidade que incluía avaliação funcional, além da contagem de doenças, reduziu a prevalência de multimorbidade de $63 \%$ para $33 \%$ em idosos (Pache et al., 2015). O CIRS-G é um índice melhor do que o $\mathrm{CCl}$ como indicador prognóstico do envelhecimento, já que inclui avaliação funcional de doenças, através da classificação de gravidade, além da contagem das doenças principais do idoso, conforme revisão sistemática realizada por Huntley e col (Huntley et al., 2012). Além do fato de ter sido um índice já utilizado em outros estudos retrospectivos, através de coleta de registros em prontuários, com confirmação de seu poder preditivo (Miller et 
al., 1992; Conwell et al., 1993; Zekry et al., 2010; Huntley et al., 2012; Sowa et al., 2016).

Quase metade da amostra apresentou perda funcional medida por atividades básicas e instrumentais de vida diária $(44,8 \%)$ e um terço evolui para morte em dez anos do seguimento $(27,2 \%)$.

Nosso principal objetivo foi o de buscar possível associação da variação de alelos do gene APOE com essas medidas de prognóstico do envelhecimento acima descritas, nos dez anos de seguimento da amostra. $O$ APOE é apontado como o gene que mais se associa a longevidade e determinadas doenças do envelhecimento nos estudos de associação ampla com o genoma (GWAS) (Walter et al., 2011; Brooks-Wilson, 2013; Pilling et al., 2016).

A distribuição dos alelos $\varepsilon 2$, $\varepsilon 3$ e $\varepsilon 4$ do gene APOE em nossa amostra não se mostrou em equilíbrio de Hardy-Weinberg. A frequência do alelo $\varepsilon 4$ foi maior do que o esperado (39,6\% para uma frequência esperada em caucasianos de $15 \%$ ), em detrimento da frequência de alelo $\varepsilon 3$. Uma das explicações poderia ser a miscigenação de raças da população brasileira, em especial a de São Paulo. Porém, estudo nacional de Bambuí/MG com 1408 idosos, mostrou frequências dos alelos semelhantes às de outras populações $(6,5 \%, 80 \%$ e $13,5 \%$ para os respectivos alelos $\varepsilon 2$, ع3 e $\varepsilon 4)$ (Fuzikawa et al., 2007). Em outra amostra brasileira de 120 controles de portadores de doença de Alzheimer, em São Paulo, com idade média semelhante à de nosso estudo, Bahia e cols encontraram frequências de $10 \%$ para o alelo $\varepsilon 4$ e $9 \%$ para o alelo $\varepsilon 2$, em equilíbrio de Hardy-Weinberg 
(Bahia et al., 2008). Desse modo, é mais provável que o desequilíbrio das frequências dos alelos encontrado em nosso estudo deva ter sido fruto de um viés de seleção dos idosos no recrutamento da amostra. É possível também, que existam fenótipos desconhecidos do alelo $\varepsilon 4$ relacionados aos critérios de seleção para o ingresso no GAMIA, ou mesmo, que tenha ocorrido redução de expressão de efeitos deletérios nos portadores do alelo $\varepsilon 4$, com aumento de sobrevida dos mesmos. Esse fenômeno é descrito em populações com altas taxas endêmicas de infecção, como na África, onde parece que $\circ$ alelo $\varepsilon 4$ apresenta efeito benéfico para a reprodução nesses ambientes. É um exemplo de interação específica gene-ambiente (van Exel et al., 2017).

Não encontramos associações genéticas dos alelos do APOE com perda funcional, ganho de multimorbidade e aumento no índice de acúmulo de déficits. Observamos apenas uma tendência de proteção de sobrevida pelo alelo $\varepsilon 2$, mas também pelo alelo $\varepsilon 4$ (Figuras 18 e 20), porém sem confirmação nos modelos de regressão de Cox analisados.

Fatores genéticos, e principalmente o gene APOE, parecem estar relacionados a longevidade e a algumas características de hereditariedade, porém não está clara a associação com outros fenótipos do envelhecimento, como o envelhecimento saudável, a sobrevivência livre de doenças e de incapacidades (Brooks-Wilson, 2013). Meta-análise de 25.000 indivíduos acima de 55 anos em estudos de associação ampla com o genoma (GWAS) não demonstrou associação do gene APOE com sobrevivência livre de doenças (Walter et al., 2011). 
Além das conhecidas associações do alelo $\varepsilon 4$ com doenças de Alzheimer e doença cardiovascular, alguns estudos têm demonstrado possíveis associações com perda de capacidade física. Estudos longitudinais de Framingham e de uma coorte dinamarquesa confirmaram essa associação (Walter et al., 2011). Kulminski também demonstrou aumento significativo de risco de incapacidades em amostra de 1805 idosos (Kulminski et al., 2008). O estudo longitudinal SEBAS com 6 anos de seguimento, em Taiwan, encontrou associação do alelo $\varepsilon 4$ com maior dificuldade em funcionalidade medida por ABVD e AIVD, talvez relacionada à obesidade (Chen et al., 2017). Por outro lado, estudo prospectivo recente com mais de 11.000 mulheres sobreviventes até 85 anos negou a associação do gene APOE com sobrevivência livre de doenças (Shadyab et al., 2017).

O alelo ع2 é reconhecidamente um fator protetor de doenças e de longevidade. Estudo longitudinal recente (Long Life Family Study, LLFS) investigou possíveis efeitos pleiotrópicos do alelo $\varepsilon 2$ no mesmo estudo, além de potencial papel de fatores biodemográficos na associação do alelo a traços genéticos mais complexos (Kulminski et al., 2016). A conclusão do estudo foi a de que o efeito do alelo $\varepsilon 2$ pode ser modulado por outros fatores de origem genética ou não genética, de maneira a revelar traços contraditórios protetores ou não de doenças.

Apesar do nosso tamanho amostral não favorecer a achados de associações genéticas, gostaria de chamar a atenção para possibilidades de efeitos desconhecidos protetores do alelo $\varepsilon 4$, assim como deletérios do alelo 
ع2. Estudos já comprovam o efeito pleiotrópico desse gene, e, além disso, existem interações epigenéticas, principalmente do ambiente, que podem interferir na expressão fenotípica do gene. Dessa forma, encontramos estudos que apontam proteção do alelo $\varepsilon 4$ para fertilidade em populações com altas taxas endêmicas de infecção, proteção contra risco de fraturas e contra risco de degeneração macular relacionada à idade. Em relação a expressões deletérias do alelo $\varepsilon 2$, encontramos associação com aumento do risco de osteoporose, câncer de cólon, piora de glomerulopatia diabética, e incidência aumentada de pneumonia (Souza et al., 2017; Xiying M et al., 2017; van Exel et al., 2017). Interações do ambiente e de estilo de vida podem interagir com a expressão dos genes. Já existem evidências de que hábitos dietéticos, por exemplo, dieta rica em ácidos graxos essenciais, e atividade física tenham o poder de modificar expressões fenotípicas, favorecendo mudanças na expressão do APOE (Boss et al., 2018).

Encontramos algumas associações de fatores não genéticos com a evolução dos desfechos estudados, principalmente na perda de capacidades em ABVD e AIVD.

Em relação aos fatores sociodemográficos, a idade mais avançada (acima de $\geq 80$ anos) associou-se com todos os desfechos, com quase 2,5 vezes chances de apresentarem perda de envelhecimento fisiológico em dez anos, e elevadas chances de apresentarem perda de capacidades em AIVD, e principalmente em ABVD. Muito idosos ( $\geq 80$ anos) apresentaram mortalidade 4 vezes maior do que faixas etárias mais baixas. Mulheres perderam menos capacidades em ABVD e AIVD nos dez anos. Não 
encontramos associação de raça para os desfechos estudados. A escolaridade baixa ( $\leq 4$ anos) apresentou associação com perda de funcionalidade para ABVD e AIVD na análise univariada, mas não confirmada na análise multivariada, embora com tendência para perda de AIVD. De maneira interessante, morar sozinho predispôs a preservação de funcionalidade para AIVD, além de associação com menor pontuação do CIRS-G ao final do seguimento. No estudo SHARE (Survey of Health, Ageing and Retirement in Europe, onda de 2010-2011) foi encontrado que o envelhecimento saudável esteve associado com estar satisfeito com a vida e realizar-se com atividades dentro de casa. Também o nível educacional foi preditor em alguns dos seis países europeus desse estudo (Sowa et al., 2016). No estudo MEDIS (Mediterranean Islands Study), houve associação de longevidade com morar sozinho, embora em estudo transversal, o que não permite estabelecer relação de causa e efeito (Foscolou et al., 2018). $\mathrm{Na}$ revisão sistemática de Depp e Jeste, a idade mais jovem e nível educacional mais alto foram preditores de envelhecimento saudável (Depp; Jeste, 2006).

Quanto aos hábitos de vida, a presença de tabagismo atual ou prévio apresentou duas vezes maior risco de se afastar do envelhecimento fisiológico esperado. O etilismo também se associou a perda de envelhecimento fisiológico, e com pior evolução de multimorbidade (média de 2 pontos a mais no CIRS-G CM2, que é um índice de maior gravidade na multimorbidade). Ser ativo fisicamente foi fator protetor contra perda de saúde de envelhecimento, apresentou 50 a $60 \%$ menos de risco de evoluir com perda de capacidade funcional por ABVD e AIVD, e perda de 
envelhecimento fisiológico. Apresentou associação com menor mortalidade apenas na análise univariada. Atividades com gasto metabólico maior, como subir dois lances de escada ou cuidar da casa diariamente, associaram-se a menor multimorbidade ao final dos dez anos, reduzindo cerca de 4 pontos em média no CIRS-G. Atividades metabólicas associaram-se também a menor perda de funcionalidade na análise univariada, não confirmada na multivariada. Estímulos cognitivos se associaram a menor perda de AIVD apenas na análise univariada.

Nossos dados estão de acordo com a revisão sistemática de Depp e Jeste para alguns fatores preditores do envelhecimento saudável, como a presença de baixa multimorbidade, atividade física regular, ausência de tabagismo, além de idade menor e melhor nível educacional (Depp; Jeste, 2006). No MEDIS (Mediterranean Islands Study), o engajamento em atividade física e atividades sociais foi um fator protetor do envelhecimento saudável (Foscolou et al., 2018). A atividade física também foi fator preditor de envelhecimento saudável no SHARE (Survey of Health, Ageing and Retirement in Europe, onda de 2010-2011) (Sowa et al., 2016). A atividade física, portanto, se apresenta até o momento como o fator preditor mais significativo do envelhecimento saudável.

Observamos que maior multimorbidade no início do estudo predispôs a perda de capacidade funcional em ABVD.

Embora não tenhamos encontrado associação da autoavaliação da saúde com desfechos, estudos apontam para autoavaliação da saúde positiva como preditor subjetivo importante do envelhecimento saudável 
(Montross et al., 2006). Também não encontramos associação de atividades sociais, especialmente a participação semanal de grupos de discussão, com qualquer um dos desfechos. Não existem muito estudos, mas em acompanhamento de amostra longitudinal de seis anos, Menec encontrou diferentes relações entre atividades e envelhecimento saudável, onde atividades sociais e produtivas estão associadas positivamente com felicidade, funcionalidade e mortalidade, enquanto atividades solitárias, como hobbies, estão associadas somente a felicidade (Menec, 2003).

A mortalidade foi cerca de três vezes maior no grupo que apresentou multimorbidade elevada medida pelo $\mathrm{CCl}$. O CCI não foi preditor de perda de funcionalidade e envelhecimento fisiológico. Assim como não houve associação significativa de nenhum preditor estudado com o $\mathrm{CCl}$. Como previa Huntley et al., enquanto o CIRS-G mostrou-se superior para avaliação de funcionalidade em nosso estudo, o $\mathrm{CCl}$ foi apenas bom preditor de mortalidade (Huntley et al., 2012).

\subsection{Limitações do estudo}

Esse estudo possui limitações, algumas estão listadas abaixo:

- Os dados foram coletados de forma retrospectiva, criticável do ponto de vista metodológico para estudos longitudinais com análises de sobrevida. Tentamos minimizar os erros provenientes da coleta retrospectiva, através da escolha de índices mais objetivos, e, no caso do CIRS-G, índice previamente utilizado em 
vários estudos de forma retrospectiva com comprovada capacidade de predição de desfechos. Além disso, tomamos o cuidado de manter apenas um pesquisador para a coleta dos dados, já que o CIRS-G pode dar margem a interpretações diferentes nas medidas de gravidade do índice. Os dados genéticos permaneceram fechados na fase de coleta dos dados.

- Amostra pequena e de conveniência, o que reduziu sobremaneira a sensibilidade do marcador genético para a predição dos desfechos propostos, ainda mais sendo um gene com múltiplos alelos;

- Apesar de algumas associações encontradas em nosso estudo, especialmente pela força de ser longitudinal com seguimento de dez anos, serão necessários estudos com representatividade populacional maior, para que esses dados tenham validade externa.

- Distribuição dos alelos do gene APOE em desequilíbrio de HardyWeinberg, o que significa que estamos estudando uma amostra não representativa da população em termos genéticos.

- As medidas prognósticas do envelhecimento foram estudadas através de parâmetros objetivos e biomédicos, inclusive para a confecção do índice de acúmulo de déficits, única maneira factível para este estudo retrospectivo. Outras dimensões, especialmente a psicossocial, deveriam sempre fazer parte de estudos 
relacionados a esse tema, para que o conceito de envelhecimento saudável seja verdadeiramente respeitado.

\subsection{Considerações finais}

Este é um estudo pioneiro na busca de associação do gene APOE com o fenótipo envelhecimento saudável, utilizando-se de um índice de acúmulo de déficits para estimar o prognóstico de evolução do envelhecimento. Além disso, buscou-se aplicar índices que representem melhor os indicadores da saúde do idoso, como: escala de Atividades Básicas de Vida Diária (Katz; Akpom, 1976); índice Atividades Instrumentais de Vida Diária (Lawton; Brody, 1969); CIRS-G, Cumulative Illness Rating Scale for Geriatrics (Linn et al., 1968); CCl, Charlson comorbidity index (Charlson et al., 1987). Não encontramos nenhum estudo que tenha tentado correlacionar a variável genética APOE como preditora do fenótipo complexo do envelhecimento saudável. Dentre os fatores preditores do envelhecimento saudável, os genéticos são os mais robustos por sofrerem a menor interferência possível de fatores ambientais, e, no nosso caso, o gene APOE parece ser, por várias evidências, a chave que abre portas para o entendimento da genética da longevidade e das doenças que se manifestam no envelhecimento. Porém, é provável que essa chave do conhecimento seja apenas coadjuvante num processo que, como Gladyshev imagina (Gladyshev, 2016), jamais possa ser explicado por genes ou processos únicos. 
7 Conclusões 


\section{CONCLUSÕES}

- O polimorfismo do gene APOE não influenciou a evolução do envelhecimento em multimorbidade, funcionalidade ou acúmulo de déficits, em dez anos da vida de idosos ambulatoriais;

- Fatores epigenéticos determinaram perda em dez anos de envelhecimento fisiológico: (1) idade avançada (maior ou igual a 80 anos), sedentarismo e tabagismo, associaram-se a perda de capacidades funcionais em atividades básicas e instrumentais de vida diária, além de ganho de multimorbidade e acúmulo não esperado de déficits; (2) presença de níveis graves de multimorbidade associou-se a perda de capacidades funcionais apenas para atividades instrumentais de vida diária; (3) atividades que contemplem alto gasto metabólico e o fato de morar sozinho, foram protetores contra o ganho de multimorbidade; (4) o etilismo associou-se a piora do nível de gravidade das doenças dentro da multimorbidade;

- Menor sobrevida em dez anos foi associada a idade avançada (maior ou igual a 80 anos), e níveis mais altos de multimorbidade e de acúmulo de déficits no início da avaliação. 
8 Anexos 


\section{ANEXOS}

\subsection{ANEXO A - Termo de Consentimento Livre e Esclarecido}

HOSPITAL DAS CLÍNICAS DA FACULDADE DE MEDICINA DA UNIVERSIDADE DE SÃO PAULO-HCFMUSP

TERMO DE CONSENTIMENTO LIVRE E ESCLARECIDO

\section{DADOS DE IDENTIFICAÇÃO DO SUJEITO DA PESQUISA OU RESPONSÁVEL LEGAL}

1.NOME:

DOCUMENTO DE IDENTIDADE No : SEXO :.$M \square F \square$ DATA NASCIMENTO: ........................

ENDEREÇO №. APTO:

BAIRRO: CIDADE:

CEP: TELEFONE: DDD ...).

2.RESPONSÁVEL LEGAL

NATUREZA (grau de parentesco, tutor, curador etc.)

DOCUMENTO DE IDENTIDADE : SEXO: $M \square F \square$

DATA NASCIMENTO.:

ENDEREÇO: № APTO:

BAIRRO: CIDADE:

CEP: TELEFONE: DDD

\section{DADOS SOBRE A PESQUISA}

1. TÍTULO DO PROTOCOLO DE PESQUISA: ENVELHECIMENTO SAUDÁVEL CORRELAÇÕES DENTRE ALGUNS DETERMINANTES CLÍNICOS, FUNCIONAIS E GENÉTICOS

PESQUISADOR : Naira Hossepian Salles de Lima Hojaij

CARGO/FUNÇÃO: Médica Assistente do HCFMUSP

INSCRIÇÃO CONSELHO REGIONAL №

UNIDADE DO HCFMUSP: Serviço de Geriatria

3. AVALIAÇÃO DO RISCO DA PESQUISA:

$\begin{array}{ll}\text { RISCO MÍNIMO } x & \text { RISCO MÉDIO } \square \\ \text { RISCO BAIXO } \square & \text { RISCO MAIOR } \square\end{array}$

4.DURAÇÃO DA PESQUISA : Dez meses 
O Sr(a). está sendo convidado a participar de uma pesquisa sobre alguns fatores que possam influenciar o seu envelhecimento, se para melhor (saudável) ou pior (não saudável). Para tal o senhor(a) realizará testes ou questionários que avaliarão o seu estado físico (a presença e a gravidade de doenças, a capacidade física, a marcha e o equilíbrio do corpo, a presença ou ausência de alterações na visão e audição), emocional (a presença ou ausência de sintomas depressivos), intelectual (presença ou ausência de problemas na memória ou em outras capacidades mentais), social e de lazer ( os relacionamentos com pessoas da família e da comunidade e suas atividades prazerosas), nutricional (como é sua rotina de alimentação, peso e altura), religiosa e espiritual, e de qualidade de vida. Além desses fatores, iremos pesquisar marcadores laboratoriais e genéticos do seu envelhecimento, através da análise do seu sangue.

Na primeira etapa da pesquisa, o sr(a). será convidado a realizar uma coleta de sangue, sem a necessidade do jejum, previamente agendada, a ser realizada no Hospital-Dia (bloco 7 do $5^{\circ}$ andar do Prédio dos Ambulatórios) por uma biomédica do Laboratório de Investigação em Neurologia deste Hospital. Esta amostra de sangue será encaminhada para a pesquisa genética que envolve alguns segmentos do DNA extraído do sangue (polimorfismos da apolipoproteína E). Na segunda etapa, o $\operatorname{sr}(a)$. será convidado a se submeter a alguns questionários (perguntas e respostas), testes rápidos de visão e audição, uma bateria breve de avaliação física (andar por 6 minutos, sentar e levantar, andar e se equilibrar) e um exame físico completo. Esta etapa será previamente agendada pela pesquisadora e será realizada no Hospital-Dia (5a andar - bloco 7 ) com a duração de cerca de 90 minutos. A terceira etapa também será a de uma coleta de sangue em jejum e urina, porém no Laboratório Central do $\mathrm{HC}\left(2^{\circ}\right.$ andar do Prédio dos Ambulatórios). Esta última amostra de sangue será utilizada para exames laboratoriais de rotina.

Todo o material encaminhado para a pesquisa genética será identificado no laboratório por código formado por números e letras e, portanto, sua privacidade e identidade serão preservadas, e somente poderá ser requisitado o resultado individualmente pelo $\operatorname{sr}(\mathrm{a})$. A eventual inclusão dos resultados em publicação científica será feita de modo a manter o seu anonimato. Será guardado, com sua autorização prévia, o material genético (DNA extraído), que somente será utilizado em novas pesquisas com novo consentimento do $\operatorname{sr}(a)$.

Todos os testes físicos serão realizados apenas para testar a sua própria capacidade, não envolvem aparelhos, portanto os riscos são mínimos. As coletas de sangue envolvem o risco apenas da punção da veia. Para quaisquer conseqüências danosas relacionadas a essa pesquisa ou informações e dúvidas sobre a mesma, o sr(a) terá o pronto atendimento pela própria pesquisadora executante Naira Hossepian Salles de Lima Hojaij, no telefone 3069-6731, Sala de Estudos da Geriatria, 5 andar, bloco 4A do Prédio dos Ambulatórios. O sr(a) poderá se negar a participar da pesquisa em qualquer etapa da mesma, tendo a liberdade de retirar seu consentimento já assinado, sem qualquer prejuízo na sua assistência dentro deste Serviço. Os dados clínicos e laboratoriais, inclusive genéticos ficarão sob sigilosa salvaguarda em mãos apenas dos pesquisadores.

Caso tenha completamente entendido o que foi explicado pelo pesquisador, queira por favor assinar este consentimento para o presente protocolo de pesquisa.

Assinatura do paciente/representante legal

Data

\section{Assinatura da testemunha}

Data

$1 /$

Para casos de pacientes menores de 18 anos, analfabetos, semi-analfabetos ou portadores de deficiência auditiva ou visual. 


\section{(Somente para o responsável do projeto)}

Declaro que obtive de forma apropriada e voluntária o Consentimento Livre e Esclarecido deste paciente ou representante legal para a participação neste estudo.

Data 
8.2 ANEXO B - Protocolo de Pesquisa - Avaliação inicial e no seguimento

Protocolo de Pesquisa - Determinantes do Envelhecimento Saudável

Etiqueta

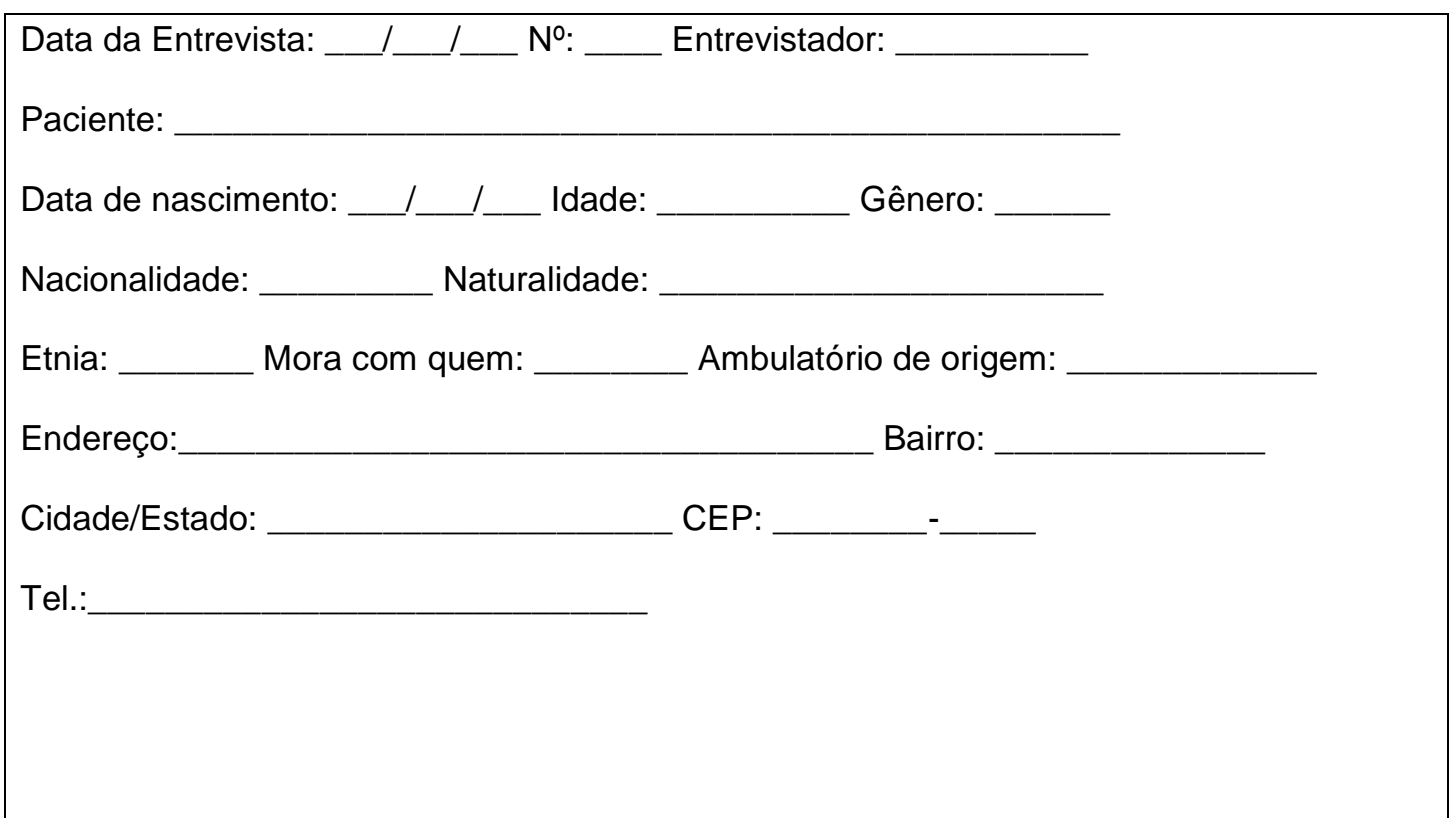


Quadro - Índice CIRS-G. Adaptado do artigo original do autor: Parmelee PA. J Am Geriatr Soc 1995;43:130-7.

\begin{tabular}{|c|c|}
\hline & ÍNDICE CIRS-G \\
\hline 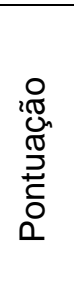 & $\begin{array}{l}0 \text { - Nenhum problema } \\
1 \text { - Problema leve atual ou significativo no passado } \\
2 \text { - Incapacidade moderada ou terapia inicial necessária } \\
3 \text { - Incapacidade grave ou constante, problema crônico incontornável } \\
4 \text { - Acometimento grave, tratamento imediato necessário, incapacidade completa }\end{array}$ \\
\hline & Coração \\
\hline & Vascular \\
\hline & Hematopoiético \\
\hline & Respiratório \\
\hline & Olhos, ouvidos, nariz, faringe, laringe \\
\hline & Digestório alto \\
\hline & Digestório baixo \\
\hline & Fígado \\
\hline & Renal \\
\hline & Genitourinário \\
\hline & Musculoesquelético/tegumentar \\
\hline & Neurológico \\
\hline & Endocrinometabólico/mamas \\
\hline & Psiquiátrico \\
\hline & Número de categorias pontuadas \\
\hline & Total geral \\
\hline & Número de categorias com nível de gravidade $\geq 2$ \\
\hline
\end{tabular}


Quadro - Índice de Charlson. Adaptado do artigo original do autor: Charlson ME. J Clin Epidemiol. 1994; 47:1245-51.

\begin{tabular}{|c|c|c|}
\hline \multicolumn{3}{|c|}{ Índice de Charlson } \\
\hline \multicolumn{2}{|r|}{ Infarto do miocárdio* } & 1 \\
\hline \multicolumn{2}{|r|}{ Insuficiência cardíaca congestiva } & 1 \\
\hline \multicolumn{2}{|r|}{ Doença arterial periférica $^{* *}$} & 1 \\
\hline \multicolumn{2}{|r|}{ Doença cerebrovascular (AIT/AVE) } & 1 \\
\hline \multicolumn{2}{|r|}{ Demência } & 1 \\
\hline \multicolumn{2}{|r|}{ Doença pulmonar crônica } & 1 \\
\hline \multicolumn{2}{|r|}{ Doença do tecido conjuntivo } & 1 \\
\hline \multicolumn{2}{|r|}{ Doença ulcerosa péptica } & 1 \\
\hline \multicolumn{2}{|r|}{ Hemiplegia } & 2 \\
\hline \multicolumn{2}{|r|}{ Doença renal moderada ou severa } & 2 \\
\hline \multicolumn{2}{|r|}{ Leucemia aguda ou crônica } & 2 \\
\hline \multicolumn{2}{|r|}{ Linfoma } & 2 \\
\hline \multirow{2}{*}{ Doença hepática } & Leve (sem hipertensão portal) & 1 \\
\hline & Moderada ou grave & 3 \\
\hline \multirow{2}{*}{ Diabetes mellitus } & Sem lesão de órgão-alvo ${ }^{* * t}$ & 1 \\
\hline & Com lesão de órgão-alvo & 2 \\
\hline \multirow{2}{*}{ Tumor sólido } & Sem metástases ${ }^{* * * *}$ & 2 \\
\hline & Metastático & 6 \\
\hline \multicolumn{2}{|r|}{ AIDS (não somente HIV +) } & 6 \\
\hline \multicolumn{3}{|c|}{ Total sem ajuste por idade } \\
\hline \multicolumn{3}{|c|}{$\begin{array}{l}\text { Adicionar um ponto a cada década de vida depois dos } 40 \text { anos } \\
\text { ( } 50 \text { anos }=1 \text { ponto } / 60 \text { anos } 2 \text { pontos e assim por diante })\end{array}$} \\
\hline \multicolumn{2}{|r|}{ Total com ajuste por idade } & \\
\hline $\begin{array}{l}{ }^{*} \text { História, não inclui se } \\
\text { ** Inclui aneurisma de } \\
{ }^{* * *} \text { Não inclui se contro } \\
{ }^{* \star \star *} \text { Não inclui se mais }\end{array}$ & $\begin{array}{l}\text { erações do ECG } \\
\text { eta } \\
\text { o diagnóstico }\end{array}$ & \\
\hline
\end{tabular}




\begin{tabular}{|c|c|c|}
\hline $\begin{array}{l}\text { Ativ. Básicas e } \\
\text { Instrumentais }\end{array}$ & Atividades cognitivas & Atividades físicas \\
\hline 1. Banhar-se & 1. Ler livro ou jornal & 1. Tênis ou Golfe \\
\hline 2. Se locomover & 2. Escrever por prazer & 2. Nadar \\
\hline 3. Vestir-se & 3. Palavras cruzadas & 3. Bicicleta \\
\hline 4. Ir ao banheiro & $\begin{array}{l}\text { 4. Jogos de } \\
\text { tabuleiros/carta }\end{array}$ & 4. Dança \\
\hline 5. Continência & 5. Grupos de discussão & 5. Exercício em grupo \\
\hline 6. Alimentar-se & 6. Instrumento Musical & 6. Jogos com times \\
\hline 1. Telefone & \multirow{4}{*}{$\begin{array}{l}\text { AVALIACÃ̃O FUNCIONAL DE } \\
\text { VIDA DIÁRIA }\end{array}$} & 7. Andar por exercício \\
\hline 2. Compras & & $\begin{array}{l}\text { 8. Subir+2 lances de } \\
\text { escada }\end{array}$ \\
\hline 3. Preparo da comida & & 9. Serviço de casa \\
\hline 4. Trabalho de casa & & 10. Cuidar de criança \\
\hline 5. Dinheiro & \multicolumn{2}{|c|}{ Total de atividades básicas } \\
\hline 6. Medicação & \multicolumn{2}{|c|}{ Total de atividades instrumentais } \\
\hline 7. Uso de transporte & \multicolumn{2}{|c|}{ Total de atividades cognitivas } \\
\hline $\begin{array}{l}\text { 8. Lava peq. peças de } \\
\text { roupa }\end{array}$ & \multicolumn{2}{|c|}{ Total de atividades físicas } \\
\hline \multicolumn{3}{|c|}{$\begin{array}{l}\text { ATIVIDADES BÁSICAS E INSTRUMENTAIS: SEM LIMITAÇÃO (1), COM } \\
\text { DIFICULDADE (2), NÃO É CAPAZ (3), NUNCA FEZ (0) }\end{array}$} \\
\hline \multicolumn{3}{|c|}{$\begin{array}{l}\text { ATIVIDADES COGNITIVAS E FíSICAS: DIÁRIO (7), VÁRIAS VEZES (4), } \\
\text { UMA VEZ POR SEMANA (1), MENSAL (0), OCASIONAL (0), NUNCA } \\
(0)\end{array}$} \\
\hline
\end{tabular}

\section{AVALIAÇ̃̃o SUBJETIVA}

Avaliação da auto-avaliação da saúde: De uma maneira geral, como o senhor (a) definiria sua saúde?

$\square$ Muito ruim; $\square$ Ruim; $\square$ Nem ruim, nem boa; $\square$ Boa; $\square$ Muito boa. 
9 Referências 


\section{REFERÊNCIAS}

Albert SM, Gurland B, Maestre G, Jacobs DM, Stern Y, Mayeux R. APOE Genotype influences functional status among elderly without dementia. Am J Med Genet. 1995;60(6):583-7.

Anand P. Capabilities and health. J Med Ethics. 2005;31:299-303.

Arking R. Envelhecimento humano. In: Arking R. Biologia do envelhecimento: observações e princípios. Ribeirão Preto, SP: FUNPEC-Editora; 2008. p.153159.

Badera G, Zuliania G, Kostnerb GM, Fellina R. Apolipoprotein E Polymorphism is not associated with longevity or disability in a sample of italian octo- and nonagenarians. Gerontology. 1998;44:293-9.

Bahia VS, Kok F, Marie SN, Shinjo SO, Caramelli P, Nitrini R. Polymorphisms of APOE and LRP genes in Brazilian individuals with Alzheimer disease. Alzheimer Dis Assoc Disord. 2008;22(1):61-5.

Baltes PB, Smith J. A Systemic-wholistic view of psychological functioning in very old age: introduction to a collection of articles from the Berlin Aging Study. Psychol Aging. 1997;12(3):395-409.

Beard JR, Officer A, de Carvalho IA, Sadana R, Pot AM, Michel JP, et al. The World report on ageing and health: a policy framework for healthy ageing. Lancet. 2016;387(10033):2145-54.

Beauvoir, Simone de. A velhice. $2^{2}$ edição. Rio de Janeiro: Ed. Nova Fronteira; 1990. 711p. 
Beloosesky Y, Weiss A, Mansur N. Validity of the Medication-based Disease Burden Index compared with the Charlson Comorbidity Index and the Cumulative Illness Rating Scale for geriatrics: a cohort study. Drugs Aging. $2011 ; 28(12): 1007-14$.

Blazer DG, Fillenbaum G, Burchett B. The APOE-E4 allele and the risk of functional decline in a community sample of African American and white older adults. J Gerontol A Biol Sci Med Sci. 2001;56(12):M785-9.

Bos MM, Noordam R, Blauw GJ, Slagboom PE, Rensen PCN, van Heemst D. The ApoE $\varepsilon 4$ isoform: can the risk of diseases be reduced by environmental factors? J Gerontol A Biol Sci Med Sci. 2018;XX(XX):1-9.

Broer L, Buchman AS, Deelen J, Evans DS, Faul JD, Lunetta KL, et al. GWAS of Longevity in CHARGE Consortium Confirms APOE and FOXO3 Candidacy. J Gerontol A Biol Sci Med Sci. 2015;70(1):110-8.

Brooks-Wilson AR. Genetics of healthy aging and longevity. Hum Genet. 2013;132:1323-38.

Butler RN. Ageism: a forward. J Soc Issues. 1980;36(2):8.

Censo Demográfico 2010 - Características da população e dos domicílios. Ministério do Planejamento, Orçamento e Gestão, Instituto Brasileiro de Geografia e Estatística - IBGE; 2011. Disponível em http://www.ibge.gov.br/home/estatistica/populacao/censo2010/. [Acesso em $17 / 11 / 2018]$

Cesari M, Pérez-Zepeda MU, Marzetti E. Frailty and multimorbidity: different ways of thinking about geriatrics. J Am Med Dir Assoc. 2017;18(4):361-4. 
Charlson M, Wells MT, Ullman R, King F, Schmukler C. The Charlson Comorbidity Index can be used prospectively to identify patients who will incur high future costs. PLoS One. 2014;9(12):1-16.

Charlson ME, Ales KA, Pompei P, MacKenzie CR. A new method of classification of prognostic comorbidity for longitudinal studies: development and validation. J Chron Disease. 1987; 40:373-83.

Charlson ME, Szatrowski TE, Peterson J, Gold J. Validation of a combined comorbidity index. J Clin Epidemiol. 1994;47:1245-51.

Chaves EP, Narayanaswami V. Apolipoprotein E and cholesterol in aging and disease in the brain. Future Lipidol. 2008;3(5):505-30.

Chen LJ, Steptoe A, Ku PW. Obesity, apolipoprotein E $\varepsilon 4$, and difficulties in activities of daily living among older adults: a 6-year follow-up study. Ann Behav Med. 2017; 51(2):251-60.

Conwell Y, Forbes NT, Cox C. Validation of a measure of physical illness burden at autopsy: the Cumulative Illness Rating Scale. J Am Geriatr Soc. 1993;41(1):38-41.

Corbo RM, Scacchi R. Apolipoprotein E (APOE) allele distribution in the world. Is APOE*4 a 'thrifty' allele? Ann Hum Genet. 1999;63:301-10.

Cosco TD, Prina AM, Perales J, Stephan BC, Brayne C. Operational definitions of successful aging: a systematic review. Int Psychogeriatr. 2014;26(3):373-81.

Curb JD, Guralnik JM, LaCroix AZ, Korper SP, Deeg D, Miles T, et al. Effective aging: meeting the challenge of growing older. J Am Geriatr Soc. 1990;38(7):827-8. 
Deelen J, Beekman M, Uh HW, Broer L, Ayers KL, Tan Q, et al. Genomewide association meta-analysis of human longevity identifies a novel locus conferring survival beyond 90 years of age. Hum Mol Genet.

2014;23(16):4420-32.

Depp AC e Jeste DV. Definitions and predictors of successful aging: a comprehensive review of larger quantitative studies. Am J Geriatr Psychiatric. 2006;14:6-20.

Diederichs C, Berger K, Bartels DB. The measurement of multiple chronic diseases - a systematic review on existing multimorbidity indices. J Gerontol A Biol Sci Med Sci. 2011;66A(3):301-11.

Dose J, Huebbe P, Nebel A, Rimbach G. APOE genotype and stress response - a mini review. Lipids Health Dis. 2016;15:121.

Duarte $Y$, Andrade CL, Lebrão ML. O Índex de Katz na avaliação da funcionalidade dos idosos. Rev Esc Enferm USP. 2007;41(2):317-25.

Fabian D, Flatt T. The evolution of aging. Nature Education Knowledge 2011:3(10):9.

Feinstein AR. The pre-therapeutic classification of co-morbidity in chronic disease. J Chronic Dis. 1970;23:455-68.

Fortin M, Bravo G, Hudon C, Vanasse A, Lapointe L. Prevalence of multimorbidity among adults seen in family practice. Ann Fam Med. 2005;3:223-8.

Fortin M, Stewart M, Poitras ME, Almirall J, Maddocks H. A systematic review of prevalence studies om multimorbidity: toward a more uniform methodology. Ann Fam Med. 2012;10:142-51. 
Foscolou A, Magriplis E, Tyrovolas S, Soulis G, Bountziouka V, Mariolis A, et al. Lifestyle determinants of healthy ageing in a Mediterranean population: The multinational MEDIS study. Exp Gerontol. 2018;110:35-41.

Franceschi C, Bezrukov V, Blanché H, Bolund L, Christensen K, de Benedictis $G$, et al. Genetics of healthy aging in Europe. The EU-Integrated Project GEHA (GEnetics of Healthy Aging). Ann N Y Acad Sci. 2007;1100:21-45.

Fries JF. Aging, natural death, and the compression of morbidity. $\mathrm{N}$ Engl $\mathrm{J}$ Med. 1980;303(3):130-5.

Fuzikawa AK, Peixoto SV, Taufer M, Moriguchi EH, Lima-Costa MF. Apolipoprotein $\mathrm{E}$ polymorphism distribution in an elderly Brazilian population: the Bambuí Health and Aging Study. Braz J Med Biol Res. 2007;40(11):1429-34.

GBD 2017 DALYs and HALE Collaborators. Global, regional, and national disability-adjusted life-years (DALYs) for 359 diseases and injuries and healthy life expectancy (HALE) for 195 countries and territories, 1990-2017: a systematic analysis for the Global Burden of Disease Study 2017. Lancet. 2018; 392: 1859-922.

GBD 2017 Disease and Injury Incidence and Prevalence Collaborators. Global, regional, and national incidence, prevalence, and years lived with disability for 354 diseases and injuries for 195 countries and territories, 1990-2017: a systematic analysis for the Global Burden of Disease Study 2017. Lancet. 2018;392:1789-858.

Gladyshev VN. Aging: progressive decline in fitness due to the rising deleteriome adjusted by genetic, environmental, and stochastic processes. Aging Cell. 2016;15: 594-602. 
Gladyshev VN. The origin of aging: imperfectness-driven non-random damage defines the aging process and control of lifespan. Trends Genet. 2013:29(9): 506-12.

Goldsmith TC. Modern evolutionary mechanics theories and resolving the programmed/non-programmed aging controversy. Biochemistry (Mosc). 2014;79(10):1049-55.

Hudon C, Fortin M, Vanasse A. Cumulative Illness Rating Scale was a reliable and valid index in a family practice context. J Clin Epidemiol. 2005;58:603-8.

Huntley AL, Johnson R, Purdy S, Valderas JM, Salisbury C. Measures of multimorbidity and morbidity burden for use in primary care and community settings: a systematic review and guide. Ann Fam Med. 2012;10(2):134-41.

Institute for Health Metrics and Evaluation (IHME). GBD Compare Data Visualization. Seattle, WA: IHME, University of Washington, 2016. Disponível em http://vizhub.healthdata.org/gbd-compare/. [Acesso em 17/11/2018].

Integrated care for older people: guidelines on community-level interventions to manage declines in intrinsic capacity. Geneva: World Health Organization, 2017.

Katz S, Akpom CA. A measure of primary sociobiological functions. Int J Health Serv. 1976; 6(3):493-508.

Katz S, Calasanti T. Critical perspectives on successful aging: does it "appeal more than it illuminates"? The Gerontologist. 2015;55(1):26-33.

Kirkwood TBL. Evolution of ageing. Mech Ageing Dev. 2002;123:737-45. 
Kolovou G, Damaskos D, Anagnostopoulou K, Cokkinos DV. Review: apolipoprotein E gene polymorphism and gender. Ann Clin Lab Science. 2009;39(2):120-33.

Kulminski A, Ukraintseva SV, Arbeev KG, Manton KG, Oshima J, Martin GM, Yashin Al. Association between Apoe E2/3/4 polymorphism and disability severity in a national long term care survey sample. Age Ageing. 2008;37(3):288-93.

Kulminski A, Yashin, Ukraintseva S, Akushevich I, Arbeev K, Land K, et al. Accumulation of health disorders as a systemic measure of aging: Findings from the NLTCS data. Mech Ageing Dev. 2006;127(11):840-8.

Kulminski AM, Arbeev KG, Christensen K, Mayeux R, Newman AB, Province MA, et al. Do gender, disability, and morbidity affect aging rate in the LLFS? Application of indices of cumulative deficits. Mech Ageing Dev. 2011;132(4):195-201.

Kulminski AM, Arbeev KG, Culminskaya L, Arbeeva L, Ukraintseva SV, Stallard E, et al. Age, gender, and cancer but not neurodegenerative and cardiovascular diseases strongly modulate systemic. effect of the apolipoprotein E4 allele on lifespan. PLoS Genet. 2014;10(1):1-12.

Kulminski AM, Raghavachari N, Arbeev KG, Culminskaya I, Arbeeva L, Wu $D$, et al. Protective role of the apolipoprotein E2 allele in age-related disease traits and survival: evidence from the Long Life Family Study. Biogerontology. 2016;17(5-6):893-905.

Kulminski AM, Ukraintseva SV, Akushevich IV, Arbeev KG, Yashin AI. Cumulative Index of Health Deficiencies as a characteristic of long life. J Am Geriatr Soc. 2007;55:935-40. 
Lan TY, Chang WC, Lan TH, Hurng BS. Apolipoprotein e genotype and risk of developing physical limitations in elderly people. J Am Geriatr Soc. 2009;57(7):1308-9.

Lawton MP, Brody EM. Assesment of older people: self-maintaining and instrumental activities of daily living. Gerontologist. 1969;9:179-85.

Liehn EA, Ponomariov V, Diaconu R, Streata I, loana M, Crespo-Avilan GE, et al. Apolipoprotein $E$ in cardiovascular diseases: novel aspects of an oldfashioned enigma. Arch Med Res. 2018 Sep 10. pii: S0188-4409(18)304284.

Linn BS, Linn MW, Gurel L. Cumulative Illness Rating Scale. J Am Geriatr Soc. 1968;16:622-6.

Lopes dos Santos R, Virtuoso Júnior JS. Confiabilidade da versão brasileira da escala de atividades instrumentais da vida diária. RBPS Revista Brasileira em Promoção da Saúde. 2008;21(4):290-6.

López-Otín C, Blasco MA, Partridge L, Serrano M, Kroemer G. The Hallmarks of aging. Cell. 2013;153(6):1194-217.

Lowry KA, Vallejo NA, Studenski SA. Succesful aging as a continuum of functional independence: lessons from physical disability models of aging. Aging Dis. 2012;3(1):5-15.

Marcourakis T, Bahia VS, Kawamoto EM, Munhoz CD, Gorjão R, Artes R, et al. Apolipoprotein $\mathrm{E}$ genotype is related to nitric oxide production in platelets. Cell Biochem Funct. 2008;26:852-8.

Marengoni A, Angleman S, Meinow B, Santoni G, Mangialasche F, Rizzuto $D$, et al. Coexisting chronic conditions in the older population: variation by health indicators. Eur J Intern Med. 2016;31:29-34. 
Marengoni A, Angleman S, Melis R, Mangialasche F, Karp A, Garmen A, et al. Aging with multimorbidity: a systematic review of the literature. Ageing Res Rev. 2011;10:430-9.

Mariolis A, Foscolou A, Tyrovolas S, Piscopo S, Valacchi G, Tsakountakis N, et al. Successful aging among elders living in the Mani Continental Region vs. Insular Areas of the Mediterranean: the MEDIS Study. Aging Dis. 2016;7(3): 285-94.

Megale RZ, Loyola Filho AI, Firmo JOA, Lima-Costa MF, Peixoto SV. Apolipoprotein $\mathrm{E}$ polymorphism and functional disability in Brazilian elders: the Bambuí Health and Aging Study. Cad Saúde Pública. 2016;32(2):1-9.

Miller MD, Paradis CF, Houck PR, et al. Rating chronic medical illness burden in geropsychiatric practice and research: application of the Cumulative Illness Rating Scale. Psychiatry Res. 1992;41(3):237-48.

Miller MD, Towers A. A Manual of guidelines for scoring The Cumulative Illness Rating Scale for Geriatrics (CIRS-G), 1991. Disponível em http://anq.ch. [Acesso em 18/12/2016].

Mitnitski A, Song X, Rockwood K. Assessing biological aging: the origin of deficit accumulation. Biogerontology. 2013;14(6):709-17.

Mitnitski AB, Mogilner AJ, Rockwood K. Accumulation of deficits as a Proxy measure of aging. Scientific World Journal. 2001;1:323-36.

Montross LP, Depp C, Daly J, Reichstadt J, Golshan S, Moore D, et al. Correlates of self-rated successful aging among community-dwelling older adults. Am J Geriatr Psychiatry. 2006;14:43-51. 
Murabito JM, Yuan R, Lunetta KL. The search for longevity and healthy aging genes: insights from epidemiological studies and samples of long-lived individuals. J Gerontol A Biol Sci Med Sci. 2012;67A(5):470-9.

Nebel A, Kleindorp R, Caliebe A, Nothnagel M, Blanché H, Junge O, et al. A genome-wide association study confirms APOE as the major gene influencing survival in long-lived individuals. Mech Ageing Dev. 2011;132:324-30.

Nicholson K, Makovski TT, Griffith LE, Raina P, Stranges S, van den Akker M. Multimorbidity and comorbidity revisited: refining the concepts for international health research. J Clin Epidemiol. 2018 Sep 22. pii: S08954356(18)30543-2.

Noncommunicable diseases country profiles 2018. Geneva: World Health Organization; 2018. Disponível em http://www.who.int/nmh/publications/ncdprofiles-2018/en/. [Acesso em 17/11/2018].

Nunes BP, Batista SRR, de Andrade FB, Souza Jr PRB, Lima Costa MF, Facchini LA. Multimorbidade em indivíduos com 50 anos ou mais de idade: ELSI-Brasil. Rev Saude Publica. 2018;52(Supl 2):1s-12s.

Nunes BP, Camargo-Figuera FA, Guttier M, de Oliveira PD, Munhoz TN, Matijasevich A, et al. Multimorbidity in adults from a southern Brazilian city: occurrence and patterns. Int J Public Health. 2016;61(9):1013-20.

Nunes BP, Flores TR, Mielke GI, Thumé E, Facchini LA. Multimorbidity and mortality in older adults: A systematic review and meta-analysis. Arch Gerontol Geriatrics. 2016;67:130-8.

Nygaard M, Thinggaard M, Christensen K, Christiansen L. Investigation of the $5 q 33.3$ longevity locus and age-related phenotypes. Aging. 2017;9(1):247-53. 
Onder G, Palmer K, Navickas R, Jurevicienè E, Mammarella F, Strandzheva $M$, et al. Time to face the challenge of multimorbidity. A European perspective from the joint action on chronic diseases and promoting healthy ageing across the life cycle (JA-CHRODIS). Eur J Intern Med. 2015;26(3):157-9.

Pagotto V, Bachion MM, Silveira EA. Autoavaliação da saúde por idosos brasileiros: revisão sistemática da literatura. Rev Panam Salud Publica. 2013;33(4):302-10.

Palmore EB. Predictors of the longevity difference: A 25 year follow-up. Gerontologist. 1982;22:513-8.

Panza F. Apolipoprotein e, dementia, and human longevity. J Am Geriat Soc. 2009;57(4):740.

Parmelee PA, Thuras PD, Katz IR, Lawton MP. Validation of the cumulative illness rating scale in a geriatric residential population. J Am Geriatr Soc. 1995;43:130-7.

Pilling LC, Atkins JL, Bowman K, Jones SE, Tyrrell J, Beaumont RN, et al. Human longevity is influenced by many genetic variants: evidence from 75.000 UK Biobank participants. Aging. 2016;8(3):547-63.

Pilotto, A., Gallina, P., Fontana A, Sancarlo D, Bazzano S, Copetti M, et al. Development and validation of a Multidimensional Prognostic Index for mortality based on a standardized multidimensional assessment schedule (MPI-SVaMA) in community-dwelling older subjects. J Am Med Dir Assoc. 2013;14(4):287-92.

Projeções da população: Brasil e unidades da federação: revisão 2018 / IBGE, Coordenação de População e Indicadores Sociais. - 2. ed. - Rio de Janeiro: IBGE; 2018. Disponível em https://www.ibge.gov.br/estatisticas- 
novoportal/sociais/populacao/9109-projecao-da-populacao/. [Acesso em 17/11/2018].

Rea IM, Mc Dowell I, McMaster D, Smye M, Stout R, Evans A; MONICA group (Belfast). Monitoring of Cardiovascular trends study group. Apolipoprotein E alleles in nonagenarian subjects in the Belfast Elderly Longitudinal Free-living Ageing Study (BELFAST). Mech Ageing Dev. 2001;122(13):1367-72.

Rijken M, van Kerkhof M, Dekker J, Schellevis FG. Comorbidity of chronic diseases. Effects of disease pairs on physical and mental functioning. Qual Life Res. 2005;14:45-55.

Rizzuto D, Melis RJF, Angleman S, Qiu C, Marengoni A. Effect of chronic diseases and multimorbidity on survival and functioning in elderly adults. $J$ Am Geriatr Soc. 2017;65:1056-60.

Rockwood K, Hogan DB, MacKnight C. Conceptualization and instrumentation of frailty. Drugs Aging. 2000;17:295-302.

Rockwood K, Nassar B, Mitnitski A. Apolipoprotein E-polymorphism, frailty and mortality in older adults. J Cell Mol Med. 2008;12(6B):2754-61 .

Rosvall L, Rizzuto D, Wang HX, Winblad B, Graff C, Fratiglioni L. APOErelated mortality: Effect of dementia, cardiovascular disease and gender. Neurobiol Aging. 2009;30:1545-51.

Rowe JW, Kahn RL. Successful aging. New York: Dell Publishing; 1999. 265p.

Ryu S, Atzmon G, Barzilai N, Raghavachari N, Suh Y. Genetic landscape of APOE in human longevity revealed by high-throughput sequencing. Mech Ageing Dev. 2016;155:7-9. 
Salvi F, Miller MD, Grilli A, Giorgi R, Towers A, Morichi V, et al. Guidelines for Scoring the Cumulative Illness Rating Scale for Geriatrics (CIRS-G). J Am Geriatr Soc. 2008;56(10):1926-31.

Santoni G, Angleman S, Welmer AK, Mangialasche F, Marengoni A, Fratiglioni L. Age-related variation in health status after age 60. PLoS One. 2015 Mar 3;10(3):e0120077.

Santoni G, Marengoni A, Calderón-Larrañaga A, Angleman S, Rizzuto D, Welmer AK, et al. Defining health trajectories in older adults with five clinical indicators. J Gerontol A Biol Sci Med Sci. 2017;72(8):1123-9.

Schupf N, Barral S, Perls T, Newman A, Christensen K, Thyagarajan B, Province M, Rossi WK, Mayeux R. Apolipoprotein E and familial longevity. Neurobiol Aging. 2013;34(4):1287-91.

Sebastiani P, Baeb H, Gurinovichc A, Soerensen M, Puca A, Perls TT. Limitations and risks of meta-analyses of longevity studies. Mech Ageing Dev. 2017;165(Pt B):139-46.

Sebastiani P, Gurinovich A, Nygaard M, Nygaard M, Sasaki T, Sweigart B, et al. APOE alleles and extreme human longevity. J Gerontol A Biol Sci Med Sci. 2018 Jul 27. doi: 10.1093/gerona/gly174.

Shadyab AH, Kooperberg C, Reiner AP, Jain S, Manson JE, Hohensee C, et al. Replication of Genome-Wide Association Study Findings of Longevity in White, African American, and Hispanic Women: The Women's Health Initiative. J Gerontol A Biol Sci Med Sci. 2017;72(10):1401-6.

Shi JS, Liu Y, Liu Y, Li Y, Qiu S, Bai Y, et al. Association between ApoE polymorphism and hypertension: A meta-analysis of 28 studies including 5898 cases and 7518 controls. Gene. 2018;675:197-207. 
Singh PP, Singh M, Mastana SS. APOE distribution in world populations with new data from India and the UK. Ann Hum Biol. 2006;33(3):279-308.

Slagboom PE, van den Berg N, Deelen J. Phenome and genome based studies into human ageing and longevity: An overview. Biochim Biophys Acta Mol Basis Dis. 2018;1864(9 Pt A):2742-51.

Small BJ, Rosnick CB, Fratiglioni L, Bäckman L. Apolipoprotein E and cognitive performance: a meta-analysis. Psychol Aging. 2004;19(4): 592-600.

Souza LS, Rochette NF, Pedrosa DF, Magnago RPL, Filho TBF, Vieira FLH, et al. Role of APOE gene in bone mineral density and incidence of bone fractures in Brazilian postmenopausal women. J Clin Densitom. 2018;21(2):227-35.

Sowa A, Tobiasz-Adamczyk B, Topór-Mądry R, Poscia A, la Milia DI. Predictors of healthy ageing: public health policy targets. BMC Health Serv Res. 2016;16 Suppl 5:289.

Strawbridge WJ, Wallhagen MI, Cohen RD. Successful aging and well-being: self-rated compared with Rowe and Kahn. Gerontologist. 2002;42(6):727-33.

Tindale LC, Leach S, Spinelli JJ, Brooks-Wilson AR. Lipid and Alzheimer's disease genes associated with healthy aging and longevity in healthy oldestold. Oncotarget. 2017;8(13):20612-21.

van den Akker M, Buntinx F, Knottnerus JA. Comorbidity or multimorbidity: what's in a name? A review of literature. Eur J Gen Pract. 1996;2:65-70.

van Exel, Koopman JJE, van Bodegom D, Meij JJ, Knijff P, Ziem JB, et al. Effect of APOE $\varepsilon 4$ allele on survival and fertility in an adverse environment. PLoS One. 2017 Jul 6;12(7):e0179497. 
Vasunilashorn S, Glei DA, Lin YH, Goldman N. Apolipoprotein E and measured physical and pulmonary function in older Taiwanese adults. Biodemography Soc Biol. 2013;59(1):57-67.

Verghese J, Lipton RB, Katz MJ, Hall CB, Derby CA, Kuslansky G, et al. Leisure activities and the risk of dementia in the elderly. N Engl J Med. 2003; 348:2508-16.

Vetrano DL, Calderón-Larrañaga A, Marengoni A, Onder G, Bauer JM, Cesari M, et al. An international perspective on chronic multimorbidity: approaching the elephant in the room. J Gerontol A Biol Sci Med Sci. 2018a;73(10):1350-6.

Vetrano DL, Palmer K, Marengoni A, Marzetti E, Lattanzio F, RollerWirnsberger R, et al. Frailty and multimorbidity: a systematic review and meta-analysis. J Gerontol A Biol Sci Med Sci. 2018b May 3. doi: 10.1093/gerona/gly110.

Walter S, Atzmon G, Demerath EW, Garcia ME, Kaplan RC, Kumari M, et al. A genome-wide association study of aging. Neurobiol Aging. 2011;32: 2109.e15-2109.e28.

Wolff JL, Starfield B, Anderson G. Prevalence, expenditures, and complications of multiple chronic conditions in the elderly. Arch Intern Med. 2002;162:2269-76.

World Health Organization. World report on ageing and health. Geneva, Switzerland: World Health Organization, 2015.

World Population Prospects: The 2017 revision, key findings and advance tables. United Nations, Department of Economic and Social Affairs, Population Division, 2017. Disponível em https://population.un.org/wpp/. [Acesso em 17/11/2018]. 
Xiying M, Wenbo W, Wangyi F, Qinghuai L. Association of apolipoprotein E polymorphisms with age-related macular degeneration subtypes: an updated systematic review and meta-analysis. Arch Med Res. 2017;48(4):370-7.

Yashin Al, Arbeev KG, Wu D, Arbeeva LS, Bagley O, Stallard E, et al. Genetics of human longevity from incomplete data: new findings from the long life family study. J Gerontol A Biol Sci Med Sci. 2018;73(11):1472-81.

Zekry D, Loures Valle BH, Lardi C, Michel JP, Gold G, Krause KH, et al. Geriatrics index of comorbidity was the most accurate predictor of death in geriatric hospital among six comorbidity scores. J Clin Epidemiol. 2010;63(9):1036-44.

Zhang F, Lewis M, Yang G, Iriondo-Perez J, Zeng Y, Liu J. Apolipoprotein E polymorphism, life stress and selfreported health among older adults. J Epidemiol Community Health. 2008;62(4):e3. 